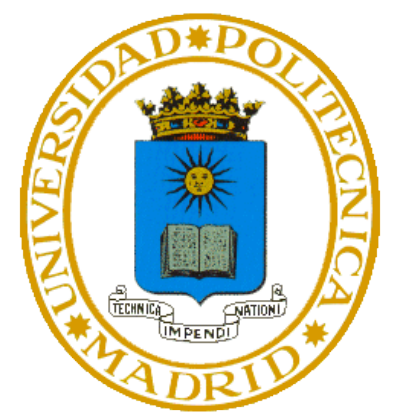

Universidad Politécnica de MAdrid

(Technical University of Madrid)

E.T.S. Arquitectura

(Faculty of Architecture)

\title{
PROPOSAL FOR A NEW TEST METHODOLOGY FOR ASSESSING THE PERFORMANCE OF REAR- VENTILATED FAÇADES AGAINST WIND-DRIVEN RAIN (WDR) AND DRIVING RAIN WIND PRESSURES (DRWP).
}

\section{Doctoral Thesis}

Architect

MARÍA ARCE RECATALÁ

Madrid|2017 



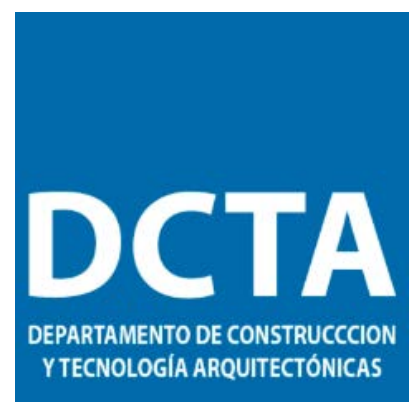

Departamento de Construcción y Tecnología Arquitectónica, E.T.S. Arquitectura

(Department in Construction and Technology in Architecture, Faculty of Architecture)

\section{PROPOSAL FOR A NEW TEST \\ METHODOLOGY FOR ASSESSING THE PERFORMANCE OF REAR-VENTILATED FAÇADES AGAINST WIND-DRIVEN RAIN (WDR) AND DRIVING RAIN WIND PRESSURES (DRWP).}

Doctoral Thesis:

María Arce Recatalá

Architect
Promotors:

Soledad García Morales

Prof. Dr. - Architect. Technical University of Madrid (UPM).

Nathan Van den Bossche

Prof. Dr. Ir. - Architect. University of Ghent (UGent). 



\section{POLITÉCNICA}

Tribunal nombrado por el Sr. Rector Magfco. de la Universidad Politéc nica de Madrid, el día. de....... de $20 \ldots$.

Presidente:

Vocal:

Vocal:

Vocal:

Secretario:

Suplente:

Suplente:

Realizado el acto de defensa y lectura de la Tesis el día de .de $20 \ldots$. en la E.T.S.I. / Fa culta d...

Calific ación

EL PRESIDENTE

LOS VOCALES

EL SEC RETARIO 


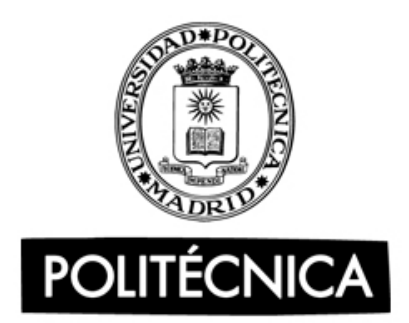



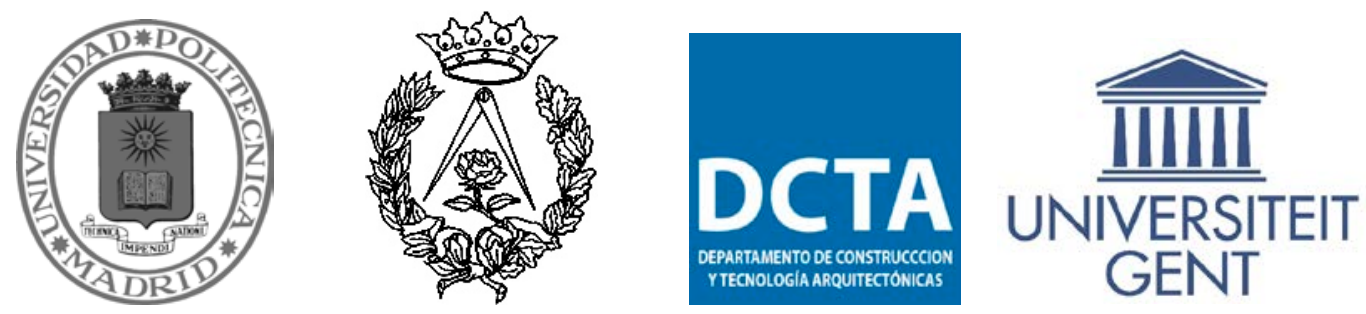

Members of the Jury on the Ph.D Defense:

\author{
Dr. Ana Sánchez Ostiz (University of Navarra) \\ Dr. Benito Lauret Aguirregabiria (Technical University of Madrid) \\ Dr. Francisco Hernández Olivares (Technical University of Madrid) \\ Dr. Joaquín Fernández Madrid (University of La Coruña) \\ Dr. Michael Lacasse (National Reasearch Council Canada)
}
Alternates:
Dr. Eva Barreira (University of Porto)
Dr. Susana Moreno Soriano (Universidad Europea de Madrid) 



\section{$\mathbf{r}$}

\section{Resumen (Summary)}

Las fachadas son la parte más sensible de la envolvente de los edificios. Pues la adecuada protección del espacio interior frente a los agentes atmosféricos depende exclusivamente de la optimización de los resultados proporcionados en la concepción y diseño de la tipología constructiva usada en la fachada. Dentro de las posibles soluciones constructivas se hallan los cerramientos de fachada ventilada; también conocida como pantalla con ecualización de presiones.

Las fachadas ventiladas son cerramientos verticales compuestos por múltiples hojas. Cada una de estas hojas tiene una función específica en la respuesta de la fachada frente a la intemperie. Se trata de una tipología constructiva considerada como solución alternativa a las soluciones constructivas propuestas en el Código Técnico de la Edificación (CTE). Por ello, se necesita un análisis específico para justificar que dichas soluciones constructivas cumplen con los requisitos esenciales establecidas en la Ley de Ordenación de la Edificación (LOE). Estos requisitos esenciales simplemente se enumeran en la LOE mientras que el CTE los desarrolla en detalle como exigencias básicas. El CTE especifica las características prestacionales relacionadas con cada exigencia básica que deben cumplir las fachadas a la vez que define los criterios de evaluación y proporciona los métodos de verificación. Sin embargo, en el caso de fachadas ventiladas el CTE no proporciona un método de verificación para justificar el cumplimiento de las diversas características prestacionales. Además, tampoco explica cómo se valoran estas características prestacionales. Respecto a la exigencia básica de protección frente a la humedad, el CTE establece tres características prestacionales: (1) Grado de impermeabilidad al agua de lluvia, (2) Capacidad de drenaje de la cámara de aire y (3) Limitación de condensaciones. De acuerdo al CTE, el grado de impermeabilidad al agua de lluvia se establece en función de la localización geográfica del edificio. Además, la idoneidad de la solución constructiva adoptada para el grado de impermeabilidad exigido se fundamenta en una descripción cualitativa de diversos parámetros derivados del uso de soluciones constructivas tradicionales. 
De manera similar, La Guía 034 del Documento de Idoneidad Técnica Europeo de sistemas de fachada ventiladas (ETAG 034), base para la emisión de los Documentos de Idoneidad Técnica Europeo (DITE) y/o las Evaluaciones Técnicas Europeas (ETE), enumera las características prestacionales a evaluar en fachadas ventiladas. Estas características prestacionales son: (1) la impermeabilidad de las juntas (protección frente al agua batiente), (2) la permeabilidad al agua del revestimiento, (3) la permeabilidad al vapor de agua de la fachada y (4) la capacidad de drenaje de la cámara de aire.

De acuerdo a la Guía 034, el grado de impermeabilidad de la fachada y la capacidad drenante de la cámara se evalúan valorando el diseño del detalle constructivo. Para ello, se consideran las características de los materiales usados, la geometría de los elementos de revestimiento y el diseño de las juntas. En este sentido, la Guía 034 propone un ensayo artificial de agua viento al sistema de fachada cuando se requiere la estanqueidad de las juntas cerradas. El procedimiento de ensayo para dicha evaluación se refiere al Procedimiento A del protocolo de ensayo prescrito en la norma EN 12865. Sin embargo, cuando se quiere valorar la gestión al agua de las juntas abiertas, la Guía 034 no sugiere ni propone ningún método de ensayo. Por ello, cuando los fabricantes de fachadas ventiladas solicitan una evaluación técnica de las prestaciones de su producto frente al agua batiente, los laboratorios de ensayos acreditados recurren a otras normativas europeas tales como: las normas UNE, las normas ISO, etc. No obstante, estas normas no son específicas de fachadas ventiladas por lo que no proporcionan medios para evaluar cuantitativamente la estanqueidad de la fachada ventilada. Así como tampoco para cuantificar la capacidad drenante de la cámara de aire. Además, las normativas de ensayo existentes, dirigidas mayoritariamente a ventanas y muros cortina, proporcionan resultados cualitativos, no cuantitativos. Pues proporcionan un nivel de prestación en función de cuando aparece la filtración de agua en la cara interior de la muestra de ensayo. Luego las normativas de ensayos estanqueidad existentes no aportan medios para cuantificar la gestión del agua en fachadas ventiladas ni cuantificar la cantidad de agua que alcanza la hoja interior de la fachada ventilada.

La obtención de valores porcentuales de infiltración a través de la fachada ventilada permitirá conocer la carga de humedad a la que se puede ver sometida las diversas hojas de una fachada ventilada durante su vida útil. Dichas cargas de humedad deben ser gestionas en el diseño del detalle constructivo de la fachada ventilada; bien mediante evaporación en la cámara o bien mediante drenaje en la zona inferior de la cámara; sin que exista ningún riesgo de filtración de agua en el intradós de la hoja interior o prematuro deterioro de algún material sensible a la humedad.

Todo lo anteriormente expuesto nos conduce a la conclusión de que la respuesta al agua batiente y al viento de las fachadas ventiladas está todavía por esclarecer. Por un lado, todavía existe un vacío en lo relativo al conocimiento de los principios que gobiernan el diseño del detalle constructivo en fachadas ventiladas para una correcta gestión del agua. Además, tampoco existen datos cuantitativos que corroboren dichos principios. Por otro lado, los detalles constructivos de este tipo de fachadas no están prescritos en las normativas vigentes, a diferencia de lo que ocurre en las tipologías más tradicionales. Asimismo, las pocas guías existentes para este tipo de fachadas se basan en la respuesta estática a cargas de viento.

Con el objetivo de proporcionar un conocimiento más detallado y profundo de la gestión al agua batiente y al viento de las fachadas ventiladas, se ha llevado a cabo la presente tesis doctoral. Durante la misma se ha desarrollado una fase de trabajo de campo, cuyo resultado ha sido la propuesta de una nueva metodología para evaluar la gestión del agua en fachadas ventiladas. Esta metodología adopta un enfoque holístico al sistema de 
fachada ventilada favoreciendo su aplicación en todo tipo de fachadas ventiladas. En la misma, la gestión del agua se basa en niveles del I al VII. Estos niveles están estrechamente relacionados con el detalle constructivo de la fachada.

Posteriormente, se ha realizado una fase de trabajo en laboratorio. En esta fase, dos prototipos de fachada ventilada se han construido a escala 1:1 para después ensayarlos en laboratorio. El diseño de cada prototipo ha tratado de reproducir las características fundamentales una tipología de fachada ventilada distinta. La realización de los ensayos en laboratorio no solo ha permitido poner a prueba la metodología de gestión del agua propuesta, sino que también ha permitido valorar la influencia de determinados parámetros en el diseño del detalle constructivo en la filtración de agua a través de los sistemas de fachada ventilada.

La presente investigación ha culminado con la propuesta de una nueva metodología de ensayo para evaluar la gestión al agua batiente y al viento de las fachadas ventiladas. Asimismo, se han propuesto algunas directrices para una buena gestión del agua en el diseño de fachadas ventiladas. 



\section{Index}

Introduction.

Chapter 01. General concepts of rear-ventilated façades: analysis of systems and state of the art.... 3

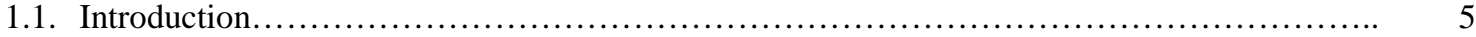

1.2. Enclosure development until the rear-ventilated façade system............................. 9

1.2.1. European traditional masonry walls....................................... 10

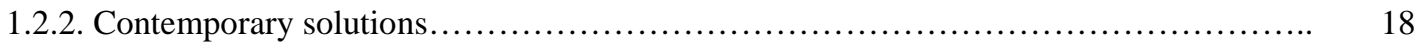

1.3. Components ofrear-ventilated façades........................................... 22

1.4. Rear-ventilated façades standards............................................ 35

1.4.1. Spanish Technical Building Code (CTE).................................... 37

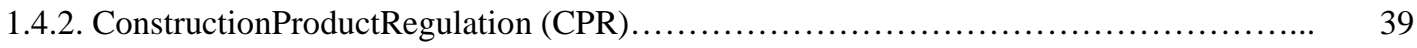

1.4.3. European Technical Assessment (ETA) ................................. 39

1.4.4. Other international standards................................................ 41

Chapter 02. Hygrothermal performance of rear-ventilated façades............................ 43

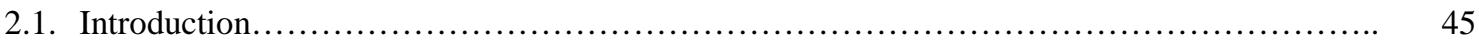

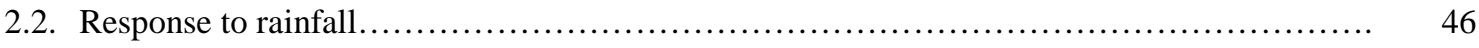

2.2.1. Wind driven rain: state of the art......................................... 51

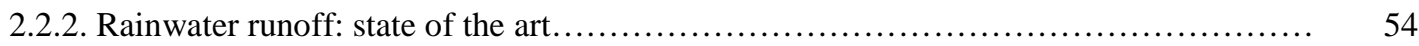

2.2.3. Rain penetration: state of the art......................................... 57

2.3. Strategies of rainwater control for enclosure design.................................... 60

2.4. Mechanisms of rainwater penetration through joints................................. 64

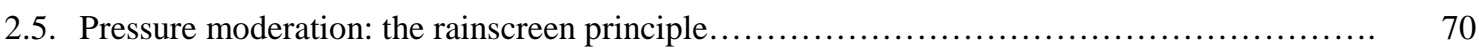

2.6. Discussion: Rear-ventilated façades.......................................... 73

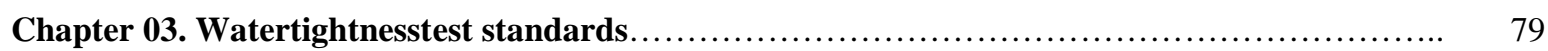

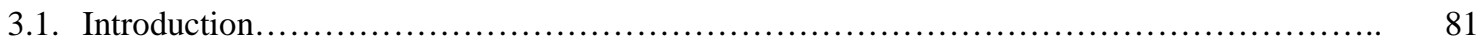

3.2. Overview of existing watertightness test standards................................ 84

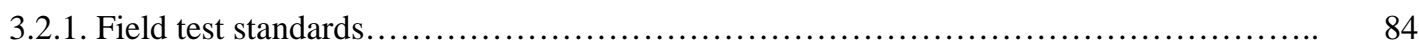

3.2.2. Laboratory test standards............................................. 87 
3.3. Comparison of laboratory watertightnesstest standards.............................. 89

3.3.1. Conditioning of the laboratory and the test specimen........................... 90

3.3.2. Apparatus............................................................... 91

3.3.3. Setup .............................................................. 91

3.3.3.1. Test specimen...................................................... 91

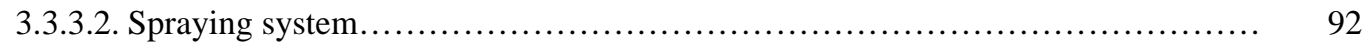

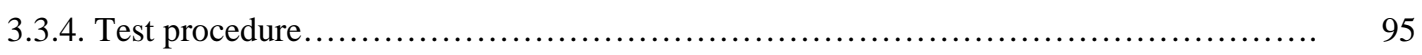

3.3.4.1. Type of test................................................... 95

3.3.4.2. Applied pressure difference........................................... 97

3.3.4.3. Duration of the test.................................................... 98

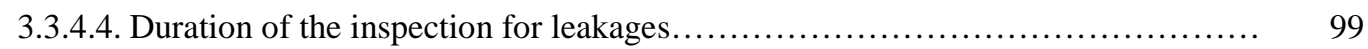

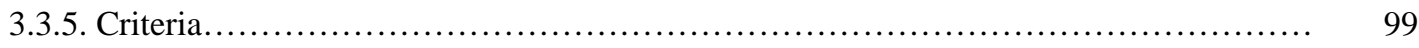

3.3.6. Applicability of test results............................................... 100

3.4. Discussion.............................................................. 100

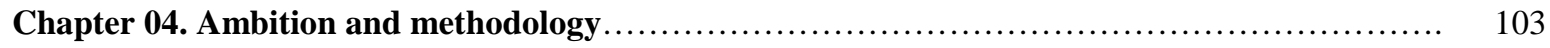

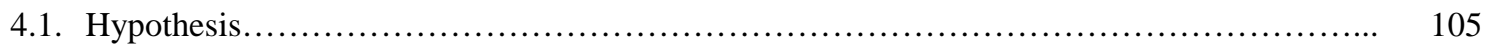

4.2. Particular goals............................................................... 106

4.3. Methodology ............................................................. 107

Chapter 05. Water management characteristics of the horizontal and vertical joints in rear-

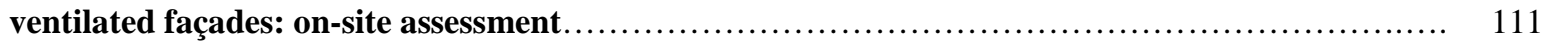

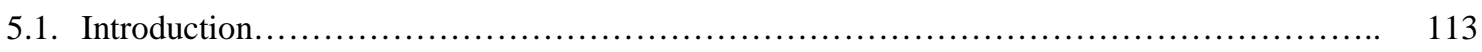

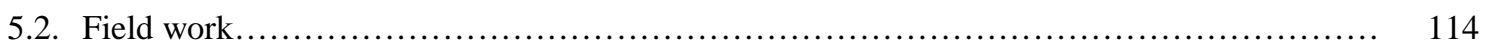

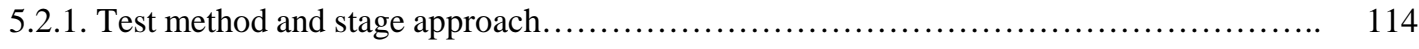

5.2.2. Case-studies.............................................................. 117

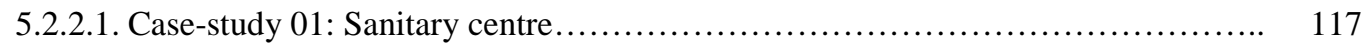

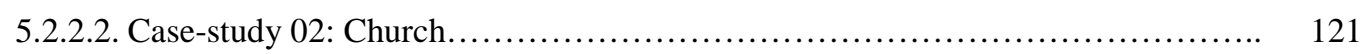

5.2.2.3. Case-study 03: Cultural centre......................................... 124

5.2.2.4. Case-study 04: Sanitary centre........................................ 127

5.2.2.5. Case-study 05: Residential compound.................................. 130

5.2.2.6. Case-study 06: Residential compound.................................. 134

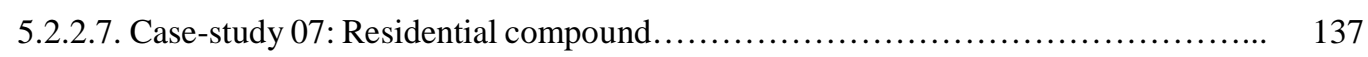

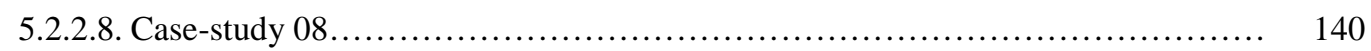

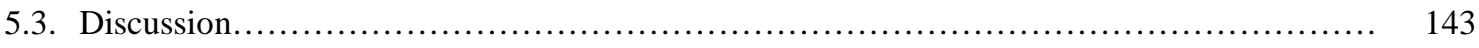

5.4. Conclusions..................................................................... 146

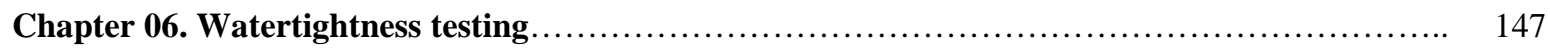

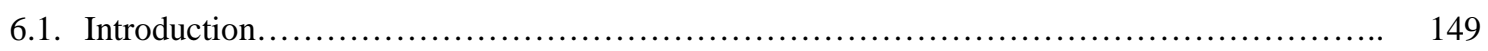

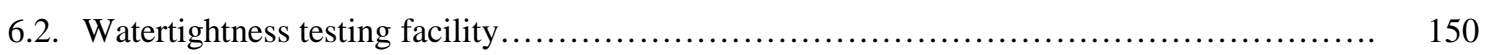




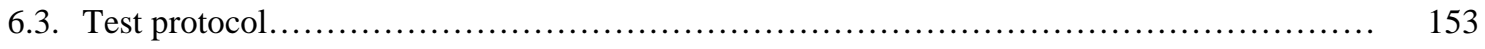

6.4. Analyzed parameters.......................................................... 156

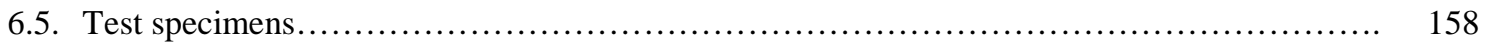

6.5.1. Mock-up 01: fibercement panels fixed to omega profiles by means of rivets............ 161

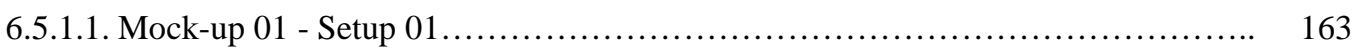

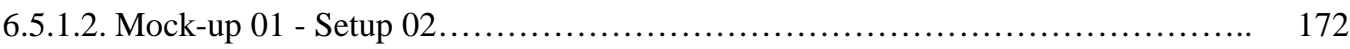

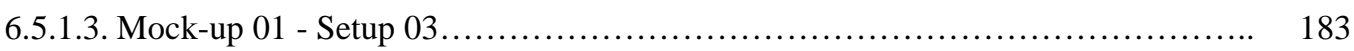

6.5.1.4. Conclusions: comparison of the results from the three setups of mock-up 01..... 192

6.5.2. Mock-up 02: fibercement panels hanged on horizontal rails, which are fixed to vertical

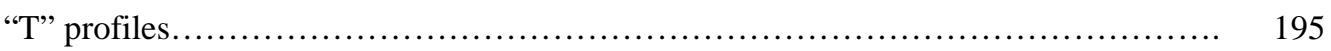

6.5.3. Conclusions: comparison of the results from mock-up 01 and mock-up $02 \ldots \ldots \ldots \ldots \ldots .214$

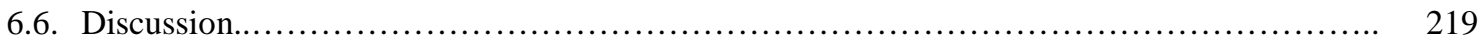

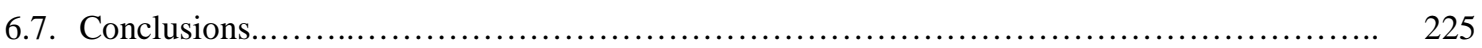

Chapter 07. Conclusions and perspectives................................................ 231

7.1. Approach................................................................ 233

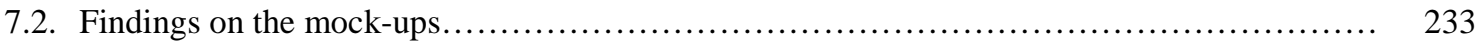

7.3. Findings on the watertightness test method and the watertightness test variables.............. 236

7.4. Findings on the rainwater infiltration through vertical / horizontal joints.................... 239

7.5. Guidelines for the design of the construction details of rear-ventilated façades................. 241

7.6. Perspectives................................................................ 243

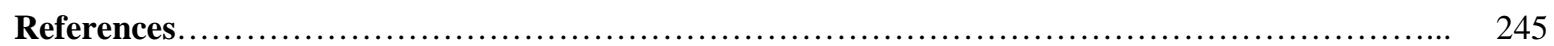

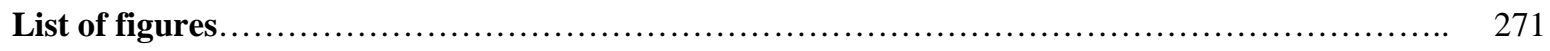

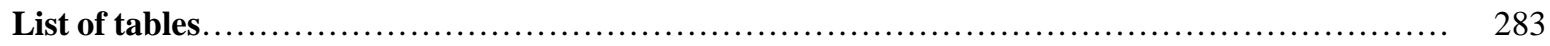





\section{i.}

\section{Introduction}

The façades are the most sensitive part of the building envelope and the provision of adequate protection against meteorological conditions rests exclusively on the optimization of the inputs raised for the design of the adopted construction typology in each building. Among these solutions lies the construction typology of rear-ventilated façades. As well referred to as pressure equalized rainscreens.

Rear-ventilated façades are vertical enclosures consisting of multiple layers with a specific role in the weathertightness performance of the overall façade system. These type of contemporary construction systems are considered as alternative technical solutions to those outlined in the Spanish Building Code (CTE). Thus, a specific analysis is necessary to confirm that they comply with the mandatory essential requirements laid down in the Law on Building Ordinances (LOE) and developed in detail in the CTE. The CTE states the demands and defines the assessment criterion of such types of façades, but it does not set up the verification method and nor explains how it valorates these performance characteristics. The façades should guarantee a watertightness degree depending on the geographical location of the building. Further, the suitability of the adopted construction solution to this watertightness degree is based on cualitative description of diverse parameters derived from the use of traditional and accepted constructive solutions. Similarly, the European Technical Assessment Guideline (ETAG) 034 establishes the performance requirements to be examined in these types of façades: the watertightness of joints (protection against driving rain), the water permeability of the cladding element, the water vapour permeability and the drainability.

According to ETAG 034, the degree of watertightness of the façade and the drainability are generally assessed by appraisal of design, taking account of the characteristics of the materials used and the geometry of the external cladding element and joints. In this sense, ETAG 034 proposes an artificial rain test on the cladding kit in accordance with EN 12865 Procedure A when the watertightness of closed joints is needed. However, it does not 
suggest any kind of artificial rain test for cladding kits with open joints. Therefore, when manufacturers request for a performance assessment of the watertightness degree of a rear-ventilated façade, accredited testing laboratories draw on other European Standards such as the ISO Standards, EN Standards and so on. However, for the time being there is any laboratory or field test standard addressed to assess the watertightness degree of rearventilated façades. Nor to assess the drainage capacity of the ventilated air cavity. In addition, the existing watertightness tests provide with qualitative results based on the appearance or not of leakages on the interior surface of the façade. These standards do not provide resources to quantify the amount of water that infiltrates through the open joints of rear-ventilated façades and nor to assess the amount of water that reaches the back wall. Securing reliable quantitative data will provide the means of determining the moisture load to which the wall is to be subjected during a rain event and for which the wall must be able to manage, either by eventual dissipation of moisture from the back ventilated cavity, moisture uptake by the inner wall (without any negative consequences), or drainage at the base of the wall.

Consequently, the watertightness performance of rear-ventilated façades is still unclear. Indeed, there is a lack of knowledge concerning both the basic principles that govern the design of features for water management of walls and reliable quantitative data that validates these principles. Besides, the construction details of rear-ventilated façades are not prescribed in standards and the few existing guidelines are firmly based in their static response to wind loads. Thereby, many presumptions have been taken in this regard by manufacturers and building practitioners, who often propose some contruction details for their products, whose effectiveness has not typically been proved.

With the intent of providing a better-defined and more in-depth understanding of the overall performance of rearventilated façades systems to wind-driven rain and driving rain wind pressures, research has been performed based on on-site assessment of case-studies and laboratory testing. The result from this research has culminated in a proposal for a new test methodology for assessing the performance of rear-ventilated façades against wind-driven rain (WDR) and driving rain wind pressures (DRWP).

The present Ph.D-work has been developed in seven chapters. In chapter 01, a brief state-of the art of rearventilated façades is presented. This chapter encompasses the general concepts of rear-ventilated façades, the evolution of the façade systems until the rear-ventilated façade system and the standards in which this construction typology is framed. Afterwards, chapter 02 provides with a fundamental insight in the state of the art of winddriven rain, rainwater runoff and rainwater penetration. This chapter ends up with a brief summary of the hygrothermal performance of rear-ventilated façades. Subsequently, an overview of the worldwide existing watertightness test standards is undertaken in chapter 03. Besides, a comparison amongst the main features of the standards has been carried out in the chapter. Thereafter, the ambition and the methodology of the research work conducted is presented in chapter 04 . The results of the research work are given in chapters 05 and 06 . On the one side, chapter 05 exhibits the results obtained from the on-site assessment of eight case-studies with rear-ventilated façades. Based on the on-site assessment, a methodology comprising a range of stages has been developed to characterize the water management features of every rear-ventilated façade typology. On the other hand, the results of the watertightnes tests conducted under laboratory conditions of two mock-ups with diverse setups are shown in chapter 06. Finally, the conclusions drawn from the present research work are reported in chapter 07. 


\section{1.}

General concepts of rear-ventilated façades: analysis of systems and state of the art

1.1. Introduction

1.2. Enclosure development until the rear-ventilated façade system

1.2.1. European traditional masonry walls

1.2.2. Contemporary solutions

1.3. Components of rear-ventilated façades

1.4. Rear-ventilated façades standards

1.4.1. Spanish Technical Building Code (CTE)

1.4.2. Construction Product Regulation (CPR)

1.4.3. European Technical Assessment (ETA)

1.4.4. Other international standards 


\section{$1.1_{\text {|INTRoduction }}$}

Rear-ventilated façades are contemporary construction systems which are widely adopted by architects and building practitioners as these offer a number of technical and aesthetic benefits in comparison to traditional façades: unventilated walls, vented walls and ventilated walls. A ventilated wall has vent openings at the air cavity (top and bottom openings) to promote air circulation [29], whereas a vented wall only has vent openings at the bottom of the wall, usually provided for drainage [2]; refer to Fig. 2.9. In contrast to traditional walls, the cladding of rear-ventilated façades is formed by independent pieces that are assembled using the open joinery system. They tend to incorporate water management features into their design and construction (as they are drained and screened walls; refer to Chapter 02, section 2.3), unlike perfect barrier systems (e.g. face-sealed exterior insulation finish systems, EIFS) and traditional construction (storage or mass buffering walls). In all cases (ventilated walls, vented walls and rear-ventilated façades), the exterior layer is separated from the interior layer by an air gap or cavity. Furthermore, rear-ventilated façades are façade systems which can be used either in renovation projects to improve the energy efficience of the building, by means of the addition of a rainscreen cladding in front of the old enclosure, or in new projects.

Some of the advantages that exhibit rear-ventilated façades in contrast to traditional walls, particulary under the Mediterranean weather conditions, are the following:

- A better performance regarding sustainability issues.

During winter time, it reduces heat loss. There is no air flow circulation inside the air cavity due to the convection phenomena as the solar heat is minimal [3]. Then, the bearing wall plays the role of heat accumulator helping on the thermal stability of the enclosure and the thermal insulation layer reduces the heat loss of the building through the walls in contact with the exterior environment [4]; refer to Fig. 1.1. Furthermore, the exterior cladding provides with some suplementarry thermal resistance to the wall system [5].

During summer time, there is a reduction of the heat load due to the combined effect of (i) the shading of the external wall over the interior wall (see Fig. 1.3) and (ii) the air flow circulation caused by natural convection into the air gap (see Fig. 1.2) [4]. In regions with high levels of solar radiation, double-skinned structures maintain the temperature of the outer shell of double-skinned buildings at a temperature close to the ambient, reducing significantly the impact of incident radiation into the interior of the building [6]. Hence, the outer covering reflects most of the direct solar radiation functioning as a heat shield in the hot season.

Furthermore, the impact of the solar radiation onto the surface of the outer shell of the building heats the cladding kit, which in turn tarsmits the heat to the air flow inside the cavity, reducing the air density and causing an upwards movement by natural convection phenomena (what is commonly known as "chimney or stack effect”). This warmed air flow goes out to the exterior through the upper holes in the cladding, allowing the entry of cool air flow inside the cavity through the lowest holes. This effect not only reduces the transmission by conduction of the heat received on the exterior face of the cladding by means of the absorption of the infrared radiation [7], but also attenuates the warming of the interior leaf of the wall since 
the heat within the cladding is dissipated at the same time as the interior of the building is thermally insulated [3]. This type of façade system keeps the temperature of the inside of the building, and therefore, reduces the energetic demand of the building. Reductions of $50 \%$ can be achieved for high values of solar radiation intensities and of the outside air temperature [8, 9, 10, 11].

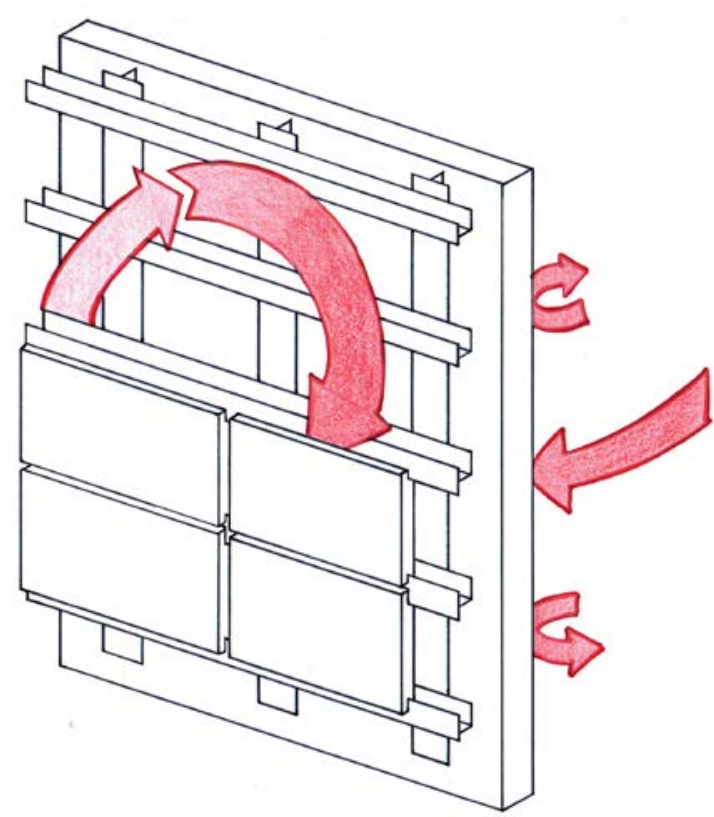

Figure 1.1. The façade plays the role of heat accummulator during the winter season.

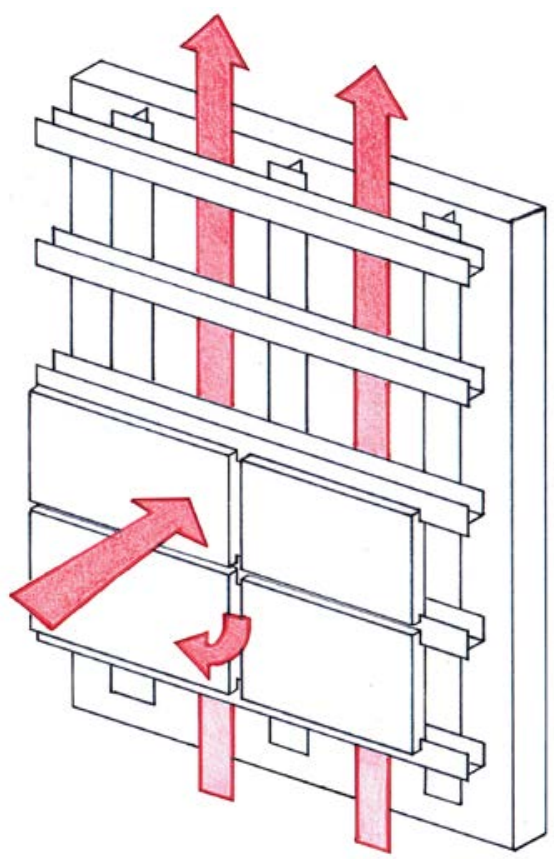

Figure 1.2. Chimney effect inside the air cavity during the summer season.

- A certain degree of independence in the induced movements.

The placement of the air cavity inbetween allows a certain independence movements of the different composing elements. In this way, it is softened the risk of breakage due to differential movements and stress-loads, such as: deflections (bending moments around the z-axis) in the cladding elements due to wind action or vertical movements of the cladding elements due to differential expansions and/or subsidence [3, 7] (see Fig. 1.4). Furthermore, the outer skin of the façade is not influenced by the movements of the building skeleton and/or the bearing wall and vice versa [19] since the fixing system is flexible enough to absorb these differential movements.

- A reduction in the thermal bridges along the enclosure of the building which yields to the prevention of condensation problems.

In contrast to traditional façades, the thermal insulation layer is laid uninterruptedly from bottom to top of the building enclosure in rear-ventilated façades $[4,7,3,19]$. Thereupon, the breaking the thermal bridges in framework edges and pillars is enabled. Nevertheless, the anchorage points are still some critical points in this regard $[12,13]$. The connection between the secondary structure and the bearing wall (interior layer) by means of metallic angle brackets may create thermal bridges if they are not well designed and/or installed. 


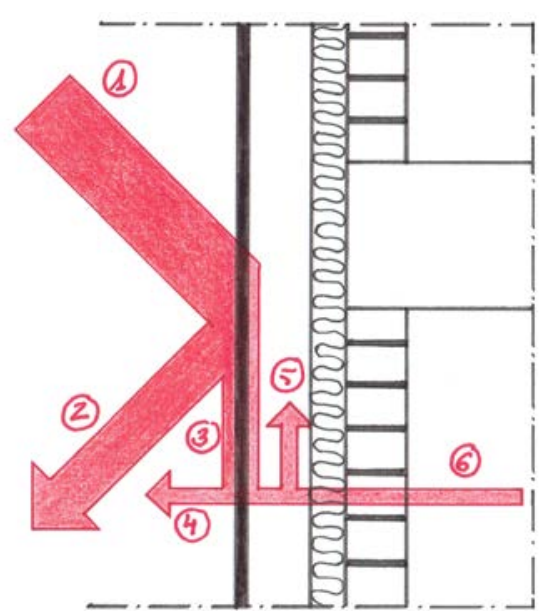

Figure 1.3. Energy efficient façade system: shading of the external wall over the interior wall, where (1) is solar radiation, (2) is reflection, (3) is conduction, (4) is material radiation, (5) is convection and (6) is the final indoor flow.

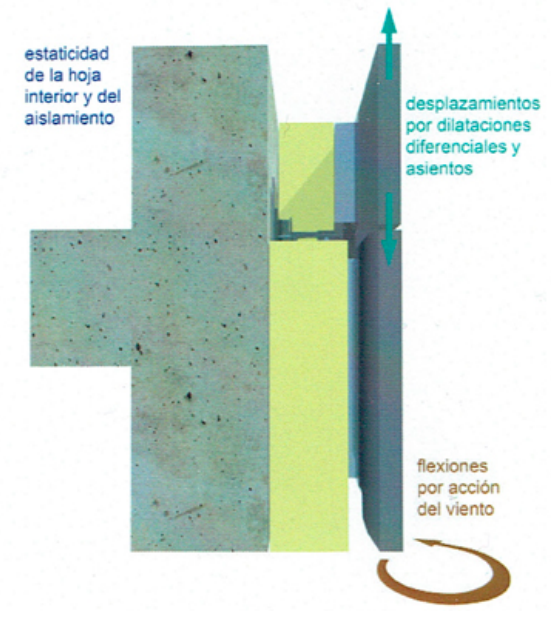

Figure 1.4. Movement independence of the different composing elements in rearventilated façade systems. [7].

- Drastic reduction in the risk of interstitial condensation problems within the wall system due to diffusive vapour flow [14].

The diffusive vapour flow is considered as the transfer of moisture in its gaseous state through the various layers of an exterior wall system or assembly. The rate and predominant direction of diffusive vapor flow is directly related to, and influenced by differences between interior and exterior vapor pressures and the individual vapor permeability of each layer in a given exterior wall system or assembly. As noted previously, moisture-related problems due to improperly located vapor retarders within an exterior wall system or assembly are often the result of improperly inhibited or otherwise restricted diffusive vapor flow. This is particularly true in mixed-humid climates, where the predominant direction of diffusive vapor flow in a given year can be difficult to accurately predict [15].

Solar-driven vapor diffusion can act to redistribute the vapor generated by the occupants inside the building within the façade towards the exterior layers, where it can condense on less capillary layers. Note that vapour often condenses on the cold side of the walls. Moreover, in some cases, it might cause damages such as moisture stains, shrinkage or lifting of the painting film... In rear-ventilated façades, the magnitude of this flow is reduced as this vapor is directly channeled to the exterior by the air cavity [16]. Within the air caviry takes place a continuos airflow exchange due to the chimney effect thereby, reducing the moisture content within the cavity. Olshevskyi et al. [17] studied the phenomenon of moisture transfer in the air gap of rear-ventilated façades taking into account the edge profile of the joints (system with or without grooved lines). In addition, the air cavity reduces the thermal gap between the exterior environmental temperatures and the interior of the building. This fact not only boosts the dimensional stability of the components [7, 14], but also avoids that the temperature within the bearing wall (interior layer or back wall) descends below the dew point temperature [4] (see Fig. 1.5). 


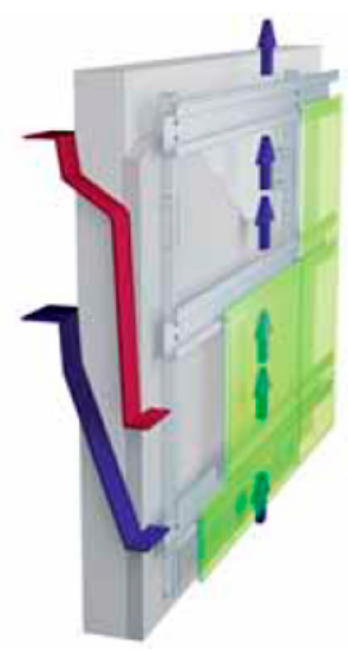

Figure 1.5. Reduction in the risk of interstitial condensation problems within the wall system due to diffusive vapour flow caused by differences in temperatures [4].

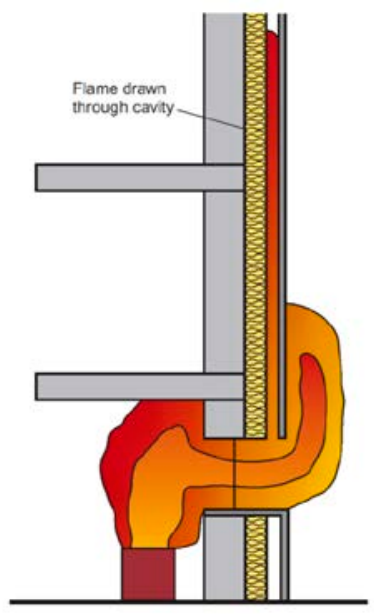

Figure 1.6. Scheme of the spread of fire flames through the air cavity of a rearventilated façade [22].

- Decrement of moisture-related problems caused by rainwater.

It is considered as a rule of thumb that the use of rear-ventilated façades avoids moisture-related problems inside the building due to rainwater impingement on the cladding. This is the main aspect I will discuss in the present Ph.D-work, demonstrating that if the water management features of rear-ventilated façades are not taken into account when designing the different connection details (horizontal joints, vertical joints and window-wall interfaces), moisture-related problems might appear in the building. Some examples of this damages have been observed in several case-studies monitored in the city of Madrid [18].

Some authors consider that when the joint width between the panels of the cladding is $5 \mathrm{~mm}$ or below, rainwater is not able to reach the inner leaf of the façade. Conversely, when it is above $5 \mathrm{~mm}$, the amount of rainwater that infiltrates into the air cavity is proportional to the size of the opennings. However, under no circumstance it will be able to reach the inner leaf [20,21]. Therefore, a runoff film might be formed on the backside of the cladding. This runoff water will be partly drained away by gravity and partly evaporated by means of the airflow circulation inside the air cavity.

- Easy dismantling and substitution of the façade elements in contrast to traditional walls.

In contrast to traditional façades, industrialized façades, such as rear-ventilated façades, exhibit simpler and easier dismantling and substitution of the façade elements when there is a problem. It is due to the layered structure of the façade and the mechanical fixing systems of the cladding kits. Note that depending on the type of fixation system of the cladding kits, these operations can become easier o tougher.

- And lastly, easy separation of the material for recycling and disposal.

As the dismantling of the façade can be undertaken by elements and materials, it becomes easier to separate them for recycling and disposal, resulting in operational actions less nocive to the environment. 
On the other hand, rear-ventilated façades also present several drawbacks. These are exposed below, where the critical points that should be taken into account in order to have a good design and performance skills in this type of façade system are also considered.

- Higher complexity in the construction of the façade system yielding to higher costs.

The assembling of rear-ventilated façade systems is so complex that requires skilled labour, which brings with higher costs than in the installation of traditional construction typologies [7].

- High risk of detachment of the cladding elements in some types of rear-ventilated façades.

Special attention and care shall be paid in the installation of the cladding elements to reduce at maximum the detachment risks. The design of an adequate fixing system to hold the panels in place reduces substantially the risk of detachment [19]. Further, a thourough control of site-work tasks should be a requirement in this type of façade systems [14].

- Fast vertical spread of fire from one floor to the next one above when the thermal insulation layer burns [14, 22] (see Fig. 1.6).

Besides of the spreading of fire through the window openings by the so-called "leap and frog" effect, typical phenomenon in traditional construction systems, in rear-ventilated façades, the ventilated cavity is a potential pathway for fire propagation in fire situations regardless of the used thermal insulation material [23]. The fire has a quick upwards spreading of the flame inside the air cavity due to the chimney effect, which promotes the circulation of air inside the air cavity from bottom to top. In addition, the open joints arrangement between cladding elements enables the permanent incorporation of oxygen to the combustion, which casuses the spread of the flame as well. In such conditions it becomes really difficult to control the fire as this process, together with the chimney effect, may lead to a flame extension five to ten times greater than of the fire plume spreading through the windows [24]. Therefore, the compartmentalization of the cavity on each floor of the building, by using appropriate barriers, is considered essential in order to prevent this type of propagation. The establishment of barriers every 3 floors or 10 meters, as is required by the Spanish Building Code (CTE) is not sufficient [23].

- High fragility of the cladding elements.

The cladding kit, especially the lower part of the façade, will be exposed to shocks and general rough treatment. As the cladding elements do not resist impacts, it is suggested to place some protections or baseboards in the plinth area when cladding elements are in direct contact with the terrain [14].

\section{2 | ENCLOSURE DEVELOPMENT UNTIL THE REAR-VENTILATED FAÇADE SYSTEM}

Basically, rear-ventilated façades have arosen from the combination of multi-wythe enclosures and the rainscreen concept. In Spain we know rainscreen claddings as rear-ventilated façades [25]. The design principles and practice of rainscreen claddings was first studied by Anderson and Gill [26]. These authors distinguished between drained 
and screened cavities from ventilated and pressure moderated cavities and pintpointed the different role played by the several layers in the overall performance of the enclosure. Rear-ventilated façades are basically composed of two leaves and a fully ventilated air cavity inbetween. In typical rear-ventilated façades, the outer leaf (cladding) is detached from the inner leaf (bearing wall, supporting wall or back wall), to which is mechanically fixed by specific anchorage points using or not a secondary structure, and the overall system is supposed to be designed following the rainscreen principle [27] (refer to chapter 02 section 2.5 for further information). When a secondary structure is used it can be made of timber or metal (steel, stainless steel, galvanized steel or aluminium). Inside the air cavity a thermal insulation layer can be placed on the exterior side of the interior wall leaf. This insulation material should be defined in accordance with an EN standard or an ETA (European Technical Assesssment).

It is important to design wall systems to manage bulk water and moisture properly as well as to be energy efficient. Walls are typically designed for performance specific to the climate where they are located. For example, buildings in high-humidity regions will require a robust wall design that may include various layers of defense for shedding water. Moisture management in hot/humid climates is additionally complicated by the need to balance a wall's ability to dry with its ability to manage inward vapour drive [28]. In this section it is presented a brief summary of the evolution and the reasons that have led to the development of rear-ventilated façade systems from the hygrothermal performance perspective: rainwater, heat and air flows management. As a resume, it can be assessed that moisture can be transported by airflow (advection and/or diffusion), or by gravity [29]. Note that advection is considered as moisture transport along a stream of moving fluid, whereas diffusion is the molecular migration of the fluid from a region of high concentration to a region of low concentration. An example of advective moisture flow is when in humid and mixed-humid climates, moisture-laden air that enters into an enclosure and comes in contact with elements below the dew point (due to the element being at a cooler temperature) [15]. The phenomenom of convection encompasses both advection and diffusion.

On the other side, rainwater can be driven through wall systems by gravity, surface tension, capillary action, wind forces, pressure differences and hydrostatic pressure [27, 30- 37 and 311 amongst others]; refer to section 2.4 of chapter 2 for detailed information.

The heat flow through a building construction depends on the temperature difference across it, the conductivity of the materials used and the thickness of the materials. Heat can be transported within the wall by conduction, advection, convection and radiation as illustrated in Fig. 1.3.

\subsection{1 | EUROPEAN TRADITIONAL MASONRY WALLS}

Initially, there were traditional walls or solid walls, which were monolithic or composite elements of high thermal mass and inertia to provide climatic protection. Such walls were built up either of readily available building materials or of elements made suitable for the purpose by simple processes, such as naturally occurring stones, squared stone, mud or fired bricks (brick masonry walls or stone walls or adobe walls) [38]. These vertical construction elements not only sheltered and delimited the indoor areas from the exterior environment, but also had a structural task in the building, which severely restricted its configuration and materiality. 
These traditional walls used to be permeable to air and water flows and they protected themselves from the exterior weather conditions by means of their thickness. Hence, their performance depended on the storage or mass buffering capacity and the water transmission characteristics [39]. In this regard, there are three rain penetration control strategies for designing the enclosure of the buildings [40]: (i) perfect barrier systems, (ii) moisture storage systems and (iii) screened and drained systems (refer to section 2.3 of chapter 2).

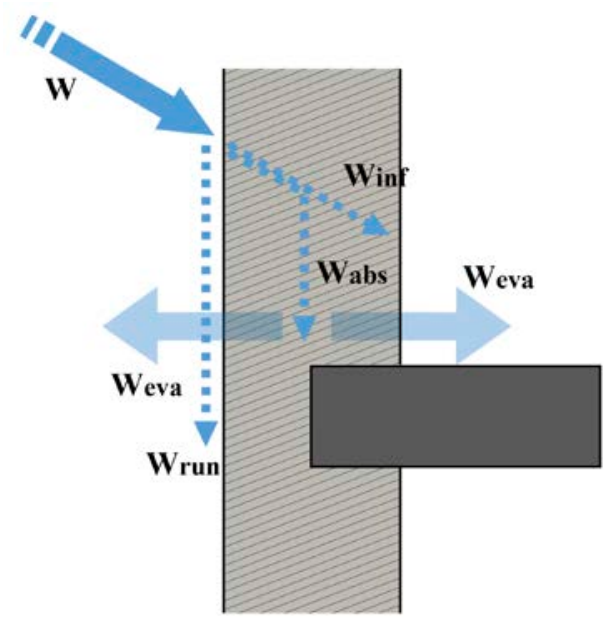

Figure 1.7. Water management in a traditional loadbearing wall.

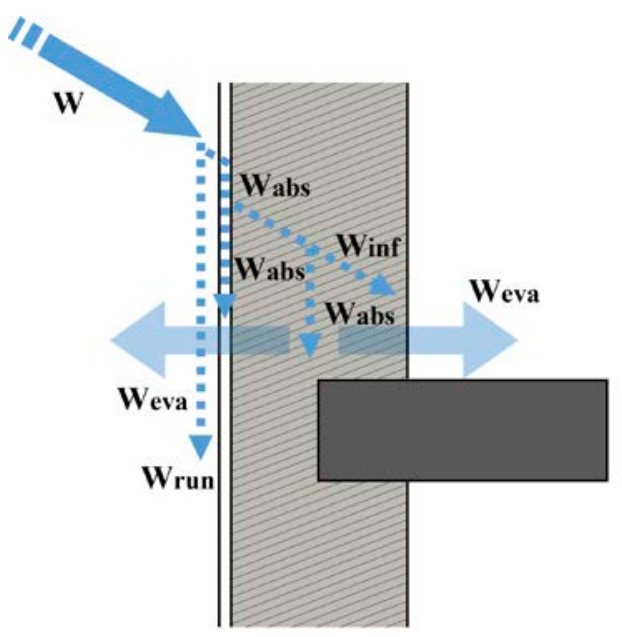

Figure 1.8. Water management in a traditional loadbearing wall to which a rendering or plastering is laid on the exterior side.

Where: $\mathbf{W}=$ water impinging on the façade, Weva = evaporated water, $\mathbf{W i n f}=$ infiltrated water, Wabs = absorbed water and Wrun $=$ runoff.

The mass and moisture tolerance of the walls was able to absorb and evaporate rainwater before it caused damages on its backside (see Fig. 1.7). Further, the interior temperatures warmed the wall, assisting with drying, and keeping the exterior surface temperature elevated in winter time and cooler in summer time, compared to the external temperatures as there was no insulation layer within the wall. In this way, the chance of freeze-thaw damage was reduced. Nevertheless, the water transmission within the wall could play a critical role in their performance [39, 40]. Then, when the wall was not wide enough or the available materials were too porous, a rendering or plastering was laid in the exterior side of the wall to improve the watertightness performance (see Fig. 1.8). The rendering absorbed many of the rainwater directly impinging on the wall, reducing the amount of water reaching the brick or stone masonry wall placed behind. I.e. by applying 15-mm thick, polymer modified cement rendering, the storage capacity is only marginally increased, but the water transmission of this outer layer, even when cracked, is so low that the rain penetration control of the system is vastly improved [39, 40].

The separation of the functions of support and enclosure in the twentieth century gave way to what we currently termed as façades: vertical enclosures which are detached from the structure of the building (what Mies Van der Rohe already named in 1924 as "skin and bones architecture" or what Le Corbusier evolved as the "Domino column system” in 1920 [41]). See the illustrations given in Fig. 1.9 and 1.10. Therein columns provide the bearing function. These columns are as far as possible enveloped into the interior of the building, while the façade leads an almost independent existence on the exterior. This improvement enabled significant advances and innovations in the elaboration of alternative solutions for the enclosure of the buildings. It also made possible the reduction of 
the wall thickness, ultimately compromising the weatherproof and thermal performance of the wall in some cases [7].

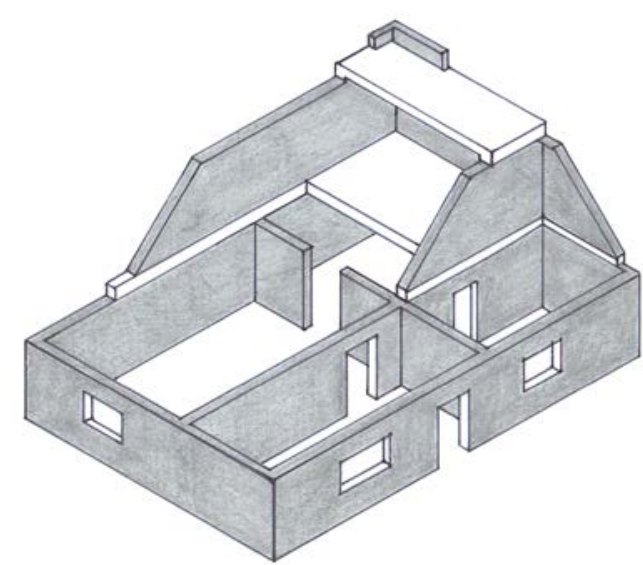

Figure 1.9. 3D perspective of a building whose structure is based on beams and load-bearing walls. There is no separation between the functions of support and enclosure.

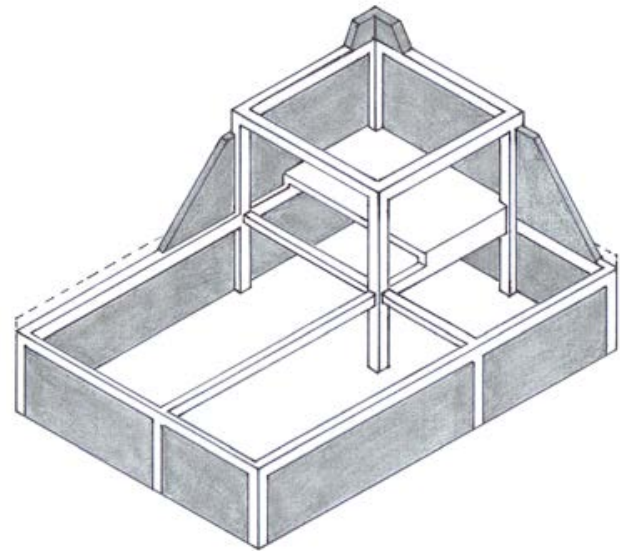

Figure 1.10. 3D perspective of a building whose structure is based on beams and pillars. There is separation between the functions of support and enclosure.

At first, these newly developed envelope walls continued being permeable to water and air flows. These relied on their mass inertia and thickness as a mean of protection against the external weather conditions (see Fig. 1.11). Like in the before-mentioned wall model, when the moisture and liquid water buffering capacity of the wall was not enough, a high-absorbing rendering or plastering was laid outside as a sacrificial layer (see Fig. 1.12). Nevertheless, a critical point appeared in this type of construction system. It was a common practice to have thermal brigdes at framework edges due to the interruption of the façade enclosure at the slabs.

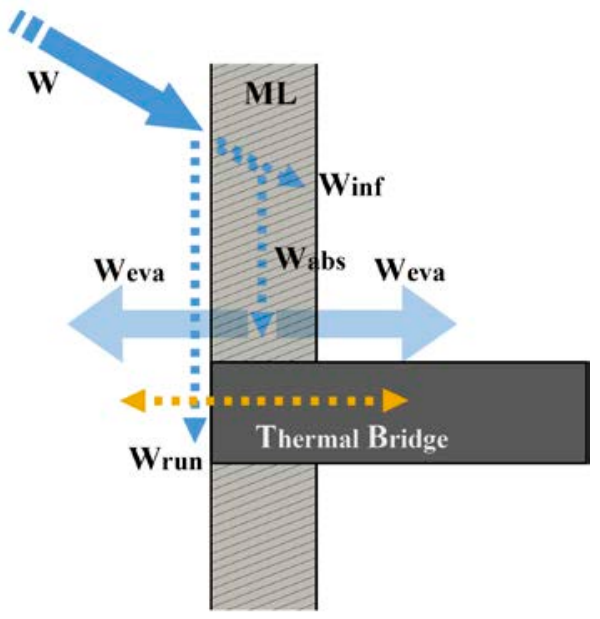

Figure 1.11. Water management in a traditional single wythe wall envelope.

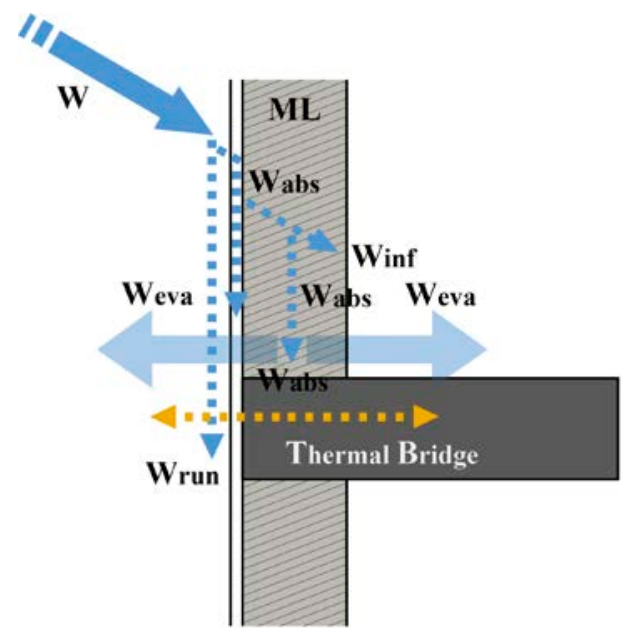

Figure 1.12. Water management in a traditional single wythe wall envelope to which a rendering or plastering is laid on the exterior side. 
Where: $\mathbf{W}=$ water impinging on the façade, Weva $=$ evaporated water, $\mathbf{W i n f}=$ infiltrated water, Wabs $=$ absorbed water, Wrun $=$ runoff and $\mathbf{M L}=$ main leaf .

At the same time and with the aim to improve the hygrothermal performance of the walls, the vertical enclosure of the buildings became multy-wythe (multiple layer systems made from different materials). The wythes came to be specialized acquiring specific purposes in the overall performance of the building shell. The detached placement of both wythes left an air space inbetween. As a result, these type of façade systems commonly know as warm façades used to comprehend three separate layers, which were used to provide protection against different environmental factors. Each layer had one or a limited number of functions [38]. The outermost wythe acted as a weatherproof layer keeping out and deflecting wind-driven rain. The middle layer (a continuous air space) functioned as thermal insulation against heat and cold in both directions. The innermost wythe separated the interior from the exterior space and was the substrate for the vapour barrier (e.g. a plaster layer) [38].

The inner and outer wythes were tied together with metal ties or bonding units (e.g. bricks bonded into both leaves of the wall in the early years [45]; refer to Fig. 1.15). Note that walls tied together by brick headers (masonry bonded hollow walls or utility walls) behave differently from walls tied together by metal ties [42]. The inner and outer wythes and the bonding units or ties were relied upon to act together in resisting lateral loads [34] and thereby, had structural functions beyond self-support under gravity [43]. Typically, the inner wythe was designed to support the weight of floors, roofs and live loads; whereas the outer wythe was mainly non-loadbearing. Out-of plane loads were shared by the wythes in proportion to their stiffnesses and the stiffness of the connecting ties. This concept of two detached walls composing the building enclosure and made of brick masonry was first described in 1898 in the Builder Journal [3] and named as Hollow Wall. Later in the twentieth century it turned into the Cavity Wall [22]. Then, cavity walls started being loadbearing wall systems, but evolved to be just selfsupporting walls under gravity. Hence, the mounting and fixing of these wythes offered two posibilities: (i) to rest both wythes on the slabs of the building skeleton or (ii) to rest the innermost wythe on the slabs and hang the outermost wythe to the innermost one.

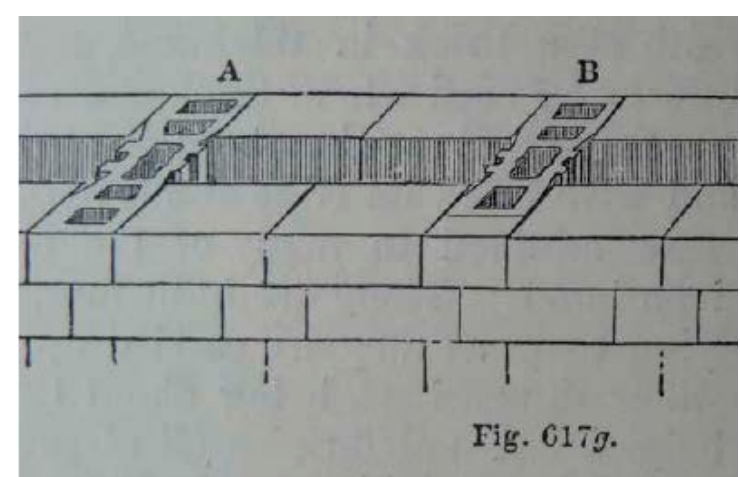

Figure 1.15. Illustration from a construction book of the late 19th century that shows two different lengths of hollow wall bonding brick [55].

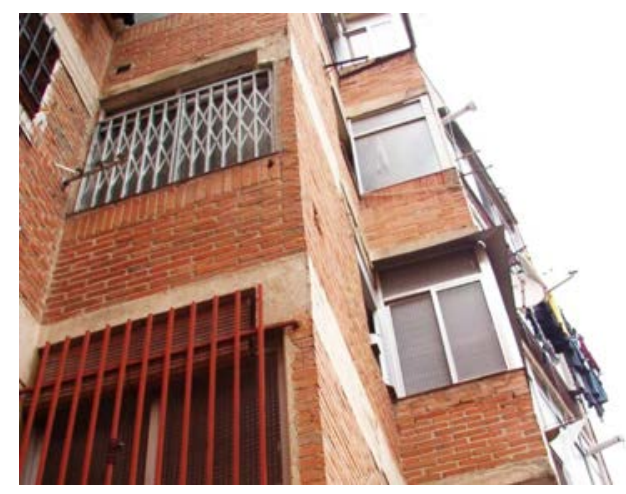

Figure 1.16. Photo of building with a brick masonry wall envelope. 
In Spain the cavity wall system was not particularly common. The Spanish equivalent wall system was the "capuchino" wall, in which either both wythes were loadbearing or the innermost wythe was it. These evolved as well and became self-supporting walls under gravity. Unlike in Europe, the envelope wall systems in Spain had a thicker outermost wythe (around $11.5 \mathrm{~cm}$ wide) namely main leaf. Hence, the mounting and fixing of these wythes in Spain offered two posibilities: (i) to rest both wythes on the slabs of the building skeleton (refer to Fig. 1.16.) or (ii) to rest the outermost wythe on the slabs and hang the innermost wythe to the outermost one [7]. Note that in Europe it was the other way round: the innermost wythe played the role of main leaf.

The thicker the masonry wythes and the deeper the gap between the wythes, the more effective the protection against wind-driven rain [45], and sometimes the warmer the enclosed air space (as the greater thermal resistance). With increased understanding of structural design, and the eventual transition from load-bearing walls to curtain walls, thinner assemblies became possible, making more efficient use of structural material and space [34]. The loss of mass and thickness, however, often led to rain penetration. The masonry cavity wall evolved in response to a need to control rain penetration through masonry walls that had become thinner [34]. The inclusion of an air gap in the construction of the building envelope was supposed to impede moisture and/or water transmitting from the outermost wythe to the innermost wythe. Accordingly, the air gap of the Cavity Wall just acted as a capillary break that prevented water from wicking from the exterior to the interior of the building.

Initially, the air space inbetween wythes was not ventilated. This non-ventilated air cavity improved significantly the thermal performance of the wall as the air trapped between the two wythes was poor conductor of heat resulting in a barrier to heat transfer [38]. Nonetheless, it was not to be the case of big non-ventilated air cavities since airflows might appear by convection [44]. For instance, a $5 \mathrm{~cm}$ deep non-ventilated air cavity provides a thermal resistance of $0.18 \mathrm{~m}^{2} \cdot{ }^{\circ} \mathrm{C} / \mathrm{W}$, whereas a $15 \mathrm{~cm}$ deep non-ventilated air cavity provides a thermal resistance of 0.16 $\mathrm{m}^{2} \cdot{ }^{\circ} \mathrm{C} / \mathrm{W}$ [44]. Hence, the optimum non-ventilated air cavity depth is $5 \mathrm{~cm}$ in terms of thermal response. To prevent or minimise the direct transmission of heat across the envelope, the inner wythe should be thermally isolated from the outer wythe. To this end, direct contact between the two layers was avoided as much as possible [38]. Heat flow was also minimised by use of materials of poor thermal conductivity [38]. However, the cavity was interrupted where bricks were used as bonding units within wythes and the bricks created direct contact by bridging between the two layers. Moisture was therefore able to transfer across the air cavity and for this reason these walls were analogous to moisture storage wall systems (Straube [40]) rather than modern cavity walls [45]. In modern cavity walls, metal or plastic ties are used to prevent capillary transfer of moisture across the air cavity.

Despite that the air cavity was supposed to reduce the thermal gap between the exterior environment and the interior conditions of the building avoiding the appearance of interstitial condensation problems, it was not to be the case. Differences in relative humidity between inside and outside air might cause vapour flows across the envelope from areas of higher vapour pressure to areas with lower vapour pressure. Consequently, interstitial condensation problems appeared under certain temperature conditions when the vapour coming from indoors was brought into contact with the cold backside of the outermost wythe (see Fig. 1.13). These interstitial condensation problems were mainly occasioned by vapour saturation inside the air cavity due to the lack of ventilation. Interstitial condenasation may contribute to efflorescence when soluble salts are present, corrosion of metal ties, desintegration of the masonry units, frost damage or mold growth [42]. Besides, a thermal bridge appeared in slab edge details as the air cavity was interrupted in that areas. 
In the early twentieth century, the appearance of thermal insulation materials led to the introduction of a thermal insulation layer between wythes to reduce the heat loss through the building shell, see Fig. 1.15. Most of the times, the insulation material filled completely the continuous air space eliminating then the air gap between wythes. Both wythes rested on the slabs of the building skeleton and thereby, this configuration gave rise to the appearance of thermal bridges at framework edges. Further, the thermal insulation layer was interrupted in that areas [7], which exacerbated the resulting problems and increase the danger of localised condensation on the inside of the inner wythe [45]. The addition of a thermal insulation layer between wythes was supposed to reduce the risk of interstitial condensation problems as the thermal gaps across the façade were restricted. Nevertheless, sometimes it increased the danger of localised interstitial condensation on the inside surface of the outermost wythe. It is important to consider that the appearance of interstitial condensation problems mainly relied on the type of thermal insulation used in each case. Permeable insulation materials, such as glass fiber mats, worsened the situation since these enabled inwards vapour flow until the cold outermost wythe, where it might condense. Condensed water on the inner surface of the outermost wythe migh wet the insulation material and consequently, reduce the thermal resistance in the meanwhile raising the wall U-value (transmitance) over the threshold required by regulations [7, 3]. Note that damp walls conduct heat more readily than dry walls. A scheme of the hygrothermal response of this type of wall system is provided in Fig. 1.14. Conversely, the use of impervious insulation materials, such as polyurethane foams, avoided inward vapour drive to the cold side of the envelope, reducing thus the risk of interstitial condensation on the inner surface of the outermost wythe.

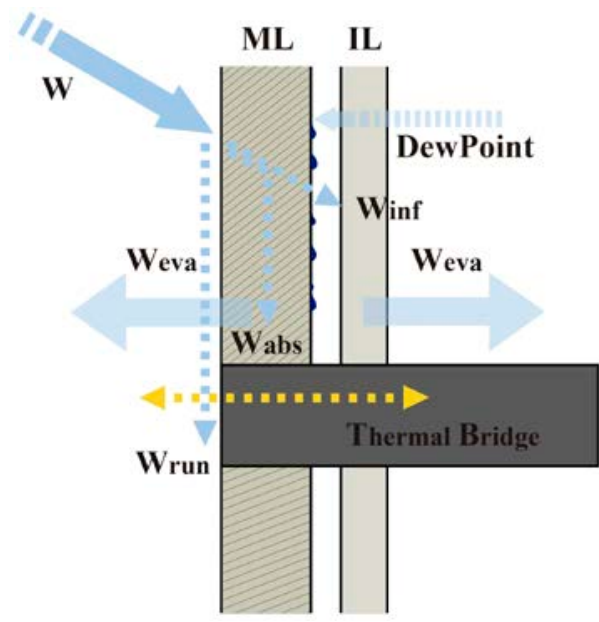

Figure 1.13. Water management in the Spanish adaptation of the hollow wall (unvented air cavity).

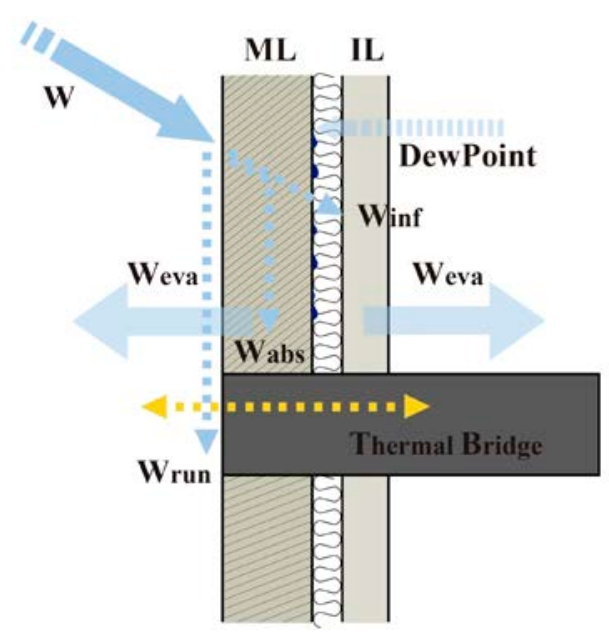

Figure 1.14. Water management in the Spanish adaptation of the hollow wall with insulation in the air cavity.

Where: $\mathbf{W}$ = water impinging on the façade, Weva = evaporated water, $\mathbf{W i n f}=$ infiltrated water, $\mathbf{W a b s}=$ absorbed water, Wrun = runoff, $\mathbf{M L}=$ mean leaf and $\mathbf{I L}=$ interior leaf.

The weathertightness performance of this type of façade continued being almost the same. Both wythes were permeable to water and air, and the air gap played the role of water stop for infiltrated rainwater. Note that in the latter case (Fig. 1.14) as the air space was suppressed by introducing the thermal insulation material as well it was eliminated the capillary break that prevented water from wicking from the outermost wythe to the innermost wythe. However, as the air cavity was not vented nor ventilated, the drying process of the façade was only possible on the 
exterior surface of outermost wythe and on the interior surface of the innermost wythe (see Fig. 1.13 and 1.14). This type of façade has been the most common construction system used in Spain for at least fifty years.

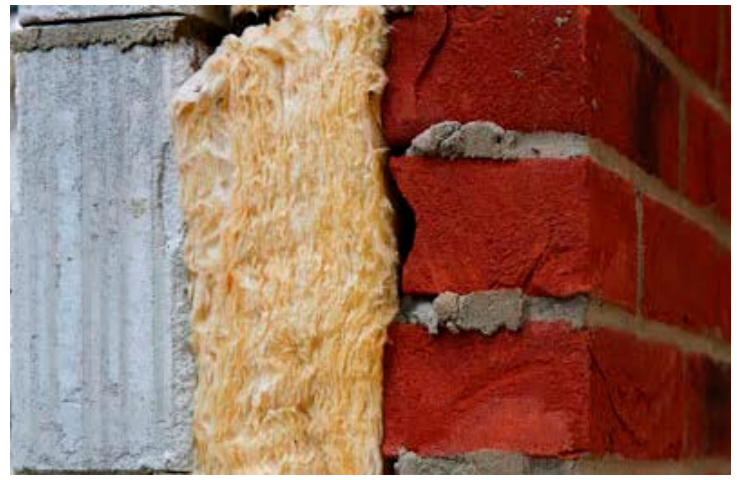

Figure 1.15. Cavity Wall with a thermal insulation layer of mineral wool placed between wythes. Source: Internet.

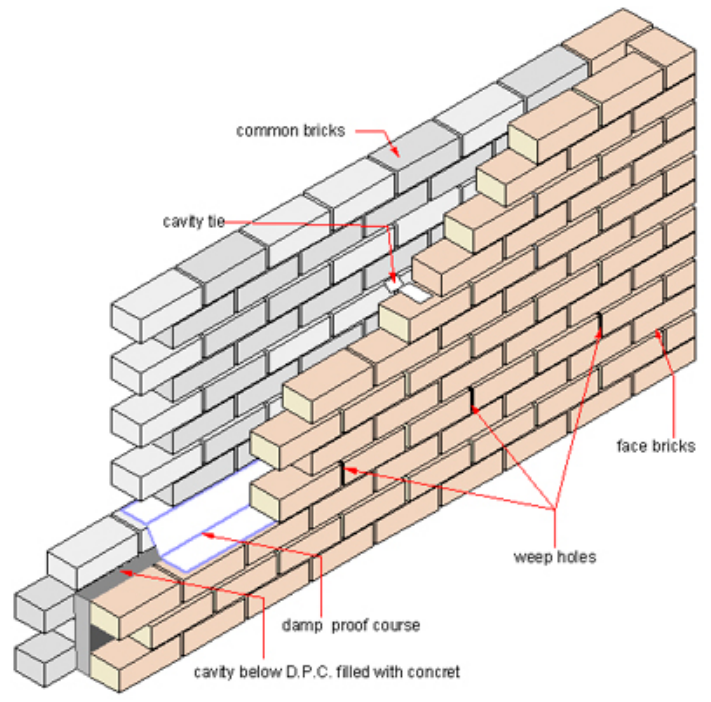

Figure 1.16. 3D scheme of a British Cavity Wall with its fundamental components. Source: Internet.

Eventually, the Cavity Wall began to use the drainage as a rain control strategy evolving to the namely British Cavity Wall. A 3D scheme of this model is given in Fig. 1.16. In the figure, the fundamental components are highlighted. The British Cavity wall improved significantly the watertightness performance of the vertical enclosure in humid and rainy weather conditions since the façade was designed so the water that penetrated the outermost wythe could not reach the innermost wythe, and would be drained back to the outside by means of drainage openings (weep holes) and flashing membranes (damp proof course) provided at the bottom of each wall section [34]. In addition, the metal anchors that tied together both wythes were intentionally shaped with folds to drain away the water that infiltrated into the air cavity [3].

This construction system of the twentieth century placed a vented or ventilated air space between wythes. A vented air space is a cavity or void that has openings to the outside air placed so as to allow some limited, but not necessarily through, movement of air [46]. In contrast, a ventilated air space is a cavity or void that has openings to the outside air placed so as to promote through movement of air [46]. The vented air cavity allowed some degree of water vapour diffusion and air mixing with the exterior environment [40] through vent openings at the top of each wall section. Note that as the wythes rested on the slabs of the building skeleton, the wall section usually had a floor height. The weep holes (drainage openings) acted in some cases as vent openings [29] (if they are not filled with capillary water) promoting a certain degree of ventilation along the air cavity, and therefore, improving the hygrothermal response of the façade. In this way, the vapour in the air cavity was dissipated and consequently, some of the evaporated/desorbed moisture was removed [29]. Hence, if the air exchange rate across the air cavity (ventilation flow) was high enough, the risk of interstitial condensation due to vapour saturation inside the air cavity was significantly reduced [7]. However, the risk of interstitial condensation on the cold side of the British Cavity Wall due to outwards driven vapour still existed when the provided ventilation was not enough. Further, 
the risk of interstitial condensation on the cold side of the inner wythe in hot-humid environmental conditions due to inwards driven vapour (solar driven summer condensation) was high. Sun-driven moisture can occur when moisture is either absorbed by the exterior wythe, or when moisture penetrates the exterior of the wall [47]. Then, heavy rain conditions might result in a relative humidity close to $100 \%$ inside the air cavity and the rainwater absorbed is subsequently driven inward as the outermost wythe is heated by solar radiation [28]. Note that sundriven moisture is a phenomenon that occurs when walls are wetted and then heated by solar radiation [47]. Upon solar heating, a large vapour pressure difference may occur between the exterior and the interior leading to the inward diffusion of moisture. Fig. 1.17 illustrates a scheme of the hygrothermal response of British Cavity Walls.

The vent and drainage openings were usually done in the outermost masonry wythe by missing the mortar in some head joints at the bottom and top parts of every pane. Therefore, rainwater infiltration across the exterior masonry wythe occurred through cracks or incomplete filling of joints or by means of the capillarity phenomena, but infiltrated rainwater was not supposed to reach the interior masonry wythe since the vented or semi-ventilated air cavity acted as a capillary break with drainage openings. However, the presence of mortar drops and debris inside the air cavity was quite usual due to the construction process of the walls. These mortar debris or drops provided waterways between wythes for infiltrated rainwater.

Although the drained cavity wall system can provide considerable protection against water ingress caused by capillarity, surface tension and gravity, this type of assembly was not able to address water transfer due to airpressure differences without the addition of other elements to the wall [34]. Note that according to Straube [40] undrained cavity walls often behave as multi-layer mass walls.

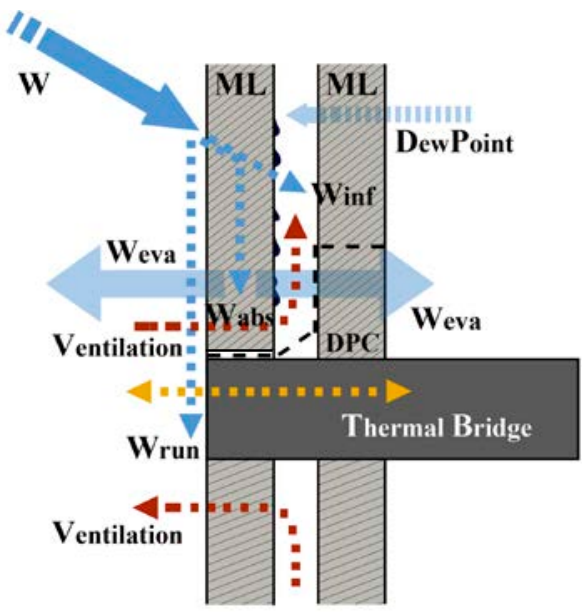

Figure 1.17. Water management in the British Cavity Wall, top and bottom gaps at each pane (vented air cavity).

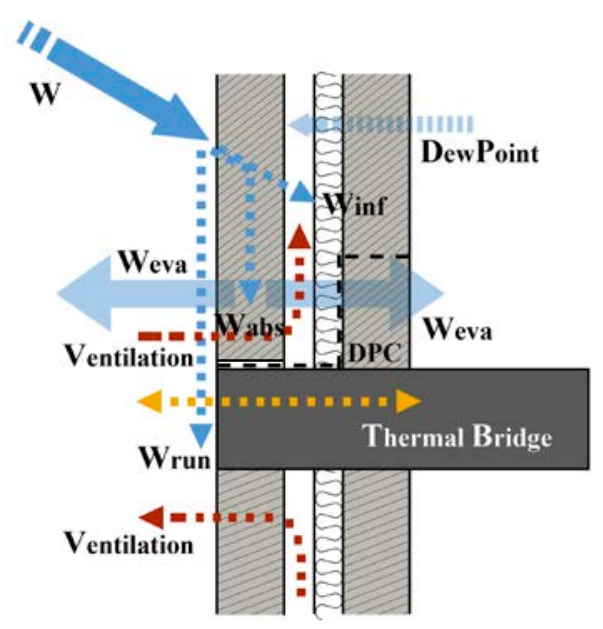

Figure 1.18. Water management in the British Cavity Wall with the addition of the thermal insulation layer inside the vented air cavity.

Where: $\mathbf{W}=$ water impinging on the façade, $\mathbf{W e v a}=$ evaporated water, $\mathbf{W i n f}=$ infiltrated water, $\mathbf{W a b s}=$ absorbed water, $\mathbf{W r u n}=$ runoff, $\mathbf{D P C}=$ damp proof course and $\mathbf{M L}=$ mean leaf.

An improvement of the system was achieved when the separation between wythes became greater and enabled to place a thermal insulation layer over the exterior surface of the innermost wythe while leaving a gap between the thermal insulation layer and the outermost wythe, as illustrated in Fig. 1.18. In this respect, the variation of the position of the thermal insulation layer with regard to the air cavity gave rise to façades with completely diverse 
behaviour against environmental factors [7]. The thermal insulation layer could be laid either adjacent to the exterior surface of the innermost wythe or adjacent to the interior surface of the outermost wythe. In the latter case, an interior air cavity with no venting options was originated. Consequently, this configuration caused several moisture-related problems in the façade, such as: interstitial condensations in the cold side of the thermal insulation layer and/or wetting of the insulation due to rainwater infiltration through cracks or pores within the outermost wythe and/or even the infiltration of water to the innermost wythe due to moisture saturation of the non-vented air cavity [7]. On the other hand, if the thermal insulation layer was laid over the exterior surface of the innermost wythe, the hygrothermal performance of the whole enclosure improved significantly [7]. This wall configuration allowed the venting or ventilation of the air cavity. This type of façades namely cold façades, are recognized because the insulating layer is separated from the climatic protection layer by a layer of air [38]. Conversely, warm façades are those where the air cavity is non-ventilated. It should be noted that the location of the thermal insulation layer inside the air cavity depended on the construction process of the wall. For instance, in Spain the wall was usually build from inside to outside and consequently, it was easier to place the insulation layer over the inner wythe.

As the discontinuity of the thermal insulation layer in slab edge details still existed, the appearance of thermal bridges in that areas was inevitable. Besides, the drying of the infiltrated water was possible along the two sides of both wythes, unlike in the previous cases, where the air cavity was not ventilated. Nonetheless, the evaporation at the backside of the outermost wythe was not much since the cavity was vented not ventilated and the air exchange was small (lower air change rates).

\subsection{2 | CONTEMPORARY SOLUTIONS}

Modern enclosures attempt to completely control airflow and its related wetting (i.e. air barrier systems are provided) [48]. This means that airflow is eliminated as means of both wetting and drying. Hence, water-resistive, vapour and air barriers are used to control the liquid water and moisture movement in enclosure wall systems. A water-resistive barrier is designed to keep liquid water from entering a building enclosure [50]. A vapour barrier (a material with low vapour permeance) controls the water vapour diffusion to reduce the occurrence or intensity of condensation [48]. By reducing the amount of water vapour in the wall, the partial vapour pressure in the wall is far less than it would normally be, and thus the likelihood of the partial pressure equaling the saturated pressure and forming condensation is all but eliminated [42]. Note that if a small crack or perforation occurs in a vapour barrier, its performance is not substantially reduced and such imperfections can be accepted [48]. On the other hand, an air barrier prevents air leakage across the building shell. So, it controls the unintended movement of air into and out of a building enclosure and thereby controls convective vapour transport [48]. Air leakage carries heat and moisture between the inside and outside of the building [42]. Further, air barriers provide a resistance to the pressure differences across the two sides of the air barrier material [50]. The need for air and vapour barriers is dependent upon climate, building use and the construction assembly that is the hygrothermal demand of the building [48]. Typically, extreme climates that have very cold winters or very humid summers are candidates for air and vapuor barriers. Moderate climates are less likely to require these membranes. In many cases, an air barrier 
may be more effective than a vapour barrier since air leakage can carry several hundred times more water vapour than vapour movement [42]. Therefore, an air barrier could be interposed between the thermal insulation layer and the inner wythe [7] of multy-wythe walls so as to avoid interstitial condensation, which will prevent the insulation from wetting, as well. It is recommended to place vapour barriers on the high vapour pressure side of the wall and air barriers on the exterior face of the inner wythe since its placement is usually not critical [42].

Industrialized façade systems emerged as a solution to the problems arosen in traditional facades (e.g. thermal bridges, condensation problems, rainwater infiltration...) [7] and as a way to shorten the construction time on site. In order to break the thermal bridge in slab edge details, the thermal insulation layer is placed uninterruptedly from top to bottom of the building over the exterior surface of the outermost wythe. Afterwards, a finishing façade render is applied (see Fig. 1.19). This construction system is commonly known as ETICS (External Thermal Insulation Composite System) or EIFS (Exterior Insulation and Finish Systems), and has been widely used in renovation projects for the last years. The quality of the EIFS and their hygrothermal performance are directly dependable on the characteristics of the components, as well as of the installation works. In terms of watertightness performance, these systems can be based on two main principles: (i) the single barrier system or the face-sealed EIFS and (ii) the barrier system with secondary weather barrier or EIFS with drainage. An example of both types is given in Fig. 1.21. Both systems are supposed to be water- and airtight. Face-sealed EIFS rely on perfect workmanship and perfect materials to keep rain out. Nonethelss, wind-driven rain will lead to potential problems with water ingress and rain penetration [53]. Rainwater might enter EIFS through cracks in the EIFS, between the EIFS lamina and windows, through failed joints, through balcony elements, through railings, through windows, through sliding doors, through service penetrations and through the roof system [54]. Note that EIFS laminas cracks are very common due to drying shrinkage or hygric stresses, embrittlement due to aging, and building movement. Once the moisture has a direct leakage into the building, serious negative consequences will start such as: accelerated deterioration, dimensional changes, delaminating processes and/or possible internal structure damages amongst others. [53]. Besides, many moisture and rain-related problems have been detected due to the difficulty in resolving the joints and the connections to windows, doors, balconies, etc. [54, 56].

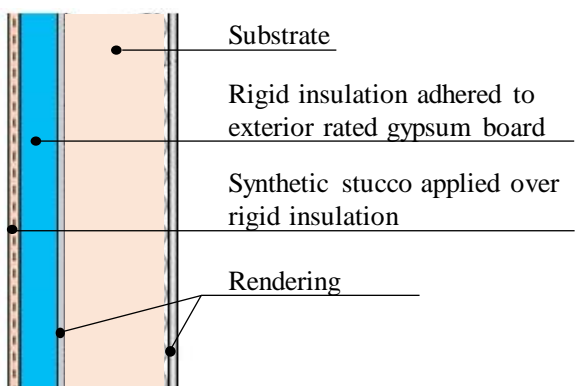

(a)
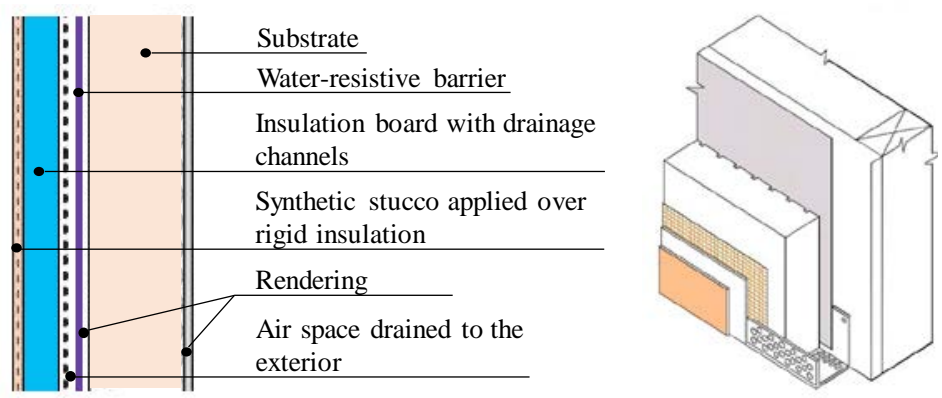

(b)

Figure 1.21. Water management in External Thermal Insulation Composite Systems (ETICS). (a) Scheme of a face-sealed ETICS. (b) Scheme of a ETICS with drainage [54]. 
On the other hand, Künzel et al. [57] assessed that damage or degradation of EIFS façades are as frequent as in conventional rendered masonry walls, but they detected a slightly greater susceptibility to microbial growth in EIF systems due to rain or condensation water.

Unlike the former, the latter incorporates water management features and it is found to provide a better response to wind-driven rain. EIFS with drainage is conventional EIFS installed over a water-resistive barrier, with provisions for discharging of incidental water that may enter behind the insulation board. In the event of a breach of the EIFS, the drainage path for moisture exists behind the EIFS to drain water to the exterior. Flashing is required where rainwater may penetrate other components and at the interface of different components.

In EIFS, the occurrence of the water vapour condensation may be caused by the vapour diffusion characteristics of the exterior render [58]. In order to prevent it, the layers of material ought to be placed in such a manner that their heat resistance increases, while the diffusion resistance decreases, regarded from the interior towards the exterior side of the wall. If the exterior render is of higher relative resistance to the water vapour diffusion, it might cause the condensation of the water vapour in the wall [58] as illustrated in Fig. 1.19. Depending on the manufacturer and the product selected, the EIFS vapor permeability may vary. EIFS are reasonably vapourimpermeable according to Straube [48]. Then, if water penetrates onto the space behind the EIFS wall through a window-wall interface, for example, the drying to the interior will not not be possible if a low-permeance barrier is used on the interior and damage can result [48]. The vapour impermeable materials that reside on both sides of the space eliminate the chance of evaporation and drying [60]. This scenario has been described as a vapour trap $[48,60]$ because after water enters the space it is unable to escape. Note that this is the infiltrated water that is shed away in EIFS with drainage. The accumulation of water through condensation has been found to cause damage to the supporting sheathing. If the dew point resides within the supporting wall the insulation within that wall can very easily be damaged by moisture. Even when the EIFS and support system can withstand the condensation that occurs, the EIFS becomes more susceptible to stresses caused by freezing and thawing.

The great construction difficulty demanded by the outer wythe in the British Cavity Wall model and the problems arised when mortar drops and debris fell inside the air cavity creating rainwater pathways between the two wythes resulted in the development of rainscreens [22]. Early examples of rainscreens can be found in the wall construction of Norwegian style barns dating back a hundred years or so. These barns, were built using a layer of open-joint wood battens or siding set over a traditional stone wall. This type of construction was later called "twostage weather-tightening” as it encompassed (i) a first line of defense that minimized rainwater passage into the wall by minimizing the number and size of holes and managing the driving forces acting on the wall; and (ii) a second line of defense that intercepts all water that gets past the first line of defense and effectively dissipates it to the exterior [33]. The rainscreen concept evolved and that under the term rainscreen there are those where pressure equalization is not required as well as those where pressure equalization is utilized. Anderson and Gill [26] differentiated between the drained and back-ventilated rainscreens, where most of the rainwater is drained off at the outermost surface of the wall providing for cavity drainage and evaporation of the remainder; and the pressureequalized rainscreens, where the aim is to eliminate penetration through the rainscreen not by tightly sealing joints, but by leaving some or all of them open to the passage of air but not of water. Hence, the rainscreen principle entails the control of all the forces handled by a drained cavity wall plus the air pressure difference acting across the cladding [63]. The rainscreen principle is further studied in section 2.5 of chapter 2 in the present Ph.D-work. 
The adaptation of the rainscreen concept to multy-wythe envelopes in Spain gave rise to a construction system namely rear-ventilated façades [25], which combined both approachs. According to Paricio and Pardal [25], the fact of accommodating the rainscreen concept to multy-wythe walls (cavity walls) expressed the little concern in solving the watertightness problems and brought relevance to the thermal response of the façade system. Rearventilated façades are thus a construction system that mainly consists in the replacement of the outermost wythe of cavity walls by an open joint rainscreen [22] (see Fig. 1.20). The open joint rainscreen allows the complete ventilation of the air cavity behind the cladding, unlike the British Cavity Wall with a vented or semi-ventilated air cavity, and the pressure equalization of the façade system. Consequently, no rainwater is expected to reach the back wall and the ventilation drying effect of the rainwater that infiltrated inside the air cavity is assumed to be promoted. Besides, the inward solar-driven water vapour of hygroscopic cladding materials is reduced [16]. Unlike in the British Cavity Wall, in rear-ventilated façades the water vapour coming from indoors and the solar driven inward vapour are channeled outside through the air cavity by means of the chimneney effect.

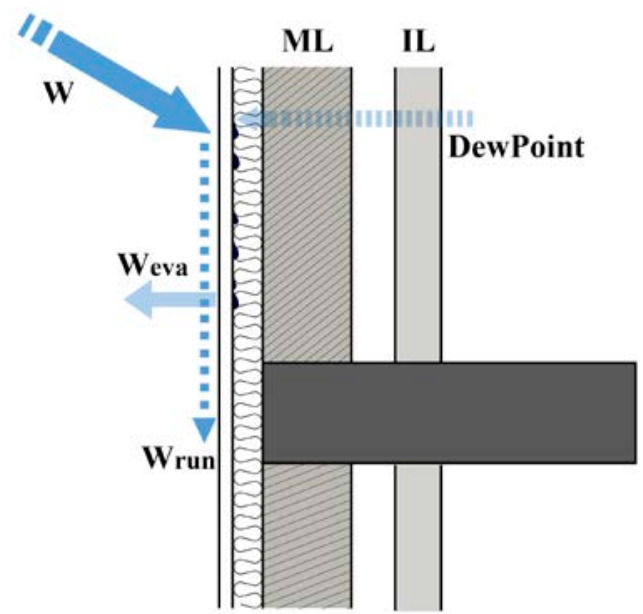

Figure 1.19. Water management in External Thermal Insulation Composite Systems (ETICS).

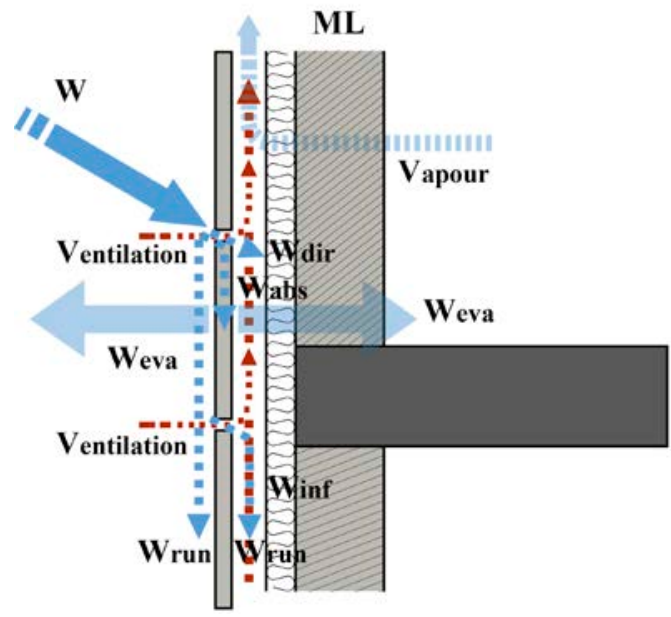

Figure 1.20. Water management in rear-ventilated façades.

Where: $\mathbf{W}=$ water impinging on the façade, Weva = evaporated water, Winf $=$ infiltrated water, Wabs = absorbed water, Wrun = runoff, $\mathbf{W d i r}=$ direct infiltrated rainwater, $\mathbf{M L}=$ mean leaf and $\mathbf{I L}=$ interior leaf.

On the other hand, the construction process of the façade avoids the presence of mortar drops and debris inside the air cavity. The only waterways between both leaves are expected to be the brackets that connect the secondary structure to the inner wythe. These surmised implementations on the hygrothermal response in rear-ventilated façades together with the problems emerged with the use of EIFS have encouraged their use over the last years in both renovation and new projects. Note that in Spain, only face-sealed EIFS have been manufactured and used up to now. Nevertheless, it should be noted that the thermal performance of the façade system will crucially depend on the width and type of thermal insulation used and the depth of the air cavity. Besides, the properly design of the detail of the window-wall interface in renovation projects with this type of façade system is still an important issue to be addressed. 


\section{3 | COMPONENTS OF REAR-VENTILATED FAÇADES}

Before going into detail, some concepts are clarified:

- The primary structure or shell of building is formed by the main load-bearing structure of the building. It transfers the loads from the façade and the building to the foundation and thereby, has structural functions beyond self-support under gravity.

- The secondary structure or framework or subframe is a set of resistant elements responsible for transmitting forces received by the cladding to the primary structure or to a self-support wall. To avoid wedging, the secondary structure is supported on its lower edge or it is suspended from above.

- The self-support wall is a resistant structural element which is part of the building and is responsible for transmitting forces to the primary structure of the building. It has no structural functions beyond selfsupporting under gravity.

A rear-ventilated façade is a construction system consisting of an external cladding, mechanically fastened to a framework (specific to the kit or not), which is fixed to the external wall of new or existing buildings (retrofit) [49]. The outer leaf (external cladding) is detached from the inner leaf (external wall), placing inbetween a fully ventilated air cavity, which shall always be drained. Inside the air cavity, a thermal insulation layer can be placed in the exterior side of the interior leaf.
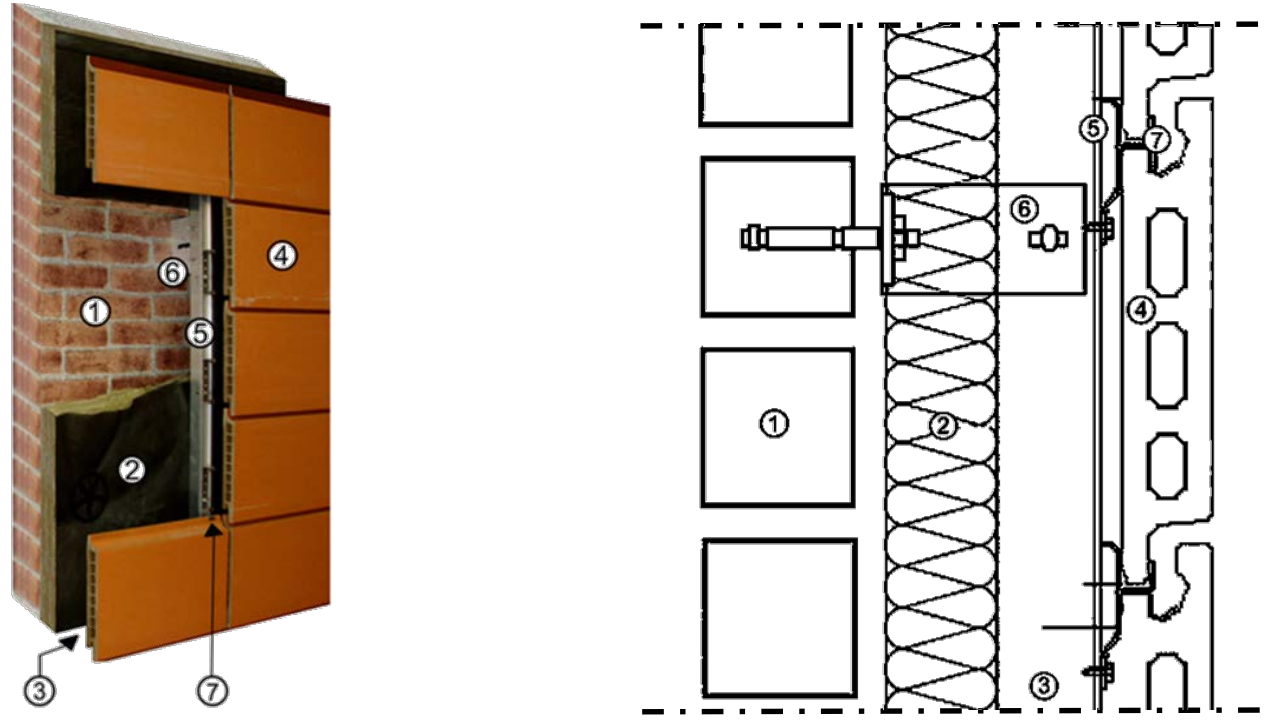

Figure 1.22. Components of a rear-ventilated façade system. On the left there is an illustration of an open joint ventilated façade with ceramic tiles, on the right the construction detail [352].

Hence, the mean components from the inside to the outside are:

- Substrate wall or external wall or interior leaf (see 1 in Fig. 1.22)

- Angle brackets or subframe fixing devices (see 6 in Fig. 1. 22)

- Thermal insulation layer (see 2 in Fig. 1. 22) 
- Secondary structure or subframe (see 5 in Fig. 1. 22)

- Air cavity (see 3 in Fig. 1. 22)

- Fixing system or cladding fixing (see 7 in Fig. 1. 22)

- Cladding elements or exterior leaf (see 4 in Fig. 1. 22)

\section{Substrate wall:}

The substrate wall is responsible of providing stability to the whole system (resistance to static and dynamic loads), the required accoustic insulation, the necessary airtightness, a relevant water vapour resistance $[7,49]$ and is the support for the interior finish. It can be part of the building shell, being then a load-bearing wall or it can just be a self-support wall, when the building shell is a grid of beams and columns.

The substrate wall can consist of: masonry walls, concrete walls, timber frame or a metal frame [49]. However, early rear-ventilated façades included a brick masonry wall (10 or $15 \mathrm{~cm}$ hollow brick or perforated brick) inserted between slabs which was leveled on the outer surface to the frame [51]. When the substrate wall consisted of a brick masonry wall, a cement or plaster rendering can be laid over the exterior surface to improve the watertightness performance of the interior leaf. So far, it is in continuous development since the interior leaf, nowadays free from a load-bearing role, tends to be substituted by a light-weight leaf built with dry construction techniques [22, 51]. Usually, it is a timber frame or a metal frame mechanically fixed to the slabs upon which the internal finishing is positioned and is used to support the thermal insulation layer and the secondary structure.

\section{Cladding elements:}

The cladding elements can be directly hung on the substrate wall by means of anchor points (which are encompassed as fixing system) when the substrate wall is resistant enough or they can be hung on a secondary structure when the substrate wall is not resistant enough. In the latter case, a fixing system is required apart from the secondary structure. The selection of the type of anchorage in the case of cladding elements directly hung on the the substrate wall is based on the material and thickness of the substrate wall. In non-load-bearing walls, the secondary structure is attached to the substrate wall by means of brackets (load-carrying and restraint brackets).

\section{Angle brackets:}

Angle brackets are elements used to mechanically fasten the secondary structure to the substrate wall [49], to which they transfer the loads exerted on the exterior leaf (wind and dead loads). Therefore, the bracket laying pattern is defined on the basis of the modularity of the cladding elements and the calculations of mechanical resistance to the weight of the secondary structure, the weight of the cladding and wind action. Depending on the function, they can be listed as restraint (sliding) brackets or as load-carrying (fixed) brackets. The formers only resist horizontal efforts which are transmitted by wind loads and seismic forces. In addition, they absorb tension forces caused by material expansion/contraction due to changes in temperature. They are placed along the substrate wall alternately on the left and the right sides of the vertical profiles (uprights). Around two or three retention brackets are required for every vertical profile, hanging upon its length. The latters not only resist horizontal efforts, but also vertical efforts due to the own weight of the secondary structure and the cladding elements. Every 
vertical profile has one, usually located in the middle, to fix the upright to the structural shell of the building (the slabs).

Notwithstanding, the disposal of brackets or any kind of anchoring that penetrate the thermal insulation layer result in the formation of thermal bridges. As these anchorings exhibit a much higher thermal conductivity than the insulation material, they effectively dissipate heat from the building in much the same way as cooling fins [12]. Hence, these points are main areas of concern extremely difficult to correct in that type of façades.

\section{Thermal insulation layer:}

A thermal insulation layer is usually attached to the external wall and these typically can be made of materials as provided in Table 1.1.

Table 1.1. Insulation materials specified for rear-ventilated facade systems in accordance with ETAG 034 [49].

\begin{tabular}{ll}
\hline \multicolumn{1}{c}{ Insulation material } & \multicolumn{1}{c}{ Material conformance standard } \\
\hline Expaned polystyrene (EPS) & EN13163 \\
Extruded polystyrene (XPS) & EN 13164 \\
Polyurethane (PUR) & EN 13165 \\
Phenolic foam & EN 13166 \\
Mineral wool & EN $13162($ WS or WL(P))* \\
\hline
\end{tabular}

* depending on national regulations

The thermal insulation layer is recommended to cover continuously the entire exterior surface of the substrate wall without interruptions at framework edges and at columns to avoid thermal bridges. In this way, sudden temperature changes are prevented as well as thermal movements [7]. Further, the thermal inertia of the façade is increased. Hence, the interior leaf and the thermal insulation layer take part in the energy efficience of the building. Consequently, the selection of the insulation material and the thickness of the layer is very important and pends on: climate conditions, thermal requirements established in the standards (DB HE of the Technical Building Code, CTE) and the material of insulation (R-value or thermal resistance). In Table 1.1 are given the insulation materials specified for rear-ventilated facade systems in accordance with ETAG 034 [49]. These materials can be found in several formats: panels in rolls, rigid or semi-rigid panels or can be directly sprayed over the substrate wall. When they are not sprayed against the substrate wall, they require fasteners to secure and retain them in place. For instance, mineral fibre-based insulation materials give rise to flexible and open cell porous insulations, which are good at the absorption of sound waves (they reduce the transmission of noise around 15dBA [64]). However, there can be moisture inside the air cavity as a result of both rainwater infiltration and condensation on the inner face of the cladding. Fibre-based insulations, like fiberglass or mineral wool, exhibit a better performance against fire and sound, but they require a protection from moisture (e.g. waterproof foil permeable to water vapour) to prevent a loss of their thermal effectiveness. Hence, it is a basic need to consider carefully the choice of the thermal 
insulation material as it shall be no-hygroscopic, rotproof and waterproof (e.g. closed cell foams). Condensation can also appear on the surface of the brackets when temperatures are below the dew temperature. In addition, the thermal insulation shall be non-combustible.

\section{Secondary structure:}

The secondary structure is an intermediate assembly of vertical and /or horizontal, wood or metal profiles, located between the cladding elements and the substrate wall [49]. This receives the loads exerted over the exterior leaf (wind and dead loads) by means of the fixing system and transmits them through the load-carrying (fixed) brackets to the shell of the building or to the substrate wall, if its resistant enough, avoiding any deflection in the mean time that might affect the geometry of the façade. It allows the detached placement of the outer leaf, providing an air gap between the inner and outer leaves. In addition, its construction favours saving in handwork since it avoids fixing every anchor to the substrate wall, boosting the use of fast anchor industrialized fixing systems.

The types of secondary structure are diverse and their shape depends on the cladding elements hung on it. So, the secondary structure is influenced by numerous variables such as architectural choices, the morphology of the building, the type and weight of the cladding elements, the choice of the type of joint between cladding elements, etc.

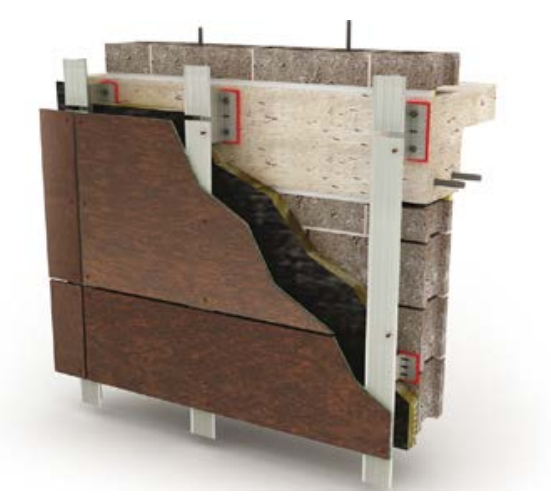

Figure 1.23. Rear-ventilated façade whose secondary structure only has vertical profiles. The fixing system consists on rivets. Source: Gamma Stone Air.

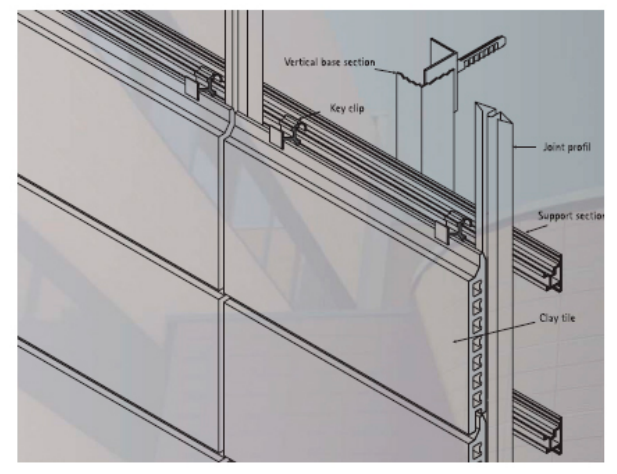

Figure 1.24. Rear-ventilated façade whose secondary structure has vertical and horizontal profiles. The fixing system consists on clips. Source: Alphaton Clay-Tile façade.

The secondary structure generally comprises a stud frame made up of vertical profiles (uprights) to which the fixing system (cladding fixing) is directly attached (see Fig. 1.23). The distances between uprights and their width are determined by the load requirements and by the type of cladding element used. Sometimes, the secondary structure can also be composed of horizontal profiles (crosspieces) affixed to the vertical profiles (see Fig. 1.24). However, it is worth noting that the fixing system can consist of horizontal rails similar to crosspieces, in some cases; refer to Fig. 1.44. In this instance, the horizontal rails cannot be considered a part of the secondary structure but as part of the fixing system that allows linear connections of the cladding elements [52]. 
Special attention should be paid in the selection of the metallic elements of the secondary structure and the cladding fixings to prevent galvanic corrosion.

\section{Air cavity:}

The air cavity is the key element of this type of façade systems. It is a layer of air between the substrate or insulation layer and cladding elements connected to the external environment [49]. One of its principal functions is to avert the direct sunshine on the interior wall. So, the interior leaf is only exposed to ambient temperatures and not to temperatures of a material heated by the sun. Further, it permits water vapour diffusion from the internal side of the wall. The fully ventilation of the cavity encourages a regulating behaviour of the façade. On a warm day, the air is sucked towards the interior of the air cavity because the already contained air has been warmed, bringing about the diminution of the density and leading to upward convection air jet. The temperatures inside the air cavity might be higher than the exterior temperature reducing the heat loss across the façade [7]. Hence, the air with higher temperatures drags the internal moisture because of the greater capacity to absorb water.

Diverse construction designs for the vertical and horizontal joints of the cladding elements can be proposed (open and closed joints), insofar as there is a sufficient ventilation of the cavity. Refer to HE-1 of the Spanish Technical Building Code (CTE) [74] to know the prescribed effective areas for ventilation of air cavities. According to ETAG 034 [49], ventilation openings are envisaged, as a minimum, at the building base point and at the roof edge with cross-sections of at least $50 \mathrm{~cm}^{2}$ per linear metre.

Regarding the CTE-HS1, one of the requirements to have a high resistance to water infiltration of the waterresistant barrier is to set a ventilated air cavity of at least $3 \mathrm{~cm}$ deep and no more than $10 \mathrm{~cm}$ deep. Alternatively, ETAG 034 [49] states that the distance between the cladding elements and the insulation layer or the substrate wall accordingly amounts to at least $20 \mathrm{~mm}$. Further, this air space may be reduced locally to 5 to $10 \mathrm{~mm}$ depending on the cladding and the secondary structure, provided that it is verified that it does not affect the draining and/or ventilation function. In this context, Sánchez-Ostiz [7] proposes 4 to $5 \mathrm{~cm}$ deep to have an appropriate ventilation. In addition, it is suggested to change the depth of the air cavity depending upon the weather conditions, the orientation of the façade and the type and color of the cladding element.

\section{Fixing system:}

It is considered as fixing system the element that joins the exterior leaf to either the building shell or to a substrate wall enough resistant or to the secondary structure. This definition encompasses profiles, brackets, screws/anchors, nails, rivets or any special fixing devices used to secure the cladding element [49]. Hence, the main purpose of the fixing system is to hold the panels in place. Consequently, it shall be designed to:

(i) transfer the dead load of the cladding element into the structure behind;

(ii) transfer loads generated by wind pressure and suction;

(iii) allow permanent expansion of the cladding elements generated by temperature and / or humidity variations;

(iv) offer relative safety from the detachment of panels and 
(v) prevent moisture build-up in particular areas acting as a dripping edge outside the interior leaf.

The fixing system might not only allow for adjusting of the cladding plane in the three directions, but also for combinations of free movements and stress accommodation at the specific location of the fixing point.

Typically, the selection of the fixing system is conditioned by the façade image and the cladding material. There is a wide range of options available in the market with diverse features and purposes. Given this wide variety, some classifications are provided in the few construction guidelines $[3,7,14,49,65,68]$ and sector documents [4, 14, 66]. These documents generally refer to them as anchors. For instance, the anchors can be listed in two groups relying on the way they connect the cladding elements to the interior wall:

(a) anchor points directly attached to the interior wall

- point connection to the interior leaf + point connection to the cladding element

- Connection to the the cladding element:

- dowel mechanism

- flange mechanism

- Connection to the interior leaf:

- fitted anchors

- mechanically fixed anchors.

(b) anchors connected to the interior wall by means of a secondary structure.

- Fixing method

- Mechanical

- Adhesive

- Mixed (mechanical and adhesive)

- Anchors

- visible

- concealed

- Connection

- Linear

- Point-based

The former group (a) are complete pieces that fix directly the cladding elements to the substrate wall. In this case, the substrate wall can be part of the building shell or it can just be a self-support wall with enough resistence. Thus, the fixation is based on points in both connections: to the interior leaf and to the elements of the cladding. It is a fixing system typically utilized in stone claddings. The connection with the cladding elements consists on either a dowel (cylindrical pin) or flange mechanism (see Fig. 1.25 and 1.26).

Nonetheless, the dowel mechanism can only be used in stone plates, whereas the flange mechanism can also be used in claddings made of ceramic tiles. In the dowel mechanism (Fig. 1.25), dowel holes of 8 mm diameter at least are predilled in the stone plates. These holes are filled with cement paste, mastic (or associate material) in load-carrying points and inserted with a plastic sliding tube (nylon bushes) in restraint points. The panels are hold in place by four points, which can be either at side faces or at top- and bottom faces. Usually the restraint anchors are located at the lower two positions of the panel while the load-carrying anchors at the upper two positions. 
Whereas the dowel mechanism is always concealed, the flange mechanism can be visible (see Fig. 1.26) or concealed. In the case of concealed flange mechanisms, the panels are manufactured with a groove which is not filled when the façade is assembled, unlike the dowel mechanism. Hence, any kind of material is interposed between panel and anchor.
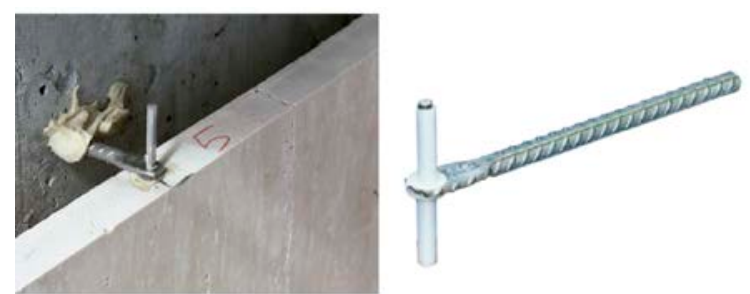

Figure 1.25. Point anchor (a) with dowel mechanism. Source: Grapamar, ref 1008.

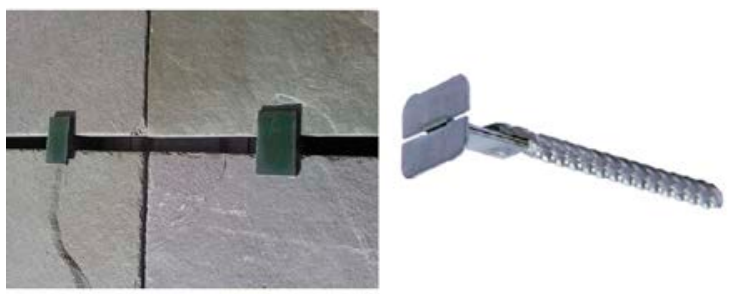

Figure 1.26. Point anchor (a) with flange mechanism. Source: Grapamar, ref 1008-R.

On the other hand, the connection to the interior wall can be executed by (a.1) fitted anchors or by means of (a.2) mechanically fixed anchors. The group of fitted anchors encloses immersion in a bonding agent, chemical immersion and injection resins [7]. The execution of fitted anchors basically consists on the drilling of an opening in the substarte wall. Afterwards, a metallic element is placed inside the opening and the voids are filled with mortar in the case of brick masonry walls or epoxy resin in the case of concrete walls. It is really important to be aware of the compatibility between anchorages, which are usually made of stainless stell, and the support material of the substrate wall. Figures 1.27, 1.28 and 1.29 exhibit some examples of fitted anchors with dowel mechanism (ribbed rod, threaded rod and strap).

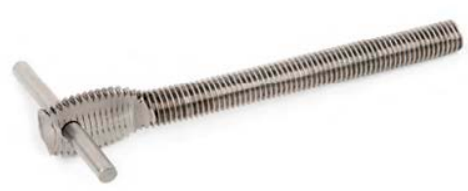

Figure 1.27. Fitted point anchor (a.1) with dowel mechanism: threaded rod. Source: INDEX Fixing Systems, ref AVR.

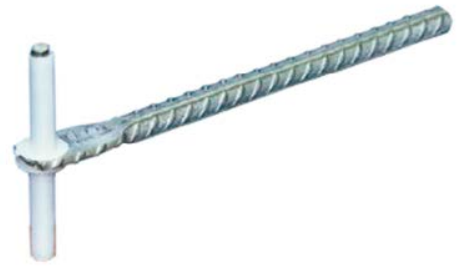

Figure 1.28. Fitted point anchor (a.1) with dowel mechanism: ribbed rod. Source: Grapamar, ref 1004.

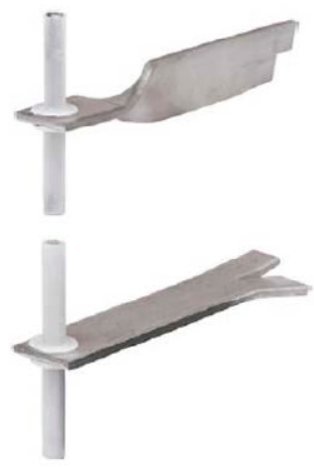

Figure 1.29. Fitted point anchor (a.1) with dowel mechanism: strap. Source: Grapamar, ref 1004.

The installation of claddings with mechanically fixed anchors (a.2) is faster than with fitted anchors due to their immediate load-bearing capacity. It implies that work can be progressed quickly as there is no need to let the anchorages dry and cure. There are several types of mechanically fixed anchors depening on their design: (a.2.1) angled profiles, (a.2.2) fastening clamps, (a.2.3) local brackets (refer to Figs. 1.30, 1.31 and 1.32) and body anchors (a.2.4). Angled profile anchors (a.2.1) are utilized when the cladding elements are not heavy and the air cavity 
width is rather small. They comprehend an "L" shaped stainless steel element, whose vertical plane is predrilled to place a screw that attaches the anchor to the substrate wall. The anchor can be adjusted to the width of the air cavity by means of an intermediate steel piece. The connection of the screw with the substrate wall is generally undertaken by expanding sockets. On the other side, fastening clamps (a.2.2) allow the employment of heavy cladding panels and small air cavity widths. They are composed of a single piece made of stainless steel, which is directly affixed to the substrate wall through a screw and lock nut. Whereas a mechanical expansion anchor is placed between the screw and the interior wall in concrete walls, a bushing is allocated for resin fixations in brick masonry walls. They are 3D adjustable anchors for cladding panels, like local brackets. The key benefits of local brackets (a.2.3) and body anchors (a.2.4) are that they are suitable for wide air cavities (a stand-off distance of 30$270 \mathrm{~mm}$ ) and heavy cladding panels (load capacity up to $1300 \mathrm{~N}$ ). Local brackets are made up of two "L" pieces arranged in parallel. On the top part they are connected by a plate and a screw with adjusting nut. Conversely, on the bottom they are separated and is disposed inbetween a ribbed or threaded rod, which is fixed using two compression cup nuts. The rod permits the regulation of the air cavity width.

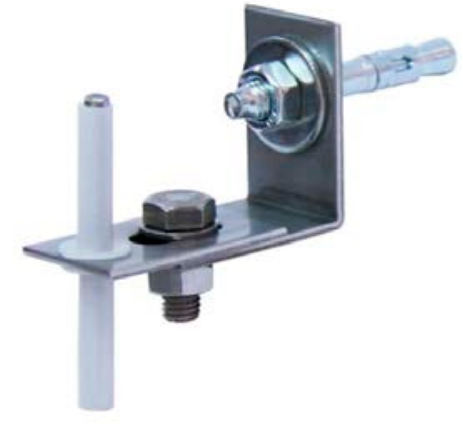

Figure 1.30. Mechanical fixed anchor by means of an angled profile (a.2.1) with dowel mechanism. Source: Grapamar, ref 1002.

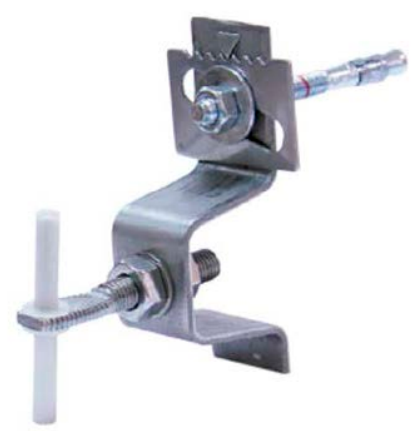

Figure 1.31. Mechanical fixed anchor by means of a fastening clamp (a.2.2) with dowel mechanism. Source: Grapamar, ref 1005

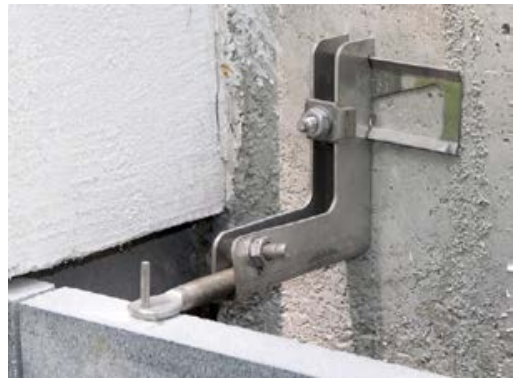

Figure 1.32. Mechanical fixed anchor by means of a local bracket (a.2.3) with dowel mechanism. Source: GutterKel.

Finally, there are the anchors connected to the substrate wall by means of a secondary structure (b). This secondary structure is required when the substrate wall is not resistant enough. These anchors use similar working principles to hold the panels in place as the anchors previously described. Nevertheless, instead of being directly attached to the substrate wall, they are fixed to vertical profiles (uprights) or horizontal profiles (crosspieces).

The fixing method between the upright or transom and the cladding element can be: (b.1) mechanical, (b.2) adhesive or (b.3) mixed (mechanical and adhesive) [69] (see Figs. 1.33, 1.34 and 1.35). Further, the anchors can be (c.1) visible or (c.2) concealed and the connection (d.1) linear or (d.2) point-based. Note that these features (b, $c$ and d) of the anchors are not mutually exclusive.

According to Fisher [67], mechanical fixing systems (b.1) present several drawbacks, amongst them, the likely appearance of internal strains. These strains might entail the premature failure of the anchorage due to overload and fatigue. The mechanical fastening method offers three possibilities:

- (b.1.1) to hang the cladding elements or 
- (b.1.2) to fix them directly to the secondary structure or

- (b.1.3) to hold the panels by means of anchors screwed to the vertical profiles.

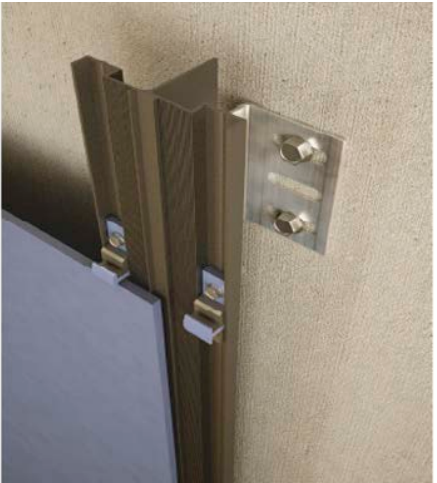

Figure 1.33. Mechanical fixing method (b.1). Source: SB Fijaciones.

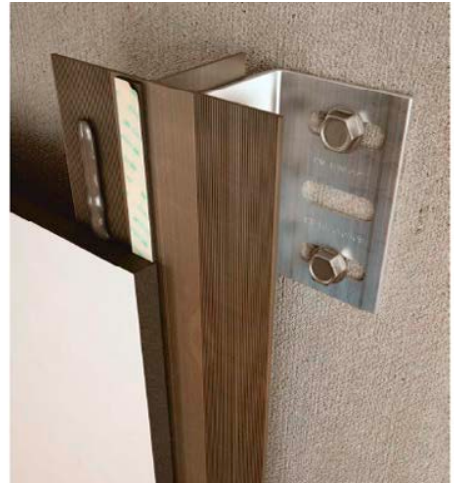

Figure 1.34. Adhesive fixing method (b.2). Source: SB Fijaciones.

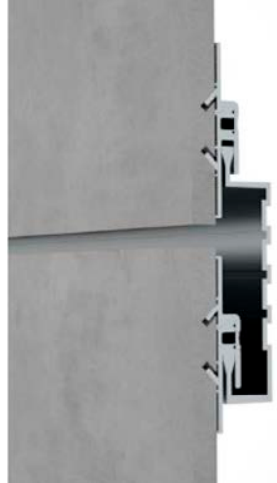

Figure 1.35. Mechanical-adhesive fixing method (b.3). Source: Wandegar.

Mechanical fixations where the cladding elements are suspended (b.1.1) or supported (b.1.3) can easily absorb the differential movements due to thermal expansion/contraction since the cladding elements are not tightly fastened to the secondary structure. Whereas the suspended cladding elements have the load-carrying connections at the upper positions, the supported cladding elements have them at the lower positions. In both cases, the connection between fixing system and cladding element can be point-based or linear.

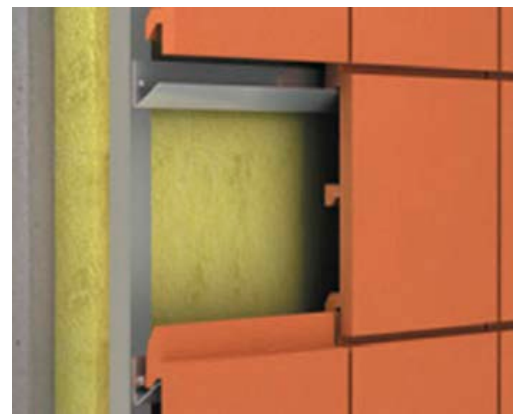

Figure 1.36. Ceramic tiles with protruding parts to hang them on horizontal rails (connection: lineal, fixing method: mechanical hanged). Source: internet.

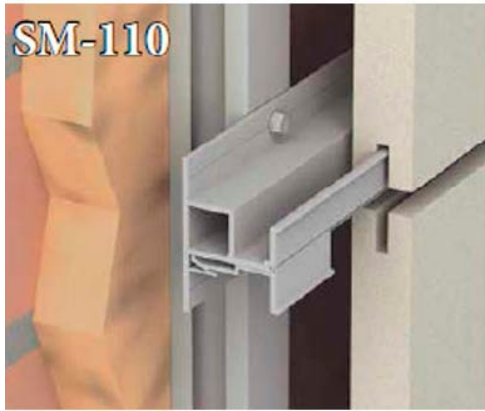

Figure 1.37. Example of a stone cladding with grooved edges held on horizontal rails (connection: lineal, fixing method: mechanical held). Source: Euroclad ref SM110.

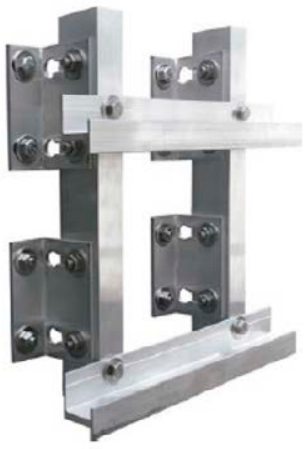

Figure 1.38. Horizontal rails screwed to uprights, where cladding elements are hanged (connection: lineal, fixing method: mechanical hanged/held). Source: Grapamar ref 1025 .

In the case of linear connections, a slit or groove is usually executed in the top and bottom edges of stone, ceramic, phenolic plywood or fibercement cladding elements (see Fig. 1.37). This slit or groove allows to support and retain the cladding element on metallic horizontal rails (see Fig. 1.38) whithout falling down. Nevertheless, linear 
connections can also be found with suspended cladding elements such as the ceramic or terracotta ones (see Fig. 1.36). For suspending them on horizontal rails, these cladding elements are manufactured with some protruding parts on the backside.

Metallic-based suspended cladding materials can either use the tongue and groove principle (see Fig. 1.39) or they can be suspended on a horizontal tray (rout and return) by the upper part (see Fig. 1.40). In the groove and tonge principle, the cladding elements are machined at the sides in order to fine-adjust with the suspended element. The suspended element is usually made of aluminium and is screwed to the vertical profile at the upper position. Further, an elastic section is fitted and adjusted to the cladding element in order to prevent vibration.

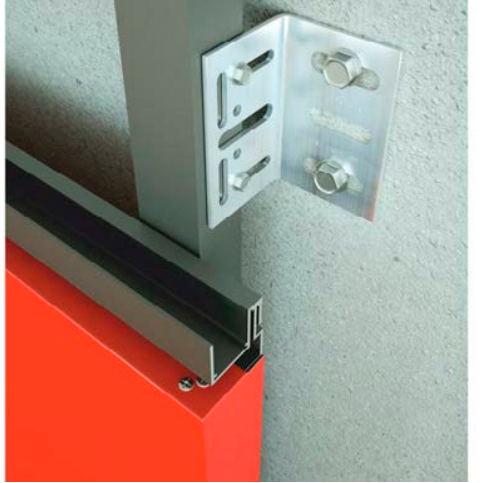

Figure 1.39. Cassettes mounted following the groove and tongue principle (connection: lineal, fixing method: mechanical hanged). Source: SB Fijaciones.

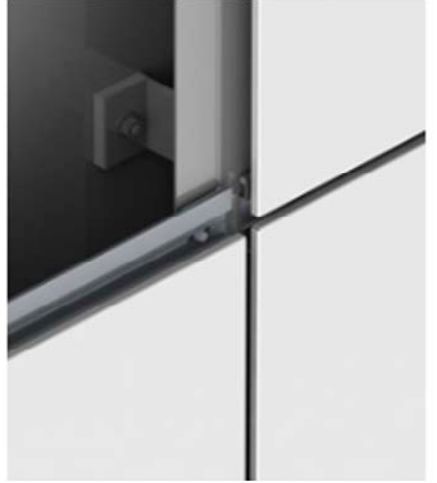

Figure 1.40. Cassettes mounted on horizontal trays (connection: lineal, fixing method: mechanical hanged). Source: Hunter Douglas ref QC200.

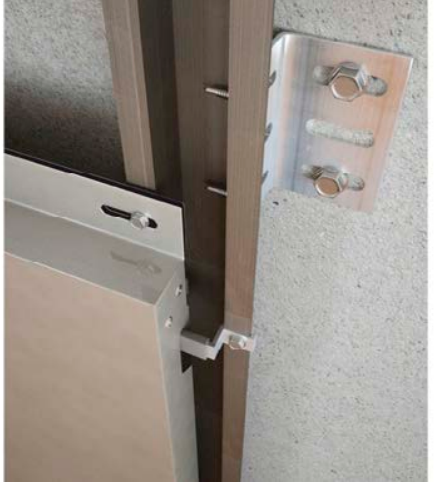

Figure 1.41. Cassettes mounted on stainless steel bolts placed in the uprights (connection: point,

fixing method: mechanical hanged). Source: SB Fijaciones.
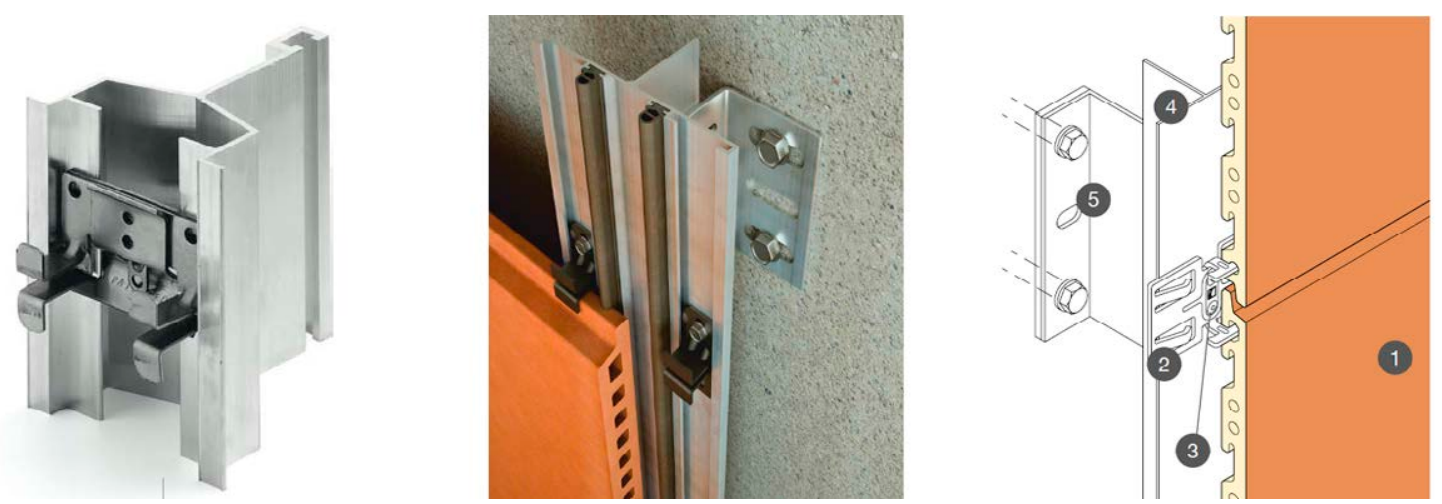

Figure 1.42. Different models of anchors. The photo on the left shows a clip from the Cotto D'Este company, "Sistema Clip Mimetiche". The photo in the middle presents a staple from the company SB Fijaciones, "Sistema CEX 90". The last photo exhibits a clamp from the company Buchtal, "KeraTwin® K20 Fastening with clamp system K20”.

The suspended point-based connection is typically used in rear ventilated façades with cassette cladding elements. An example of this type of fastening is illustrated in Fig. 1.41. As shown in the figure, the cassettes are suspended 
on stainless steel bolts placed between opposite faces in "C" vertical profiles. Further, an additional solid aluminum plate with a slot can be attached on the returned panel edges of the cassette. In this way the hanging points of the cassette are reinforced. This fixation system enables to withstand medium to high wind load cases.

On the other hand, there are many solutions available in the market for the supported point-based connections: clips, staples, clamps, cramps... Different names for anchors with slight differences due to patent issues that work with similar principles (see Fig. 1.42).

The anchors of this type of connections can be either attached to vertical profiles (uprights) or to horizontal profiles (crosspieces), when there are (see Fig. 1.24). Then, the anchor is installed into the metallic profile in a rail lane. Furthermore, the fixed anchors are screwed on one of its sides to the secondary structure (in the load-carrying point of the cladding element), whereas the sliding anchor is left loose (the restraint point of the cladding element). This ensures the cladding element and allows the movemevent along the profile in the sliding points (thermal expansion and shrinkage of the cladding element). These anchors are often made of stainless-steel or aluminium. Supported point-based connections are employed with diverse cladding materials, such as: ceramic, terracotta, stone, fibrecement or phenolic sheets among others. Notwithstanding, it is recommended to apply either an elastic adhesive or a vertical joint profile or a metallic spring between the vertical profile and the rear surface of the cladding element, when the backside of the cladding element is flat (it has no protruding parts). Thus, the lateral moving and vibrating of the cladding element is prevented.

Lastly, there are the cladding elements mechanically fixed to the secondary structure (b.1.2) by means of screws or rivets. These are point-based connections that can be done either between the cladding element and the vertical profile (upright) (see Fig. 1.43) or between the cladding element and the horizontal profile (crosspiece) (see Fig. 1.44). Like in the supported point-based connections. The cladding elements can be pre-drilled in the factory, or drilled on site with special tools. This fixation method can be used in claddings made of ceramic, CRC, fibrecement, composite, metallic or phenolic sheets amongst other materials.

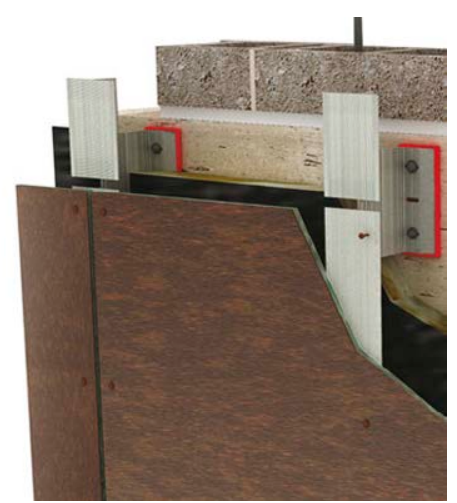

Figure 1.43. Riveted fixing system to vertical " $T$ " profiles (connection: point-based, fixing method: mechanical fixed). Source: Gamma Stone Air.

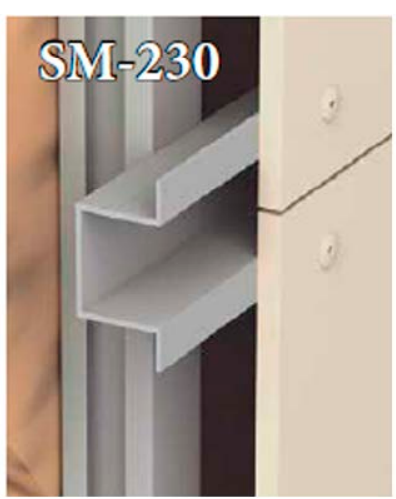

Figure 1.44. Riveted fixing system to horizontal omega profiles (connection: point-based, fixing method: mechanical fixed). Source: Euroclad ref SM230.

The adhesive fixing method may just form linear connections (b.2 - d.1); refer to Fig. 1.34. An advantage of adhesive connections is averting the machining of the cladding element, which prevents the appearance of internal 
localized strains. Further, they provide a more even distribution of stresses and they withstand higher cyclic loading and fatigue. Nevertheless, they require a careful preparation of the base materials, a thourough control of the installation process and some time to enable the proper state of cure of the adhesives [67]. In addition, site bonding is limited to application within the temperature range from $5^{\circ} \mathrm{C}$ to $35^{\circ} \mathrm{C}$ and only in dry weather conditions. It is a fastening method that basically consists on applying two beads of structural elastic adhesive over the whole length of the vertical section of the uprights. The two beds of elastic adhesive are laid parallel to the edges of the profile. Previously, the surfaces in contact with the adhesive material have been cleaned and treated with primers to avoid adhesion failures. Each bead has a particular function in the fastening. On one hand, the double-sided tape of closed cell polyethylene foam of at least $3 \mathrm{~mm}$ thick controls the spread of adhesive as the cladding element is applied. It also provides initial contact retention whilst the adhesive cures. On the other hand, the polyurethane-based adhesive moisture cure will keep the cladding elements attached during their entire lifespan (40 years according to laboratory testing). For the time being, it is not recommended to be used in building façades of more than four floors. Moreover, any transfer of loads or movements from the substrate wall to the vertical substructure and the adhesive joint has to be avoided.

So, it seems reasonable expecting that the mechanical-adhesive fixing method (b.3) combines the benefits of the mechanical and adhesive methods while avoiding the disadvantages that each fixing method has. Hence, on the one hand, the mechanical fastening will not only offset the impact of high temperatures on the adhesive fastening, but also enable a minimum strength whilts the curing of the adhesive. On the other hand, the adhesive fastening will withstand the mechanical stresses and will allow to hide the fixing system. This type of fastenings has given rise to the concealed anchor typology (back face anchors). Back face anchors can be executed with linear or pointbased connections. In both type of connections, the fastening works by the compression exerted by the system on the back of the cladding element, which is suspended on horizontal profiles (crosspieces).
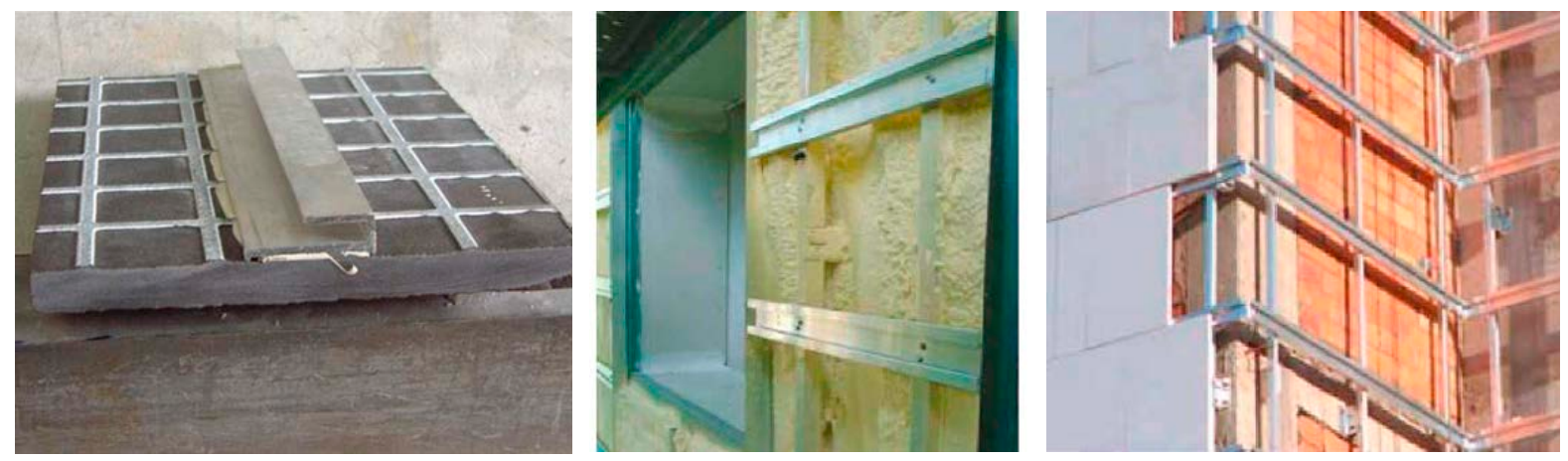

Figure 1.45. The image on the left shows the grooved manufactured cladding element, in which the aluminium profile is inserted using adhesive. The photo in the middle exhibits the secondary structure required to hang the cladding elements. The third picture presents an on-site example of the façade system. Source: Mecanogumba, "Mecanofas Karrat S7".

In the case of linear connections (b.3 - d.1), an aluminium profile is inserted and fixed with an MS adhesive putty on the rear face of the cladding element. For it, the cladding element is industrially mechanised in a longitudinal way at the top and bottom of its back with a $45^{\circ}$ groove in the shape of a dovetail. This groove is used to place the 
profile. Between the profile and the cladding element is interposed an adhesive that covers the whole contact surface. This adhesive absorbs the expansion movements of the profile and the cladding element. The main advantage of this fastening is the reduction in the thickness of the cladding element. Further, it eliminates the risk of detachment of the cladding parts if they are broken from an impact. Figure 1.45 illustrates an example of a linear connection with mechanic-adhesive fixing method.

Nonetheless, there are mechanical fixing methods with concealed anchors as well. These are assembled on site, unlike the mechanical-adhesive fastening. In Fig. 1.46 is given an example of a back face anchor that uses a mechanical fixation method. These fastenings basically consist on the installation of a kind of hanger over the rear face of the cladding element on the fixed and sliding points. The hangers of the cladding element are not visible from the exterior of the façade. Consequently, the building façade has a smooth unbroken exterior surface, like when using adhesive fixations. These hangers are installed with small expansion bolts in specially drilled holes (undercut anchors) on the backside of the cladding element. These drilled holes are mechanised and have two diameter sections: narrower (around $7 \mathrm{~mm}$ ) in the mouth of the bore and wider into the bore (around $9 \mathrm{~mm}$ ). A conical piece (plug) with an exterior smooth surface and threaded inside is first inserted in the hole. Later, the expansion bolts are installed. The interior part of the plug expands when the bolt is inserted. The hangers are suspended onto horizontal rails, which are fixed to vertical profiles. Hence this type of fastening creates pointbased connections (b.1.3 - d.2).

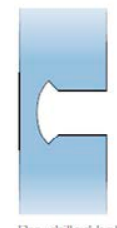

Pre-drilled hole
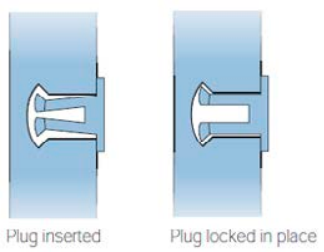
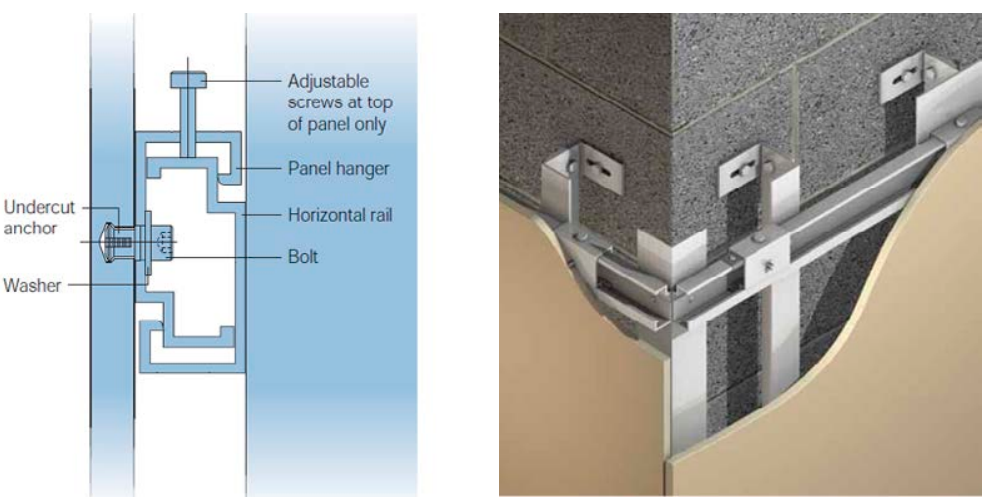

Figure 1.46. In the photo on the left is schematically exposed the working principle of the undercut anchor. The second one presents a vertical section of the back face fixing system and the last one shows a 3D example. Source: Eternit, "Mechanical secret fix".

Opposing to the principle for point anchors (a) with dowel mechanism, back face anchors have the load-carrying function at the upper anchor positions. Alternatively, the lower anchor positions have a restraint function only. It is also worth mentioning that the pull-out loads for back face fixings are typically 4-6 times higher than the breakout load for point anchors (a) with dowel mechanism at edge dowel holes [70].

\section{Cladding elements:}

The exterior leaf of a rear-ventilated façade replaces the exterior wythe of a traditional façade [7]. It is responsible of providing with the aesthetic aspect of the façade (image of the building). It also closes the air cavity and protects the thermal insulation layer from the weather conditions. For there to be ventilation of the air cavity and pressure 
equalization across the exterior leaf, a discontinuous covering with open joints is used. Hence, the exterior leaf is composed by a modular face wall attached to a secondary structure or to the interior leaf by means of a visible or concealed fixing system. This modular face consists in cladding elements that are usually assembled according to a specific technical design for joints and construction discontinuities, which forms part of the product description [49]. So, the open joint assembling pursues not only aesthetic aspects, but also technic criteria.

In order to have good ventilation of the air cavity (air exchange rate), the air cavity depth and the width of the vertical and horizontal joints shall be carefully studied and designed. The distances between the panels at joints (joints width) must also ensure that the cladding elements can freely deform without cracking and/or causing compression between them. Therefore, the joint width is influenced by the following parameters:

- the cladding element dimension and production tolerances;

- the cladding element dimensions and expected differential movements induced by temperature and moisture variations;

- permanent expansion of the material of the cladding induced by temperature and moisture;

- thickness of anchor plates;

- expected tolerances at installation and

- expected tolerances and deformations at the building structure.

Moreover, the connection between the exterior leaf and the substrate wall or secondary structure shall not be rigid to prevent cracking and spalling of the cladding elements in the anchorage points.

The cladding of rear-ventilated façades can be made of wood based panels, plastic, fibre cement (like the products of Euronit), fibre reinforced cement (like the Naturvex panels, which are reinforced with cellulose), concrete (as the Ulma polymer concrete panels), metal sheet products (as the zinc panels and cassettes from VMZ), aluminium composite materials (like the cassettes or panels made of two metal sheets with a low density polyethylene inside core manufactured by Alucobond, Alucoil, Stacbond and Reynobond), high pressure laminated panels, HPL (like the Formica, Prodema,Trespa Meteon or Max4 manufactured products), stone (like Strow systems), ceramic (like the products Frontek) or terra cotta tiles (like the products Favemanc, ArGeTon, Stonker or Porcelanosa FV).

ETAG 034 [49] also considers other elements such as the cavity barrier and the breather membrane. In it, the cavity barrier is defined as any element placed in the air space to separate horizontally or vertically two compartments of air space (for fire or wind pressure purposes). Alternatively, as breather membrane is considered the membrane placed in the cladding kit which contributes to the watertghness of the wall.

\section{4 | REAR-VENTILATED FAÇADES STANDARDS}

Rear-ventilated façades are contemporary construction systems which are widely adopted by architects and building practitioners as these offer a number of technical and aesthetic benefits in comparison to traditional façades (unventilated walls, vented walls and cavity walls). Therefore, the evaluation of their performance has 
become a major issue for manufacturers and building practitioners. In this context, the Spanish framework is constituted by:

- $\quad$ The Law 38/1999, dated November 5, on Building Ordinances (Ley 38/1999, de 5 de noviembre, de Ordenación de la Edificación, LOE) [72] and

- $\quad$ The Spanish Building Code (Código Técnico de la Edificación, CTE) [74].

The Law on Building Ordinances defined the mandatory basic requirements for buildings. These were subsequently taken up by the Spanish Building Code and developed more in detail by the Basic Documents of the Spanish Building Code.

Rear-ventilated façade systems are considered alternative technical solutions to those outlined in the Basic Documents of the CTE. Thus, a specific analysis is necessary to confirm that they comply with the basic demands prescribed in the CTE. To demonstrate this, suitable methods can be used to verify that the performance of the evaluated rear-ventilated façade system is within the threshold values and assessment criteria established for the performance specification associated with each basic requirement outlined in the Basic Documents of the CTE. In this regard, some of the system's performance specifications can be verified by directly using the Basic Documents, but a more specific analysis is required to verify other characteristics. In this last case, it is necessary to establish threshold values and verification methods that are appropriate for the type of enclosure system being analysed.

In addition to the CTE and the LOE, the following reference document shall be considered as well:

- The Construction Product Regulation (CPR) 305/2011 [71], whose implementation in harmonised technical specifications for the elaboration of harminized standards is especified in the Annex ZA.

There are other European Standards that may be consulted since their use is voluntary:

- The European Technical Approval Guidelines (ETAGs) regarding the methods verifying the specific characteristics for certain construction products. ETAGs were established by the European Organisation of Techncial Approvals under the Construction Products Directive - 89/106/EEC (CPD) - upon mandates of the European Commission. According to Art. 66(3) of the Regulation (EU) No. 305/2011. ETAGs may be used by Technical Assessment Bodies (TABs) organised in EOTA as European Assessment Documents (EADs) for issuing European Technical Assessments (ETAs).

- European Technical Assessments (ETAs). It is a document based on an agreement between the manufacturer and the Technical Assessment Body (TAB) concerning those characteristics for which the manufacturer wishes to declare the performance and which might be relevant for the intended use. It is the documented assessment of the performance of a construction product as it has just been manufactured, in relation to its essential characteristics.

- Similar to the ETAs, there are the Document of Assessment for fitness of Use (DAU) in Spain. This document is the statement of a favorable opinion on the performances of an innovative product or system regarding its intended uses and defined constructive solutions, within the field of building and civil engineering construction. 
- $\quad$ The International Organization for Standarization (ISO Standards). ISO creates documents that provide requirements, specifications, guidelines or characteristics that can be used consistently to ensure that materials, products, processes and services are fit for their purpose.

- $\quad$ The German Institute for Standarization (DIN Standards), and so on. DIN develops norms and standards for rationalization, quality assurance, environmental protection, safety and communication in industry, technology, science, and government, as well as the public domain. DIN standards provide a basis for quality, safety and minimum functionality expectations.

\subsection{1 | SPANISH TECHNICAL BUILDING CODE (CTE)}

The aim of the Spanish Technical Building Code [74] is to have in place a set of basic quality demands for buildings in order to meet the mandatory essential requirements laid down in the Law on Building Ordinances [72]. These basic demands are developed in more detail in the Basic Documents of the Spanish Technical Building Code. The Basic Documents characterize and quantify the basic demands by means of performance levels or threshold performance values, on the one hand. On the other hand, these also determine the procedures allowing for the compliance of such requirements with enough technical guarantees.

The diverse construction solutions for rear-ventilated façades are not completely enclosed in the Basic Documents of the Spanish Technical Building Code. Consequently, a large part of rear-ventilated façade systems shall be considered as alternative technical solutions to those outlined in the Basic Documents of the CTE. Therefore, evidence of their compliance shall be provided by means of the establishment of equivalences in the performances with regard to those obtained when the Basic Documents are applied. There are two possible alternative methods for demonstrating compliance with the basic requirements of the CTE:

(i) Adopting technical solutions based on standardized details provided in Basic Documents (DB), whose application demonstrates compliance by common practice.

(ii) Adopting alternative technical solutions that require specific proof of compliance with the basic requirements.

Hence, the performance specifications applicable to an alternative construction system can be listed in "levels":

1. Specification that is fully defined in the DBs, including the threshold value or assessment criterion and verification method and which, therefor, can be shown through the direct application of the DBs.

2. Specification that is partially defined in the DBs. In this regard, it is found that there are:

a. Specifications indicated in the DBs whose threshold value or assessment criterion are defined, but the verification method is not.

b. Specifications indicated in the DBs whose verification method is defined, but the threshold value or assessment criterion are not.

c. Specifications indicated in the DBs with no threshold value, assessment criterion or verification method defined.

3. Specification which is applicable to the alternative construction system, but are not defined in the DBs. However, the basic requirement is defined in the CTE. 
In this context, Table 1.2 provides a summary of the requirements, the basic demands and the performance characteristics with the related levels of definition in the Basic Documents applicable to rear-ventilated façades. Nonetheless, the current Ph.D-work focus on the water management characteristics of rear-ventilated façades. Hence, the protection against dampness is the basic demand of interest and thereby, the one being addressed in the present work. According to Table 1.2, this demand has three performance characteristics:

(i) the watertightness degree,

(ii) the drainage capacity of the air cavity and

(iii) the condensation constraints.

The two formers will be studied in the following lines, whereas the latter remains out of the scope. On the one hand, it is surmised that the watertightness degree should be assessed not only for the exterior leaf (rainscreen) of rear-ventilated façades, but also for the interior leaf. Thereupon, an assessment criterion is defined in the DB-HS [74]. Nonetheless, it does not set up the verification method [75].

Table 2.2. Requirements, basic demands and performance characteristics with the related levels of definition in the Basic Documents applicable to rear-ventilated façades [73].

\begin{tabular}{|c|c|c|c|c|}
\hline Requirement & Demand & Characteristic & Applicable to & Level \\
\hline \multirow{2}{*}{ Structural safety } & $\begin{array}{l}\text { Resistance and } \\
\text { stability }\end{array}$ & Mechanical resistance and stability & $\begin{array}{l}\text { Inner leaf } \\
\text { Outer leaf }\end{array}$ & 1 \\
\hline & Fitness for service & $\begin{array}{l}\text { Deformations (deflection and } \\
\text { collapse) }\end{array}$ & $\begin{array}{l}\text { Inner leaf } \\
\text { Outer leaf }\end{array}$ & 2 \\
\hline \multirow{3}{*}{ Fire safety } & Internal spread & Fire reaction of the inner face & Inner leaf & 1 \\
\hline & \multirow{2}{*}{ External spread } & Fire reaction of the outer face & Outer leaf & 1 \\
\hline & & Fire resistance & Inner leaf & 1 \\
\hline \multirow{4}{*}{$\begin{array}{l}\text { Health, hygiene } \\
\text { and environmental } \\
\text { protection }\end{array}$} & \multirow{3}{*}{$\begin{array}{l}\text { Protection against } \\
\text { dampness. }\end{array}$} & Watertightness degree & $\begin{array}{l}\text { Inner leaf } \\
\text { Outer leaf }\end{array}$ & 2 \\
\hline & & Drainage capacity of the air cavity & Outer leaf & 2 \\
\hline & & Condensation constraints & Inner leaf & 1 \\
\hline & $\begin{array}{l}\text { Hazardous } \\
\text { substances }\end{array}$ & $\begin{array}{l}\text { Content or emission of hazardous } \\
\text { substances }\end{array}$ & $\begin{array}{l}\text { Component } \\
\text { materials }\end{array}$ & 3 \\
\hline \multirow{2}{*}{$\begin{array}{l}\text { Safety of use and } \\
\text { accessibility }\end{array}$} & Risk of impact & Impact resistance & $\begin{array}{l}\text { Inner leaf } \\
\text { Outer leaf }\end{array}$ & 3 \\
\hline & $\begin{array}{l}\text { Risk of lightning } \\
\text { strike }\end{array}$ & Equipotentiality & $\begin{array}{l}\text { Inner leaf } \\
\text { Outer leaf }\end{array}$ & 3 \\
\hline $\begin{array}{l}\text { Accoustic } \\
\text { protection }\end{array}$ & $\begin{array}{l}\text { Accoustic } \\
\text { protection }\end{array}$ & $\begin{array}{l}\text { Insulation against airborne noise } \\
\text { from the outside }\end{array}$ & Inner leaf & 1 \\
\hline \multirow{2}{*}{$\begin{array}{l}\text { Energy saving and } \\
\text { thermal insulation }\end{array}$} & \multirow{2}{*}{$\begin{array}{l}\text { Restriction of the } \\
\text { energy demand }\end{array}$} & Thermal insulation & Inner leaf & 1 \\
\hline & & Air permeability & Inner leaf & 2 \\
\hline \multirow{3}{*}{$\begin{array}{l}\text { Additional } \\
\text { requirements }\end{array}$} & \multirow{2}{*}{ Durability } & Corrosion & $\begin{array}{l}\text { Metallic } \\
\text { components }\end{array}$ & 3 \\
\hline & & Reaction to accelerated ageing & $\begin{array}{l}\text { Component } \\
\text { materials }\end{array}$ & 3 \\
\hline & $\begin{array}{l}\text { Identification of } \\
\text { components }\end{array}$ & $\begin{array}{l}\text { Characteristics of the components } \\
\text { related to performance of the system }\end{array}$ & Components & 2 \\
\hline
\end{tabular}

The façades of the building should guarantee a watertightness degree depending on the geographical location of the building. This geographical location takes into account the wind and rainfall exposure of the building. 
According to the demanded watertightness degree, the DB-HS [74] evaluates the suitability of the adopted construction solution for the façade system. It provides a cualitative description of diverse parameters based on the use of traditional and accepted constructive solutions [76].

On the other hand, the drainage capacity of the air cavity shall be assessed as well. However, in this case, the DBHS [74] does not specify a threshold value, nor an assessment criterion and nor the verification method.

Therefore, it can be concluded that the specifications established in the Basic Documents of the Spanish Technical Building Code for façade systems are very general and do not reflect the rear-ventilated façades reality. Further, DB-HS [74] prescribes that the façades shall be watertight, but at no stage clarifies how to achieve it. Neither explains how it valorates these performance characteristics.

\subsection{2 | CONSTRUCTION PRODUCT REGULATION}

The aim of the Construction Product Regulation (CPR) 305/2011 [71] is not to define the construction product safety, but to ensure the reliability of the information presented in terms of performance and CE marking. Thus, the CE marking certifies that the information provided with the product has been obtained in accordance with the regulations.

The CPR 305/2011 [71] establishes two options for the CE marking of a construction product:

- Harmonised Standards (hEN), where the CE marking is mandatory and

- European Technical Assessment (ETA), where the CE marking is voluntary.

Note that the implementation in harmonised technical specifications for the elaboration of harminized standards (hEN) is especified in the Annex ZA of the CPR 305/2011 [71].

In this sense, there is any harmonised Standard that covers rear-ventilated façade systems for the time being. Therefore, manufacturers are adviced to request for European Technical Assessments of their products as a demonstrated evidence of the product performance.

\subsection{3 | EUROPEAN TECHNICAL ASSESSMENT (ETA)}

The European Technical Assessment (ETA) is an alternative for construction products not covered by a harmonised standard. This is issued by a Technical Assessment Body (TAB) based on the specifications stated in European Technical Assessment Guidelines (ETAGs) or European Assessment Documents (EADs). The ETAGs set out the performance obligations to demonstrate 'Fitness for Purpose' and address the essential requirements of the Construction Products Directive (CPD) [71]: Structural safety, Fire safety, Health, hygiene and environmental protection, Safety of use and accessibility, Accoustic protection, Energy saving and thermal insulation and Aspects of durability and serviceability; refer to Table 1.2. Alternatively, the EADs are harmonised technical specifications for construction products. Hence, an ETA is a document providing information on the intended use and 
performance assessment of a product. Besides, it offers a way for manufacturers to draw up the Declaration of Performance (DoP) and affix the CE marking. Note that each construction product covered by a European harmonised standard or for which a European Technical Assessment has been issued is in need of a DoP. Further, when a DoP has been done for a product, the CE marking of such product is compulsory.

Therefore, the performance assessment of rear-ventilated façade systems is done in accordance with ETA procedures. In this context, ETAG 034 Part 1 [49] and Part 2 [77] should be carefully studied. This Guideline covers kits for vertical exterior wall claddings consisting of an external cladding, mechanically fastened to a framework (specific to the kit or not), which is fixed to the external wall of new or existing buildings (retrofit). However, the Guideline does not cover cladding kits where the cladding is bonded directly to the subframe. Further, the guideline applies when the manufacturer delivers together all the components of a kit for external wall cladding.

ETAG 034 Part 1 [49] classifies the cladding kits in cladding families according to the methods of fixing. The suggested eight cladding families in the Guideline are listed below:

(1) Cladding elements mechanically fastened to the secondary structure by means of through fixing (e.g. nails, screws, rivets, ...);

(2) Cladding elements mechanically fastened to the secondary structure by a specific anchor placed in an undercut hole and anchored by mechanical interlock (at least 4 anchors);

(3) Cladding elements installed on a horizontal grid of metal rails or pins (e.g. dowel anchor), screwed to a vertical secondary structure;

(4) Cladding elements, integrated with adjacent elements by interlocking together at top and bottom with an overlap, fixed to the secondary structure by mechanical fixings positioned on the top edge and masked by the edge of the upper elements;

(5) Cladding elements fixed to the secondary structure by mechanical fixings positioned on the top edge and masked by the edge of the upper plank;

(6) Cladding elements mechanically fastened to the secondary structure by at least 4 metal clips or rails; (7) Cladding kits suspended on the secondary structure and

(8) Tile-hung cladding kit

In addition, ETAG 034 [49] sets out (i) the performance requirements to be examined in order to satisfy the relevant Essential Requirements of the CPD [71]; (ii) the verification methods used to examine the various aspects of performance in relation to the requirements for the works; (iii) the assessment criteria used to judge the fitness for intended use and (iv) the assumptions and recommendations for design, installation and execution under which the assessment of the fitness for use according to the ETAG can be made.

The research topic of the current Ph.D-work lies within the demand of dampness control. Under this demand, the performance requirements to be examined in agreement with ETAG 034 [49] are the following:

- $\quad$ The watertightness of joints (protection against driving rain);

- The water permeability of the cladding element (resistance to water diffusion);

- The water vapour permeability and 
- $\quad$ The drainability

Rear-ventilated façades are not watertight systems [49]. The degree of watertightness of the façade is generally assessed by appraisal of design, taking account of the characteristics of the materials used and the geometry of the external cladding element and joints. In this sense, the Guideline 034 proposes an artificial rain test on the cladding kit in accordance with EN 12865 Procedure A (600 Pa maximum) [78] when the watertightness of closed joints is needed. However, it does not suggest any kind of artificial rain test for cladding kits with open joints. Moreover, the performance result of such artificial rain test is a pass / fail criteria and the level of pressure just before water penetration is given. The Guideline just states two requirements to be satisfied for the intended working life of the kit: (i) the water running down the wall shall not reach the inside face of the wall and (ii) the materials likely to be adversely affected by water (adhesives, insulation fixings subject to corrosion, etc) shall not become damp.

Concerning the drainability performance requirement, ETAG 034 [49] proposes an assessment by appraisal of design taking into account of the characteristics of materials used and geometry of external cladding and joints. The cladding kit shall be designed and installed so that water which penetrates in the air space or condensation water shall be drained out of the installed kit without accumulation or moisture damage or leakage into the substrate or the wall cladding kit. Again, no test method is proposed and nor the perfomance levels of such requirement.

Finally, the performance requirements of water permeability and water vapour permeability are not considered relevant in façades with ventilated air cavities [49]. Besides, they are out of the scope of the present research.

\subsection{4 | OTHER INTERNATIONAL STANDARDS}

There are several European standards focused on characterizing and quantifying the essential requeriment of structural safety, for instance. These can be used to evaluate the performance requirement of mechanical resistance and stability in rear-ventilated façade systems. E.g. DIN 18516:1990, UNI 11018:2013, UNE 41957-1:2000, UNEEN 13116:2006 ... However, very few European standards characterize and quantify the demand of protection against damp of façades. Some examples are: DIN 4108-3:2001, EN 12865:2002, ASHRAE Standard 160:2016, but any of them is addressed to the construction typology of rear-ventilated façades.

Conforming to the Spanish Building Code, the watertightness degree of rear-ventilated façades should be assessed. Thereupon, an assessment criterion is defined in the DB-HS [74]. Nonetheless, the CTE does not set up the verification method [75]. When consulting the ETAG 034, something similar happens. The Guideline establishes that the water running down the wall shall not reach the inside face of the wall and that the materials likely to be adversely affected by water shall not become damp. However, it does not provide with a verification method. Therefore, when manufacturers request for a performance assessment of the watertightness degree of rearventilated façades, accredited testing laboratories draw on other European Standards such as the ISO Standards, EN Standards and so on. Notwithstanding, it should be borne in mind that there is not any laboratory or field test standard to assess the watertightness degree of rear-ventilated façades. Nor to assess the drainage capacity of the ventilated air cavity. A review of the existing field and laboratory watertightness test standards is presented in Chapter 03. 


\section{2.}

Hygrothermal performance of rear-ventilated façades.

2.1. Introduction

2.2. Response to rainfall

2.2.1. Wind-driven rain: state of the art

2.2.2. Rainwater runoff: state of the art

2.2.3. Rain penetration: state of the art

2.3. Strategies of rainwater control for enclosure design

2.4. Mechanisms of rainwater penetration through joints

2.5. Pressure moderation: the rainscreen principle

2.6. Discussion: Rear-ventilated façades 


\section{$2.1_{\text {| INTRoduction }}$}

Buildings contend with several moisture sources during their service life. Built-in moisture, rising damp, rain, water heads, accidental leaks, water vapor contribution to sorption, surface condensation and interstitial moisture deposits are some of them. However, this research will focus on the rain moisture source, one of the most damaging [61] and less regarded by the architects in the design of their buildings, who can fail to implement the prevention of rainwater infiltration in the detailing of wall components [79].

The penetration of water through the building envelope causes damage to exterior walls, thereby shortening their service life and increasing maintenance costs [81-86]. Water penetration also reduces the performance of insulation and the resulting energy savings from the building enevelope [87-89] and affects the health of the building occupants [75,91-94].

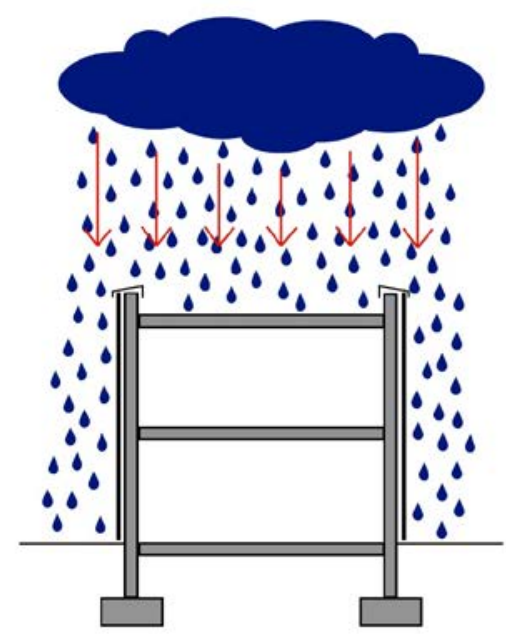

(a)

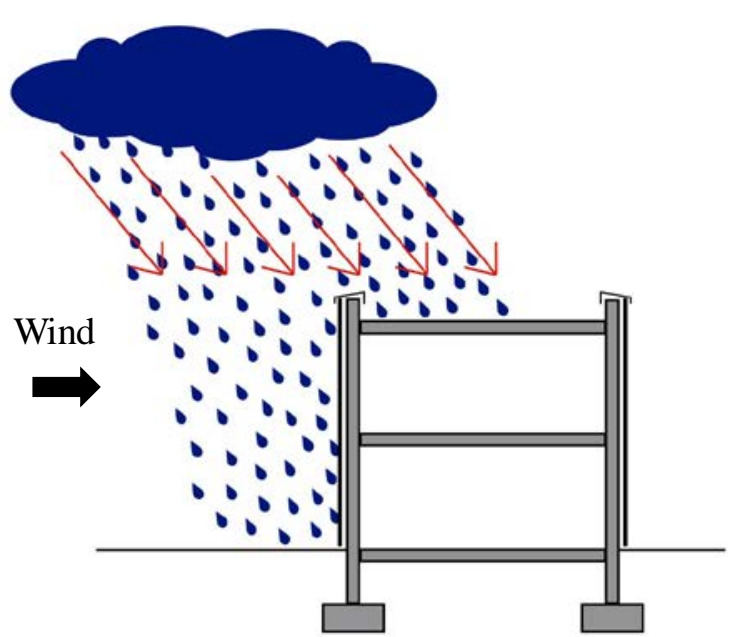

(b)

Figure 2.1. Modelling of the trajectory of rainwater droplets during (a) a rain event without wind and/or wind gusts, only atmospheric precipitation and (b) a rain event in which the atmospheric precipitation is accompanied by wind gusts.

Atmospheric precipitation falls down vertically by gravity in rain events in which wind and/or wind gusts are not present (see a in Fig. 2.1). Under these circumstances, only a minimal amount of rainfall occasionally impinges on the vertical enclosures of the building shell. However, the occurrence of these weather events is uncommon. Generally, atmospheric precipitation is accompanied by gusts of wind. Wind during atmospheric precipitation adds a horizontal component to the fall velocity of each raindrop [81], giving water droplets an oblique trajectory and causing them to impinge the exterior surface of building walls; refer to b in figure 2.1. Consequently, the amount of water impinging onto the vertical planes of the building envelope becomes greater and their occurrence much more frequent. Moreover, the action of wind pressure together with the effect of wind-driven rain (simultaneous action of atmospheric precipitation and wind) allows rainwater to penetrate the façades of buildings [95] through the pores and cracks. After contact with facades, rainwater infiltrates into the building and can alter 
construction materials via frost damage [96, 98-102, 127], moisture induced salt migration [96, 101, 103], discoloration by efflorescence [96, 100], structural cracking due to termal and moisture gradients [96] and other moisture-related causes [100, 104]. Wind-driven rain impact and runoff are also responsable for the appearance of surface soiling patterns on façades [100, 105-112].

In this regard, it is worth highlighting that this situation might become even worse in rear-ventilated façades as these are façade systems which use the open joinery system. Rear-ventilated façades are not watertight systems [49]. The degree of watertightness of the façade is generally assessed by appraisal of design, taking account of the characteristics of the materials used and the geometry of the external cladding element and joints. As such, rear-ventilated façades incorporate water management features into the design and construction. These water management features should account for the combined action of wind-driven rain and wind in order to prevent future moisture-related damages within the wall system. As Vos [113] assessed: "But the question how to design our buildings so that no rain will penetrate can only be answered if the amount of water we have to resist is known".

\subsection{RESPONSE TO RAINFALL}

At this point, the questions that arise are: (i) which is the probability of a rain droplet to impinge on the vertical enclosures of the building and (ii) what happens to this rainwater droplet at and after impacting the vertical plane of the façade. This is why the study of wind-driven rain (simultaneous action of atmospheric precipitation and wind) in building science consists of two parts, namely (1) assessment of the impinging wind-driven rain on vertical building walls (before raindrop impact) and (2) assessment of the response of the building walls to the impinging rain (after raindrop impact) [81] (see fig. 2.2). The impinging wind-driven rain is the total amount of rainwater that comes into contact with the building surface [114]. It is a part which comprises the study of the movement and distribution of raindrops as they fall from the clouds and are carried by the wind in the atmospheric boundary layer until they impinge on the building façade [115]. The quantification of wind-driven loads is beyond the scope of this Ph.D-work, but not the response of the building enclosure after the raindrop impact. The study of the response of the building to wind-driven rain loads encloses surface phenomena such as spreading, splashing, bouncing, adhesion and absorption of raindrops, film forming, runoff, evaporation, film absorption and the distribution of the moisture in the wall (wetting-drying) [115]. Also other parameters should be taken into account in this regard, such as: impact velocity of the drop, drop diameter and impact angle [117, 118, 139]. This second part also includes the study of the wide variety of rainwater penetration mechanisms such as hydrostatic pressure, wind pressure, surface tension and gravity [119], which has been widely discussed by Straube [40]. Last but not least, there are comprised as well the development and execution of watertightness tests [81].

In this sense, it is supposed that when a raindrop collides with a vertical wall, a part of the impinging water is lost by splash, absorption and immediate evaporation; a part creates the runoff film along the vertical plane, a part remains adhered to the surface of the wall and a part is absorbed when the wall material is porous, as shown in (b)

of figure 2.2.

Hygrothermal performance of rear-ventilated façades | 46 


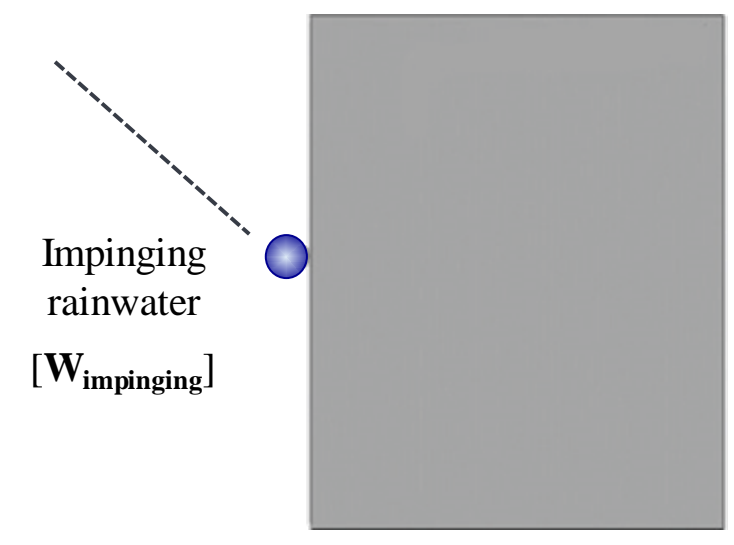

(a)

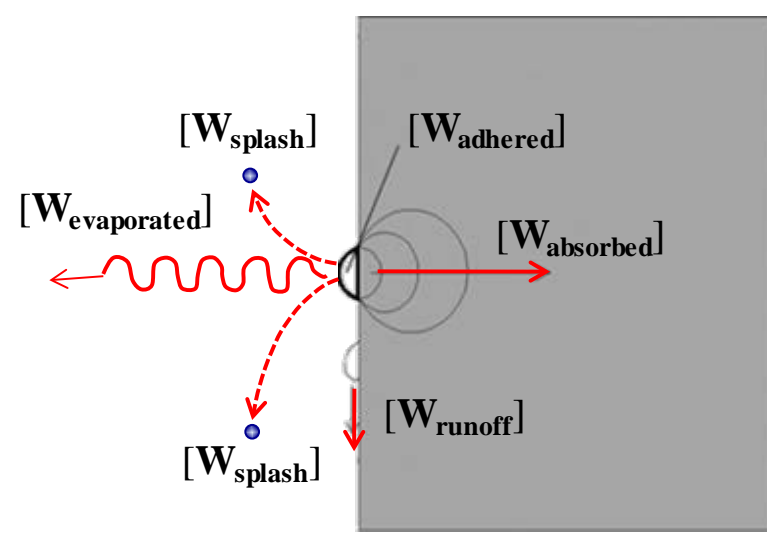

(b)

Figure 2.2. Schematic representation of the two parts in wind-drive rain research: (a)assessment of the impinging wind-driven rain intensity (before raindrop impact) and (b) assessment of the response of the building wall (at and after raindrop impact). So, considering the mass balance of a rain droplet: Water impinging $=$ Water splashed + Water evaporated + Water adhered + Water runoff + Water absorbed [115].

By far most research has focused on the first part of the study of wind-driven rain in building science, in which the amount and intensity of wind-driven rain across building façades is assessed by measurements (e.g. Lacy [120], Hagentoft and Hogberg [121], van Mook [122, 138], Tang et al. [82], Blocken and Carmeliet [123-125], Nore et al. [126], Briggen et al. [127], Kubilay et al. [128]), semiempirical formulae (e.g. Lacy [120], Sanders [89], Straube [40], Blocken and Carmeliet [129], Blocken et al. [130], Blocken et al. [131]) and numerical simulations based on Computational Fluid Dynamics (CFD) (e.g. Choi [32], Blocken and Carmeliet [125, 132, 133], Blocken et al. [137], Tang and Davidson [134], Abuku et al. [135], van Mook [136], van Mook et al. [139]). An extensive review of research on this first part of wind-driven rain research has been provided by Blocken and Carmeliet [81, 129]. The second part in wind-driven rain research however has received much less attention [119]. Rain deposited on a wall can either be drained (the term shed is often used in the context of the exterior surface of a wall, or surface drainage), stored (absorbed by capillarity or attached by surface tension), or transmitted further into the wall (rain penetration or infiltration are other common terms) [40]. When having a look at the state of the art of the assessment of the response of building walls to the impinging rain (study the effects at and after raindrop impact), three different approaches are taken. On the one side, researchers such as: Blocken et al. [115], de Vogelaere and Pacco [140], Blocken and Carmeliet [119], Chew and Tan [141], Van den Brande et al. [142] amongst others focused their studies on the rainwater runoff from building façades. On the other side, researchers like Couper [143], Rhein [144], Reis et al. [146], Abuku et al. [147], Liu et al. [148] or Erkal et al. [149] studied the contact and surface phenomena such as spreading, splashing and bouncing on vertical building surfaces. And lastly, a third group of researchers (e.g. Birkeland [30, 151], Vos and Tammes [150], Beijer and Johansson [152], Beijer [153], Carll [83], Girma et al. [154], Sahal and Lacasse [155], Lacasse et al. [156, 235, 370, 371, 394], Teasdale-St-Hilaire and Derome [157], Teasdale et al. [158, 159], Bomberg and Shirtliffe [160], Nusselt [161], El-Shimi and Fazio [162], Hall and Kalimeris [163, 205]; Hall and Hoff [164, 206]) analysed the absorption and the distribution of the moisture within the façade. These enclosing not only the rain penetration, but also wetting-drying processes, wetting patterns and surface soiling patterns. 
To assess the moisture behaviour of building components, the prediction of impinging wind-driven rain loads on building façades and the quantification of the water infiltration loads on the back wall need to be combined with a Heat-Air-Moisture (HAM) models [142]. Hence, the study of wind-driven rain could be divided in three parts instead of two:

(i) before raindrop impact,

(ii) during the wetting process (during raindrop impact and inmediately after raindrop impact) and

(iii) after the wetting process.

Then, the second part of the study would just enclose the assessment of the response of the building walls during the impinging rain, that is the contact and surface phenomena, the rainwater runoff and the rainwater infiltration. And the third part of the study would comprehend the assessment of the response of the wetted building façade, that is the hygrothermal simulation, where the wetting-drying processes within the wall enclosure are analyzed. As the conductivity of building materials is not the same when these are dry as when these are moistened due to rainwater. And thereby, studying to what extend the amount of rainwater infiltration influences the thermal response and the evaporation of the building enclosure is relevant in the overall building performance.

Numerical Building Envelope Heat-Air-Moisture (BE-HAM) transfer models are generally used to analyse the hygrothermal behaviour and durability of building facades. Most of these models take the impingement and absorption of wind-driven rain on building façades into account [165-168, 142, 147], but generally only in a simplified way considering them as boundary conditions. Examples are WUFI and WUFI ORNL/IBP [165, 169], DELPHIN [170, 171], HYGirc [172-174] and HAMFEM [145]. However, the socalled "secondary effects” of wind-driven rain, such as splashing and bouncing of raindrops and the runoff of moisture along the surface, have not yet been implemented in HAM models [142]. Neither has it been the rainwater runoff [115, 142]; refer to table 2.1 .

Table 2.1. Required parameters and specific requisite information or examples for experimental simulated rainwater insertion into a building envelope by HAM models [175].

\begin{tabular}{|c|c|}
\hline Required parameter & Specific information required or examples \\
\hline Climate element & Rainfall, wind speed, and wind direction \\
\hline Impinging wind-driven rain & $\begin{array}{l}\text { Rainfall, local wind speed and direction, building geometry, location on } \\
\text { building façade }\end{array}$ \\
\hline Wind-driven rain infiltration & Defect location, size and geometry, driving forces for infiltration \\
\hline Rainwater runoff & $\begin{array}{l}\text { Cladding absorption and water conduction properties, moisture content during } \\
\text { rain shower, duration of rain shower }\end{array}$ \\
\hline Form of insertion & Point, linear, or planar \\
\hline Temporal form of insertion & One-time load, deterministic pattern or quasi-stochastic load \\
\hline Location of insertion & Depends on study objectives \\
\hline
\end{tabular}

In the table are given the listed required parameters for the experimental simulation of rainwater insertion into a building envelope and specific required information or examples [175] by HAM models. The wind-driven rain 
infiltration loads into the building envelope represent the moisture loads to which the enclosure system as a whole is to be subjected during a rain event and must be capable of managing. Given that methods have been developed to determine the rate of impinging wind-driven rain, the next step in a simulated wind-driven rain infiltration methodolgy is to find the proportion of the impinging rain that infiltrates through the enclosure wall [175]. While no field measurements of actual rain infiltration into the back wall have been documented (rain infiltration beyond the weather resistance barrier) some have been carried out under laboratory conditions. Most of it, measured the rain infiltration through envelope defects (such as missing portions of sealant at junctions). There are a large number of variations that describe envelope defects, and these cannot be averaged or evaluated in a stochastic type analysis, therefore, it is difficult to reproduce a typical defect and quantify the infiltration characteristics [175]. In essence, there is, to date, little information yet published about the proportion of the impinging rain that infiltrates through the enclosure wall. As well, there is no method that considers wind-driven rain infiltration loading [175]. Moreover, these loads have not been yet clearly determined for a range of wind-driven rain loads. Consequently, many standards prescribe a default value in absence of these quantitative data (e.g. ASHRAE Standard 160 [176]). Such information can be readily be used as input to HAM models, the results of which would be used to assess the vulnerability of wall systems to rainwater ingress. Nonetheless, it is useful to consider that the results obtained with HAM models are particularly sensitive to the moisture boundary conditions, that is, the moisture loads assumed for a model [176]. In this sense, Abuku et al. [168] concluded that simulations typically tend to significantly overestimate the measured average moisture content in façades. Note that the hygrothermal models can use a statistical approach varying the exposure conditions and the material properties to undertake a risk analysis of the probability of water attaining the back wall systems.

Therefore, would it be possible to do a estimation of the amount of rainwater that might resist the different layers within the wall system of rear-ventilated façades during a rain event? Which are the main parameters that should govern the design of wall assemblies in rear-ventilated façades so these remain free from rainwater infiltration and moisture-related damages? The factors affecting water leakage differ for different cladding materials and enclosure systems. Each system behaves and deals with water in a different way. This behaviour is mainly derived from the intrinsic and extrinsic characteristics of the used materials (e.g. extrinsic such as the roughness and intrinsic such as the porosity) and the construction detail of the façade system (e.g. storage wall systems, perfect barrier systems and rainscreen systems), besides of the rain event characteristics (amount of water impinging on the wall surface, water droplet velocity, drop diameter and impact angle).

As a starting point, it is worth mentioning that the aerodynamic behaviour of rear-ventilated façades (a type of double skin façades, DSF) is very different from the aerodynamic response of traditional façades [177]. This results from the presence of three possible surfaces subjected to wind pressure: the exterior surface of the outermost leaf, the interior surface of the outermost leaf and the exterior surface of the inner leaf [178] and consequently, all three exposed to the combined action of rainfall and wind (wind-driven rain). The work of Lou et al. [179] studied the different pressure coefficients involved with different air cavities depths in a tall building using wind tunnel tests. Conversely, only one surface is subjected to wind pressures in traditional façades and thereby, to wind driven rain, the outermost surface. Nevertheless, the researchs focused on wind-driven rain issues (concerning both parts: quantification of wind-driven loads and study of the response of the building to these loads) are mostly adressed to solid walls made of porous materials (like brick masonry walls). In such cases, a part of the impinging water creates the runoff, a part is absorbed and a last part is lost by evaporation, as shown in (a) of figure 2.3. When the 
absorption capacity of the façade material is exceeded, water can penetrate towards the air cavity, resulting in wetting of the thermal insulation layer. The response in rear-ventilated façades is diverse although, as part of the impinging water forms the runoff film at the exterior surface of the outer leaf, a part is absorbed by the cladding elements if these are porous materials, a part splashes into the air cavity, a part is infiltrated through the open joints, a part remains stagnant within the joints by surface tension and a last part is lost by evaporation inside the air cavity due to the chimney effect, refer to (b) in figure 2.3. Hence the model becomes a little bit more complex and less predictable. Besides, in rear-ventilated façades, the wetting and runoff pattern are not only influenced by the cladding material, but also by the secondary structure and the fixing system of the panels, which in turn go in hand with the cladding material. In addition, the majority of problems arise in claddings made of stone plaques and originate from the type of joint. In this sense, Sahal and Lacasse [155] stated that the watertightness of a wall system is highly sensitive to the intensity of the rainfall when the openings on the cladding are numerous enough or of sufficient size $(>1 \mathrm{~mm})$ as to permit ease of water entry. They also assessed that under such conditions, the wall systems are less sensitive to variations in wind loads, unlike in traditional façades, where rather small openings are present if there are any.

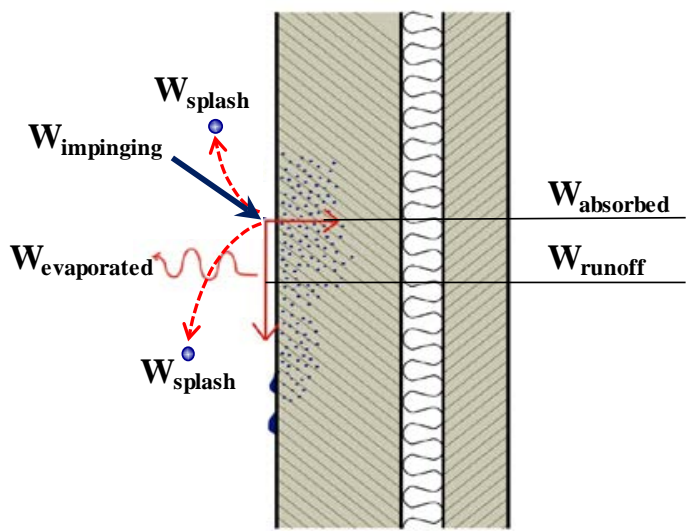

(a)

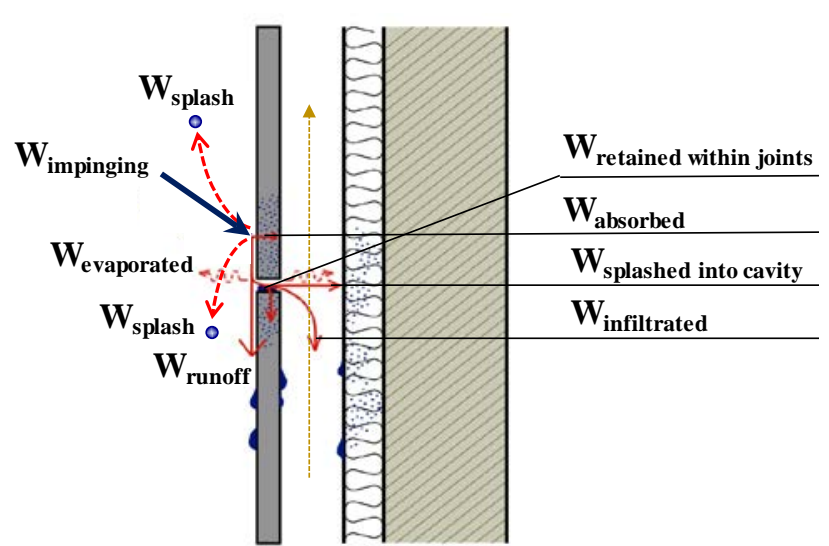

(b)

Figure 2.3. Schematic response to rainwater of (a) a typical Spanish façade compared to (b) a rear-ventilated façade. Taking into account the mass balance of a rain droplet, whereas in (a) Water impinging = Water splash + Water evaporated + Water absorbed + Water runoff, in (b) Water impinging = Water splash + Water evaporated + Water absorbed + Water runoff + Water retained within joints + Water splashed into the cavity

+ Water infiltrated.

However, whichever water management features are present in rear-ventilated façades, the hygrothermal performance of the whole enclosure system might nonetheless not work properly due to, e.g., improper design of constructive details, construction flaws in the façade, or other gaps in the practitioners understanding of the mechanisms of rain infiltration causing water to penetrate the interior wall assembly [18, 180-183]. According to Bomberg et al. [1999], failure is recognized when water penetrates through an entire assembling to the inner surface of the wall or whether the transmission of rainwater reaches a sensitive layer of the wall assembly and is likely to cause damage, degrade performance, or affect its durability. Hence, a better-defined and more in-depth understanding of the overall performance of rear-ventilated façades systems to wind-driven rain and driving rain 
wind pressures, might provide tools and guidance to building practitioners and companies on the design of the construction details as well as enhance the knowledge of boundary conditions (the moisture loads assumed for a model) for hygrothermal simulations (HAM models).

\subsection{1 | WIND-DRIVEN RAIN: STATE OF THE ART}

Wind-driven (WDR) or driving rain is defined as rain carried along by wind and moving at certain angle to the vertical $[184,207]$. This inclination is a function of the wind speed and the drag coefficient. Then, the joint occurrence of wind and rain causes an oblique rain intensisty vector [81, 151]. The International Council for Building Research, CIB, adopted the term "wind-driven rain intensity" from the literature on hydrology and earth sciences [151]. It is defined as the component of the rain intensity vector causing rain flux through a vertical plane situated onto a point in the building enclosure. The other component of the rain intensity vector, that causes rain flux through a horizontal plane located outside of the influence of the building or other nearby obstructions, is termed (horizontal) rainfall intensity [81]; see fig. 2.4.

Wind driven rain is one of the most important moisture sources affecting the hygrothermal performance and durability of building façades [81, 100, 128, 147, 185-187, 189, 191, 195]. Consequences of its destructive properties can take many forms. Moisture accumulation in porous materials can lead to rain water penetration [190, 191], frost damage [96, 98, 99, 100, 101, 127], moisture induced salt migration [96, 101, 103], discolouration by efflorescence [96, 100], structural cracking due to thermal and moisture gradients [96], to mention a few. Characterising the exposure to wind-driven rain and the co-occurring wind pressure (driving rain wind pressure, DRWP) for a given location is therefore a primary goal when designing building enclosures that minimise these problems [2, 83, 193, 194].

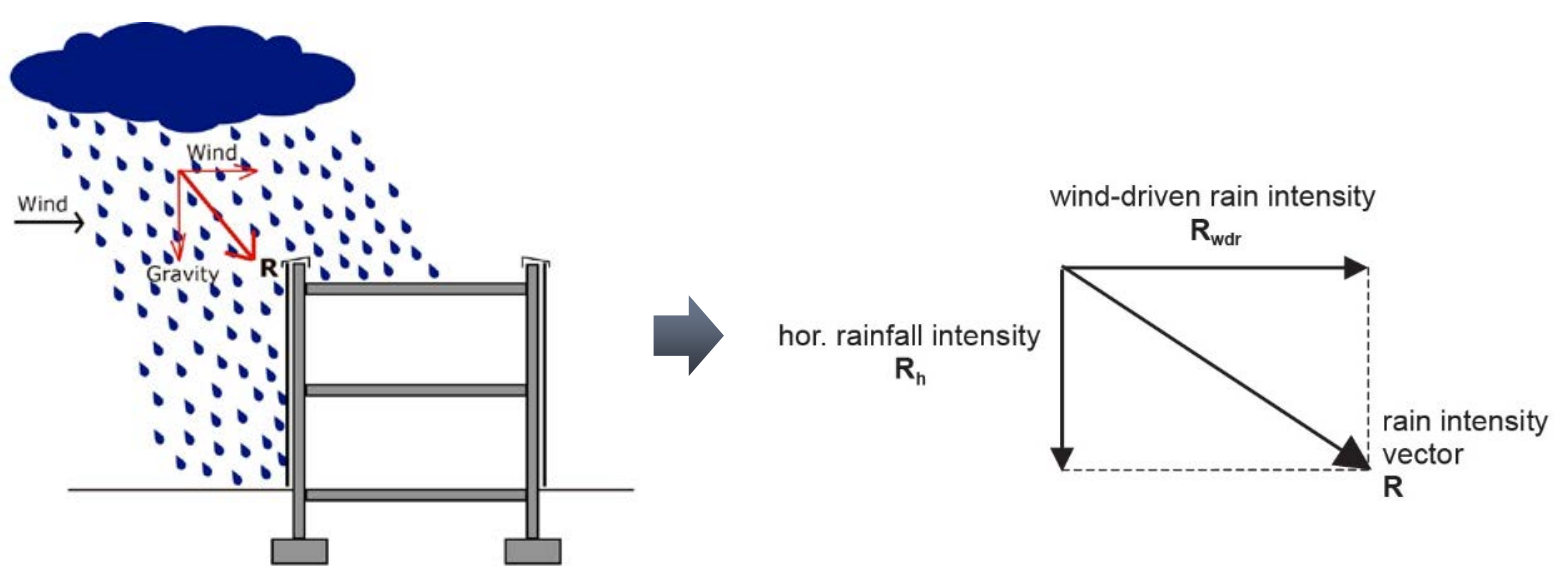

Figure 2.4. Rain intensity vector $\mathbf{R}$ and its components: wind-driven rain intensity $\mathbf{R w d r}$ and horizontal rainfall intensity $\mathbf{R h}$.

Since wind-driven rain is not routinely measured by weather stations, the ability to predict wind-driven rain using the available and extensive records of rainfall and wind speed would be useful [40]. It cannot, however, be assumed 
that the wind and falling rain can be modelled as statistically independent events. There are three cathegories of methods for assessing WDR: (i) measurements, (ii) semi-empirical methods and (iii) numerical simulation based on Computational Fluid Dynamics (CFD). An extensive literature review on these methods was provided by Blocken and Carmeliet [81]. However, assessing the intensity of WDR on building façades is complex, because it is a variable influenced by a wide range of parameters [196], which are function of the nature of the rain and vary depending on the building characteristics. Consequently, wind-driven rain is difficult to characterize and reproduce in the laboratory [175] as well. According to Bitsuamlak and Simiu [196] and Blocken and Carmeliet [81], these parameters are: building geometry, environment topography, position on the building façade, façade orientation, wind speed, wind direction, turbulence intensity, rainfall intensity and raindrop-size distribution. Teasdale and Derome [175] also included the duration of rainstorm, the frequency of rainstorm and the sheltering effects of surrounding buildings and trees to the previous ones. In this regard, some findings have been revealed in literature relating the impact of these parameters on the wind-driven rain intensity. These have been summarized by Teasdale and Derome [175] and are the following:

- The smaller the horizontal rainfall rate, the smaller the average raindrop size in the distribution and vice versa. Since smaller raindrops have a lower inertia, their trajectory is more influenced by the force of the wind [116, 132, 208, 197].

- Increasing the wind speed has an impact on impinging rain [200] by increasing the horizontal component of the velocity of raindrops, more so for small than large raindrops [132, 208, 197]. Hence, the intensity of impinging wind-driven rain increases both with increasing horizontal rainfall and wind speed. Note that the rain drop trajectory changes with the wind velocity field, especially for locations in close proximity to the building, where the wind pattern becomes a function of the roof and building geometry [198].

- The highest rate of impinging wind-driven rain occurs when the wind acts normal to the building façade; however, when the wind direction is not normal to the surface, the impinging wind-driven rain generally decreases as the wind angle increases [199].

- The greater the duration of wind-driven rain events, the greater the absorption of water by the cladding and, with time, the cladding materials, e.g., brick can become saturated, hence increasing the amount of rain runoff and increasing the amount of rain reaching a specific location on the envelope.

- A greater rate of impinging wind-driven rain occurs at the top edge [197], when no overhang is present, and at the sides of a building façade compared to the middle area for windward wind perpendicular to the façade [132, 208, 200, 201].

- Tall buildings receive more wind-driven rain at the top and edges than short buildings [200] since wind speed increases with height; Choi's [208] numerical work also found that the greater the width-height ratio, the smaller the impinging wind-driven rain over the entire building façade for a constant building height and depth.

- The sheltering effect of architectural elements is less pronounced when the wind speed is high and less so when the horizontal rainfall is low $[132,200]$.

In either method for quantification of wind-driven rain (WDR) on buildings and the co-occurring wind pressure (DWRP), the results relate rainfall rate and wind speed to the rate of water deposition on a vertical façade [155]. Hence, the models require the rate of horizontal rainfall, the wind speed, and the wind direction as input data, which are typically selected from weather databases for a given climate. The empirical methods include: anual 
driving rain index (aDRI), directional driving rain index (dDRI), UK method [202], Lacy method [120], Sanders method [89], Straube and Burnett method [200], Sahal and Lacasse method [155], ISO 15927-3:2009 Standard [203] and Pérez-Bella et al. [204]. These models are based on the WDR relationship and assume that all the raindrops have the same size, and the wind flow is uniform, steady and horizontal. In the numerical models, the wind flow patterns are first calculated using Computational Fluid Dynamics. Then, the trajectories of raindrops of various sizes within the calculated airflow pattern are obtained. Afterwards, the specific catch ratio is determined based on the configuration of the calculated raindrop trajectories. Subsequently, the catch ratio is calculated from the specific catch ratio and from the raindrop-size distribution. Note that the catch ratio is defined as the ratio of the intensity of raindrops of radius "d" landing on a specific zone on the building face to the intensity of the rainfall on a horizontal plane away from the local effects of the building [175]; refer to figure 2.5. Finally, catch-ratio charts are constructed for different position at the building façade. Numerical methods were first developed by Choi [80, 207, 212]. Based on this method, additional work has since been carried out by Choi [32, 184, 199, 208, 210, 214, 215], as well as Karagiozis et al. [213], Sankaran and Paterson [209], Blocken and Carmeliet [132, 217, 218], Van Mook et al. [139]. Later, other models have been developed by Blocken and Carmeliet [129], Blocken et al. [130] and Blocken et al. [137] to estimate the expected maximum WDR and DWRP to which a façade may be subjected under its operating conditions at a fixed return period for each of the parameters.

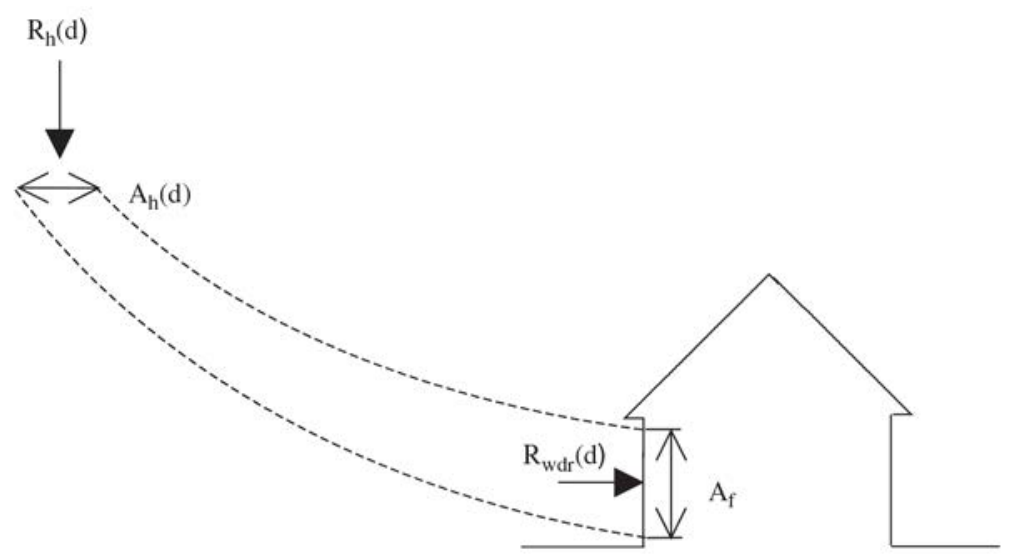

Figure 2.5. Stream tuve bounded by two raindrop trajectories. The specific catch ratio $\eta_{d}$ for zone $A_{f}$ and for raindrops with diameter $\mathrm{d}$ is determined based on conservation of mass for the raindrops in the stream tube [125].

Where $A_{f}$ is the area of the zone on the building facade where $\eta_{d}$ is to be determined and $A h(d)$ is the area of the horizontal plane bounded by the injection positions of the raindrops of diameter "d" ending on the corner points of $A_{f}$.

In summary, all of the aforementioned methods suggest the use of the exposure parameters (WDR and DRWP) calculated for a given operating situation and climate conditions as a basis for the development of standardized test parameters for watertightness testing [175, 204]. As according to Choi [32], one of the reasons for the failure of the building envelopes to the meteorological phenomena is the lack of information (the amount of wind and rain expected on the site), so that it is extremely difficult to assess that the building envelope fulfills the weathertightness requirements. In line with this statement, Blocken et al. [115] also pinpointed the lack of 
appropriate quantitative data for wind-diven rain and runoff. An understanding of the level of exposure to winddriven rain (WDR) that a building envelope component is exposed to is a fundamental requirement for establishing designs that minimise moisture-related issues [204]. The not availability of these data yields the architects to the thoughtlessness of meteorological information in the design of the facades' details and in the selection of the best enclosure systems or proper cladding materials for a particular site and type of building. Currently, also the industries are not able to offer a tested assessment ranging the material cladding or the enclosure system to these phenomena to the architect, since the standard parameters used in current watertightness tests do not reflect real weather conditions [155, 204].

\subsection{2 | RAINWATER RUNOFF: STATE OF THE ART}

Then it can be concluded that wind-driven rain is the result of the interaction of airflow and rainfall [168]. However, the amount of water that reaches a particular location on a building façade is a function of the impinging wind-driven rain and the water runoff from above [175].

Basically, in order to have a sense of droplet dimension and shape, it can be said that water drops are generally between $2 \mathrm{~mm}$ in diameter and $6 \mathrm{~mm}$ in diameter with the smaller raindrops spherical in shape and the larger drops having flattened bottoms and maybe a depression due to the pressures on the bottom [116].

Before going deep into the rainwater runoff on building façades, it is worth mentioning the research efforts on the topic of water droplets impacting on surfaces (contact and surface phenomena). Part of the impinging wind-driven rain intensity on the building façade can be lost by splashing or bouncing (see Figs. 2.2 and 2.3), while another part can evaporate, can spread on the surface, can be absorbed if the material is porous or remain stuck to the building façade by adhesion. Spreading, splashing and bouncing on building surfaces have been investigated by Couper [143], Abuku et al. [147, 168] and Erkal et al. [149], although a comprehensive review of the liquid drop impact on solid and liquid surfaces was carried out by Rein [144]; refer to Figure 2.6 and 2.7.

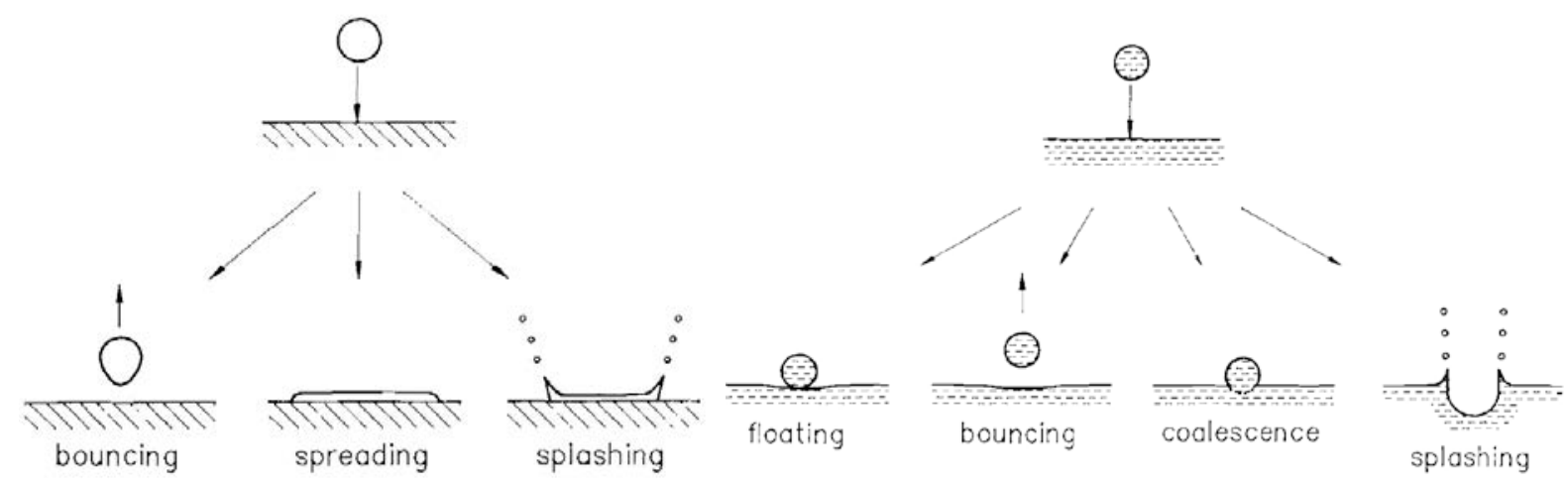

Figure 2.6. Impact of a drop on a solid surface: bouncing. spreading. and splashing [144].
Figure 2.7. Impact of a drop on a liquid surface: floating, bouncing, coalescence, and splashing [144]. 
According to Rein [144], after a contact is formed between a drop and a solid surface, the liquid normally starts spreading out. Note that the spreading length of the rain drop is an important parameter for absorption and evaporation [140]. When the kinetic energy of the drop is extremely small, the process of spreading is dominated by intermolecular forces. If the drop strikes the surface with a finite velocity, spreading is greatly influenced by the kinetic energy of the drop. Further, its surface energy is important. A drop is said to splash whenever it disintegrates into two or more secondary droplets after colliding with a solid surface [144]. High impact velocities yield splashing whereas spreading is obtained at low-speed impacts. In these phenomena, the relevance of the kinetic energy of the drop and the surface tension are therefore confirmed.

Abuku et al. [147] carried out laboratory experiments to study the impact of water drops with different diameters, impact speeds and impact angles on a porous building material surface (ceramic brick) concluding that rainwater drops with big diameter splash at its impact, whereas rainwater droplets with a small velocity bounce and thereby, are not entirely loaded onto the façade as a moisture source. Furthermore, the authors assessed that splashing and bouncing can be different for façade surfaces due to different surface phenomena and that the occurrence of bouncing reduces the maximum spreading length and width. Engel [211] showed that the pressure variation inside the droplet during impact was the key factor that caused splashing. Studies of droplet impacts at velocities over $100 \mathrm{~m} / \mathrm{s}$ against a rigid surface showed that splashing may be attributed to a pressure-related shockwave, which is initiated due to the compression of the front part of the droplet at the beginning stage of contact against the rigid solid surface [148, 216, 219, 225, 220- 225]. Even at low-speed impacts the pressure can rise appreciably [144]. Then, when the momentum of the liquid droplet cannot convert into the flow momentum along the impact surface during the impact process, splashing occurs at the location where the surface energy is the least [148, 226-228]. Splashing may be enhanced when a drop collides obliquely with a surface [144] since on impact the drop experiences a sudden force tangential to the surface. Besides, Xu's results [229-231] confirmed that splashing should increase with increasing spreading velocity. Nonetheless, experimental evidence demonstrated that with increasingly oblique impact angles, spreading velocity increases, but splashing reduces [148]. This shows that the occurrence of splashing is more attributable to the relative velocity between the spreading droplet and the surrounding gas (velocity of the ambient air near the droplet). Note that often the impact velocity is assumed to equal the terminal velocity of the drops [144]. Thereupon, Wallis [232] presented a general calculation procedure for the terminal velocity concluding that the impact velocities obtained sometimes deviate from actual values by more than $10 \%$; leading to an error in the kinetic energy of the drop of more than $20 \%$. In this regard, an exploratory study by the Division of Building Research of Australia, CSIRO, investigated the splash from building materials with different surface textures resulting in significant factors in the conversion of WDR to surface run-off [143]. In the study, it was obtained that a sheet of glass had almost a $0 \%$ of splash, whereas a sheet of acrylic had $24 \%$ despite both materials had a clean and polished surface. In line with previous authors, the smaller splashing was obtained on materials with rough surfaces. De Vogelaere and Pacco [140] suggested that the considerable difference between glass and acrylic, which had similar surface textures, might be attributed to their different surface wetting characteristics since runoff on glass panel appeared as a relatively continuous thin film of water, meanwhile on the acrylc panel it appeared in rivulets. Therefore, two types of film run-off can be clearly differentiated. Film runoff can be discontinuous, i.e. narrow streams of water running down (also called fingering or rivulets), or continuous, i.e. the film has a width and length that are several orders of magnitude larger than the film thickness $[115,140]$. 
On the other side, the impact of water drops onto wet surfaces has been studied by Mutchler and Hansen [233]. These authors concluded that the splash formation caused by water drop impact at terminal velocity in thin horizontal water layers increases with drop size. For increasing water depth, splash size increases to a maximum at a depth of one-third diameter of the raindrop, see Fig. 2.7. Splash size then decreases to a constant size for depths greater than three drop diameters.

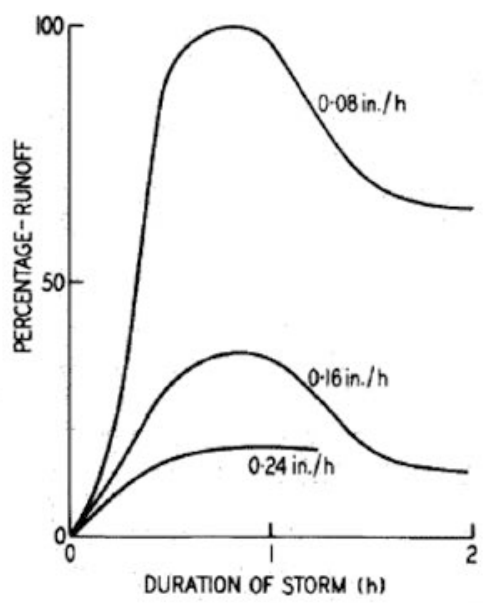

Figure 2.8. Typical percentage-runoffs for smooth, non-absorbent surfaces for storms of different durations and intensities measured on the vertical surface [143].

As soon as the WDR intensity exceeds the rate of absorption in porous materials (these become saturated) or when the building façade is made of impervious materials, a water film will start to build up at the wall surface. Several droplets, specially if spreading occurs, can coalesce and eventually form a film. As the size of the coalesced droplets or the film thickness increases, gravity forces will eventually exceed surface tension forces, allowing the film to run down along the façade [115]. Couper [143] noticed that only a small proportion of the rain which strikes the building surface remained on the surface as runoff and that the percentage-runoff for any given wall surface depended upon the texture and absorption characteristics of the wall material. This assessment was corroborated by Cronshaw [234], who concluded that under conditions of moderate exposure, the runoff down the face of the wall is considerably less than the volume of WDR striking the wall, even when the latter is saturated. The maximum percentage-runoff decreases as the intensity of WDR increases since the higher the intensity of WDR, the more droplets are bounced and splashed off the wall [140]. Besides, when the maximum percentage-runoff is achieved, a further increase in the duration of the storm will not result in a further increase in the percentage of runoff [140]; refer to figure 2.8. In addition, the total runoff for any series of wall panels mounted vertically above each other may not be the cumulative sum of the individual panels [143].

Rainwater runoff has a higher potential of putting moisture tolerance at risk since water running down or water pooling on quasi-horizontal surfaces can enter cracks or faulty junctions into the building envelope system, which is generally referred to as rain penetration [115]. Furthermore, WDR impact and runoff are responsible for the appearance of surface soiling patterns on façades that have become characteristic for so many of our buildings [105, 108, 112]. The combined effect of atmospheric deposition of pollutants and WDR on the facade leads to "white washing” and "dirt washing” [119]. At the top of the façade or in the places where high WDR intensities 
are recieved, the WDR rinse away the dirt ("white washing”) and move it to the lower façade parts, where it is deposited (“dirt washing”). As runoff accumulates on its way down, a maximum runoff rate is found at a certain distance from the top (where the most WDR is received), after which it decreases to zero, at the point where the surface is not yet capillary saturated and no runoff film has yet developed [115]. Uncontrolled rain runoff flow off a façade made of impermeable surfaces has been shown to be the single most important factor that brings about staining [141].

Research on rainwater runoff is performed by field observations, field measurements, laboratory measurements and analytical and numerical modelling. Some important rainwater runoff studies have been conducted in the past. Most of these studies, have been field studies were quantitative experimental or qualitative observational data was obtained (e.g. Ritchie and Davison [236], Harrison and Bonshor [237], Cronshaw [234], Isaksen [239], Beijer and Johansson [152], Beijer [153]). However, very few laboratory measurements have been conducted to characterize the rainwater runoff as according to Blocken et al. [115], laboratory experiments of rainwater runoff have been almost exclusively focused on testing rain penetration of different types of horizontal and vertical joints. Only Beijer [153] performed laboratory tests of runoff on vertical surfaces of concrete, apart from the field measurements. A limited number of analytical and numerical models for runoff have been developed in building engineering and building physics. They are generally combined with a water absorption model, because on many building façades absorption and runoff are coupled processes [115]. Analytical rainwater runoff models were suggested by Couper [143], Beijer and Johansson [152], Beijer [153], El-Shimi et al. [109], Hall and Kalimeris [163, 205] and de Vogelaere and Pacco [140]. A simplified numerical model for run-off film flow, based on the continuity of mass at the surface, was developed by Blocken and Carmeliet [119]. The main advantage of the model was that it could easily be integrated into 2D and 3D HAM models. Later, the authors implemented the model with the surface and contact phenomena; and validated the combination of the two models by means of field measurements for a window glass surface in a two-storey house [114].

\subsection{3 | RAIN PENETRATION: STATE OF THE ART}

Given that methods have been developed to determine the rate of impinging wind-driven rain and the rainwater runoff film, the next step in a simulated wind-driven rain infiltration methodology is to find the proportion of the impinging rain and rainwater runoff that infiltrates through the envelope [175]. So, the quantity of water entry within the wall system can be determined in relation to climate loads. According to ASTM [240] it is considered water infiltration as "a process in which water passes through a material or between materials in a system and reaches a space that is not directly or intentionally exposed to the water source.” In this regard, Sasaki [241] discussed the importance of laboratory tests for evaluating enclosure elements in terms of rain infiltration.

Many laboratory experiments for rain infiltration have been reported: Day et al. [190], Skeen [242], Vos and Tammes [150], Selvarajah and Johnston [243], Beaulieu et al. [244], Lacasse et al. [235], Teasdale and Derome [157], Derome et al. [245] and Bomberg et al. [246] among others. Conversely, no field measurements of actual rain infiltration into the back wall have been documented, that is, rain infiltrating beyond the weather resistance barrier [175]. The conducted experimental work in laboratory conditions used similar approaches to quantify water 
infiltration rates through deficiences in the building envelope. The different types of wall systems are subjected to simulated wind-driven rain at loads and for time periods in keeping with current industrial standards (e.g. EN 12865 [78], EN 12155 [247], ASTM E 514 [248], ENV 13050 [249] and so on). An overview of the existing watertightness test standards is given in Chapter 03 of the present Ph.D-work. Typically in industrial performance tests, wind-driven rain is simulated by the simultaneous application of water spray, per unit time and specimen surface area, and pressure difference across the specimen. Evidently the spray is intended to emulate the deposition of water on the façade due to rainfall whereas pressure difference mimicks the action of wind.

In this way, intentional deficiencies and/or defects are practiced (such as: extrusions of mortar in the cavity [250, 251] or missing portions of sealant beads [252] or addition of artificial cracks [256] or open head joints [253] or gaps left between the water resistive barrier and the flashing at the sill [235] or caulkless system [254] or air gap in the drainage plane [254] or not using backer rod at vertical joints [255] amongst many others) in the wall specimens with and without window elements. As seen, there are a large number of variations that describe envelope defects, and these cannot be averaged or evaluated in a stochastic type analysis, therefore, it is difficult to reproduce a typical defect and quantify the infiltration characteristics [175]. Note that results from field studies have shown that water penetration and infiltration in building envelopes are more likely to occur at interfaces such as wall-window junctions rather than within the fabric of the envelope itself [257-259, 175].

In addition, current industrial standards are diverse. In literature, there is still a discussion in respect to the worst case scenario for watertightness testing; i.e., should testing be conducted under static or cyclic or dynamic pressure conditions? For instance, Mayo [260-262] suggested that more severe test conditions are created when there is a cyclic and dynamic variation in the applied pressure. Conversely, Van den Bossche [263] suggested that different failure mechanisms require different test protocols underscoring that static test conditions are more suitable to evaluate the drainage capacity of the façade systems, whereas cyclic test pressures are more suitable to assess the watertightness of face-sealed façade systems. Not in line with the previous author, Brown et al. [264] measured higher drainage rates in test specimens made of EIFS with cavity (a drainage system) under dynamic pressure conditions. Besides, they observed that any water that penetrated past the cladding was drained through the drainage plane and directed out of the wall. Thereupon, Sasaki [241] stated that an important requirement for a good rain penetration test is that it should simulate the lateral deflection of runoff water across the façade and its accumulation in vertical joints. While the static test cannot simulate these features, the dynamic test can reproduce pressure variations and lateral runoff flows. Ishikawa [265] and Bielek [266] performed tests with a set-up similar to that of Sasaki [241]. Other laboratory experiments have been conducted by Brown [267], Rathbone [268], Hens et al. [253], Lacasse et al. [235] and Van Goethem et al. [256] subjected brick masonry walls to static and cyclic pressure conditions measuring the water entry rates at the backside of the wall. Brown et al. [264], Teasdale and Derome [157] and Olsson [255] subjected walls with exterior insulation finish systems, which included a window element, to dynamic air pressure differences in the case of the work completed by Brown et al. [264] and to static air pressure differences for the other two studies. These authors measured the water ingress to the drainage plane through the sill junction, where they introduced several intentional defects. And lastly, NAHB [254], Lacasse et al. [235] and Sahal and Lacasse [252] measured leakage rates through specific defects in walls with siding cladding under cyclic in the case of the work completed at the NAHB [254], and static air pressure differential for the latter two cases. 
However, all previous studies have shown that there are several factors that influence wind-driven rain infiltration in wall systems [175]:

- The amount of water reaching the defect location;

- The pressure difference in the envelope at the boundaries of the defect;

- The location of the defect and

- The size, geometric configuration, and orientation of the defect.

The effect of rainwater infiltration through open joints has been studied by several authors [13, 51, 239, 265, 269272, 275, 277- 282]. The research of these authors has only focused on the rainscreen cladding elements and/or the geometrical parameters of the joint, not on the performance of the whole façade system. Consequently, they only evaluated the amount of water passing through the open joints, not the amount of water reaching the back wall. Isaksen [273, 276] was the exception, although he provided with rather qualitative results. Isaksen [272-276] conducted laboratory tests to evaluate the effects of joint width and cavity depth on the amount of water passing through the cladding joints. Similarly, Hérbert [277-278] and Hérbert and Harrison [279] studied the effects of parameters such as panel edge thickness, joint width variation and edge profile of the joints on the amount of water entering the cavity. Huedo et al. [280] studied the impact of the wetting system on water ingress, whereas Mas et al. [281] studied the influence of panel thickness and joint design, concluding that the influence of panel thickness on rainwater infiltration becomes insignificant for large joint widths and that the beneficial effects of a non-planar panel edge in joints with large widths are minimal. In both latter cases the testing devices and test setup was much more rudimentary than the above mentioned studies, and no air pressure differential was applied to the specimens. Conversely, Bassett and Overton [282] measured water leakage rates through a horizontal jointer profile between sheets of cladding as function of air pressure difference statistically and dynamically applied. These authors found that the water leakage performance limit was dependent on the presence of air leakage paths, either in the form of vents in cavity closers or due to some misfit between flashings and claddings. On the other side, Herbert and Harrison [279] tested the rainwater infiltration through vertical and horizontal labyrinth joints.

In essence, there is, to date, little information yet published about the proportion of the impinging rain that infiltrates through the enclosure wall and reaches the back wall. As well, there is no method that considers winddriven rain infiltration loading in HAM models [175] despite they gather wind-driven rain loads on building façades. Moreover, these loads have not been yet clearly determined for a range of wind-driven rain loads. Consequently, many standards prescribe a default value in absence of these quantitative data (e.g. ASHRAE Standard 160 [176]). Given that wind-driven rain infiltration has been established as an important potential moisture source in building envelopes and that occurrences of wind-driven rain infiltration can be realistically expected, methods must be formulated to investigate the effect of such failures experimentally and to set winddriven rain infiltration loading in the context of building envelope testing $[157,175]$. The results of which would be used to assess the vulnerability of wall systems to rainwater ingress. Nonetheless, it is useful to consider that the results obtained with HAM models are particularly sensitive to the moisture boundary conditions, that is, the moisture loads assumed for the model [176]. In this sense, Abuku et al. [168] concluded that simulations typically tend to significantly overestimate the measured average moisture content in façades. 


\section{3 | STRATEGIES OF RAINWATER CONTROL FOR ENCLOSURE DESIGN}

“A key design element for exterior walls is the control of rain penetration. Lack of attention to design principles or failure to implement them in the detailing of wall components may lead to premature deterioration of wall elements” [79]. Moisture vulnerability, or degree of risk, affects the probability of a problem occurring and may be considered to be a function of three potential: wetting, storage and drying [40]. For example: using a material that is not supposed to be affected by moisture damage in locations with high wetting potential (such as at sill or at corners of high buildings) often leads to a problem.

The holistic state of the art approach to rain control can be described by the three-D's: Deflection, Drainage / Storage / Exclusion, and Drying [283]. Hazleden and Morris [284] and Kerr [285] proposed four-Ds instead: Deflection, Drainage, Drying and Durability, where Durability is a result of the first three strategies rather than a strategy itself, but it can be argued strategies such as using pressure treated lumber instead of normal lumber is a durability strategy [286].

The first level of moisture management is deflection and the first line of defense is the siting of the building. Exposure to wind-driven rain can be reduced by planting, lanscaping, and by choosing lower building designs. Moreover, peaked roofs and overhangs protect the building walls from rain by shadowing and redirecting airflow [287]. However, as buildings get taller, overhangs offer less protection against rain, windspeeds increase, and walls get much wetter [286]. Once the rainwater is on the wall, surface features such as trim, surface texture and openings can greatly affect the flow paths of the runoff film, either concentrating or dispersing surface flows [283]. Besides, deflection can also be ensured with design details such as drip edges or ridges in the wall cladding that direct water away from construction elements such as windows, and to stop water from running along the bottom of edges of materials back towards the enclosure [286].

Attempting to entirely deflect rainwater from contacting walls is difficult and impractical [286]. Hence, it must be assumed a wall system will be exposed to rainwater. There are three main control strategies for handling externally applied liquid moisture: Exclusion (perfect barrier walls), Storage (mass walls), and Drainage (drained and screened walls) [40, 85]. An enclosure wall categorisation system based on the method by which the wall system controls rain penetration is presented in Figure 2.9 [40]. SimilarLY to the overall systems, the joints can also be designed in accordance with the three rain penetration control strategies [31, 263]

Storage or mass walls are the oldest strategy. This approach requires the use of an assembly of materials with enough storage and moisture tolerance to absorb all rainwater that is not drained or otherwise removed from the outer surface [283]. If a balance between wetting and drying is maintained, moisture will not accumulate over time, and moisture-related problems at the backside of the wall or at the back wall are unlikely [40]. In essence, performance of mass walls depended on the storage or mass buffering capacity and water transmission characteristics of the wall system [39]. Thereupon, there are two ways of taking profit of the mass capacity of the building envelope materials:

- Mass buffering capacity to fluid water.

These construction systems are supposed to absorb all rainwater that is not drained or otherwise removed from the outer surface. Then, moisture is removed by evaporative drying before it reaches the inner surface of the 
wall. An example of these systems will be the thick masonry walls or the adobe walls. Nonetheless, the water permeance of the various layers and interfaces within the wall system can play a critical role [39, 40]. Any treatment that reduces surface water absorption while not reducing the water storage capacity of a wall will increase the ability for the assembly to control rain [40]. This is the reason why when the wall was not wide enough or the available materials were too porous, a rendering or plastering was laid in the exterior side to improve the watertightness performance of the wall. By applying a thin $15 \mathrm{~mm}$ cement-based rendering, the storage capacity was only marginally increased, but the permeance of this outer layer was so low, even when cracked, that the rain penetration control was vastly improved [39, 40].

- Moisture buffering capacity to water vapour.

These systems are intended to adsorb (vapour is adsorbed by a solid element) and absorb (the vapour is condensed and afterwards absorbed) the water vapour from the ambient relative humidity. The water vapour adsorption affects the fluid water absorption since a damp material tends to absorb rainwater faster. For this purpose, hygroscopic materials are often used. A hygroscopic material has the ability to adsorb and store moisture from the surrounding air. When the relative humidity changes, a difference in the vapour partial pressure results in the material absorbing or desorbing moisture in order to reach equilibrium. Research into dynamic moisture storage in hygroscopic building materials has renewed interest in the moisture buffering capacity of building materials and shown the potential for these materials to improve indoor humidity, thermal comfort and indoor air quality in buildings [291].

The extent and duration of wetting, storage, and drying must, however, always be considered when assessing the risk of moisture damage as the maximum quantity of rain that can be controlled is limited by the storage capacity available relative to the drying conditions.

Another enclosure strategy developed to control rain penetration is the perfect barrier system, which is based on the principle of exclusion [286]. They are commonly known as single barrier systems (or one-stage tightening barrier [182]) since they are supposed to stop all water and air penetration at one layer [34, 40]. Hence, this layer plays the role of drainage plane (or moisture barrier or water resistive) and air barrier. Perfect barrier systems that use the exteriormost layer as the rain control plane are termed faced-sealed; refer to Figure 2.9. In order to work properly, perfect barrier systems might require a completely free of openings exterior wall. However, it is almost impossible since the building enclosures are composed by building components that are part of larger systems, and even with the recent technology, it is very difficult to construct a durable impervious skin which can withstand different environmental variations. Examples of face-sealed barrier walls construction are barrier-type EIFS, some panelized metal wall systems and some metal and glass curtain wall systems. Perfect barrier systems perform very well, as long as they are perfect [263]. It very difficult to construct a wall as a perfect barrier system, so most walls are designed as an imperfect barrier system, using either the storage or drainage strategies [40, 286]. An example are the concealed barrier walls (EIFS with drainage or water-managed EIFS), see Fig. 2.9. A "concealed barrier” approach functions to resist rain penetration in two ways: (1) the exterior cladding layer sheds most water at its outer surface, and (2) it anticipates that some water will be driven behind the outer surface and will then be intercepted and managed by the drainage plane, which is sandwiched between the backside of the exterior cladding and the sheathing [289]. Note that unlike in drained-screened walls where rain penetration is controlled by reducing the successive fractions of water that are transmitted inward, the drainage is provided at one layer only in concealed 
barrier walls $[2,40]$. Bulk water is intended to migrate down the face of the water resistive barrier and escape from behind the exterior cladding layer at the weep screeds or flashing or can evaporate. In some instances, water may reach the face of the concealed barrier and, if the cladding is in contact with the concealed barrier, water can become trapped behind the absorptive cladding [289]. Concealed barrier approaches tend to have better performance than face-sealed systems as the key components are less exposed to temperatura and radiation extremes [283].

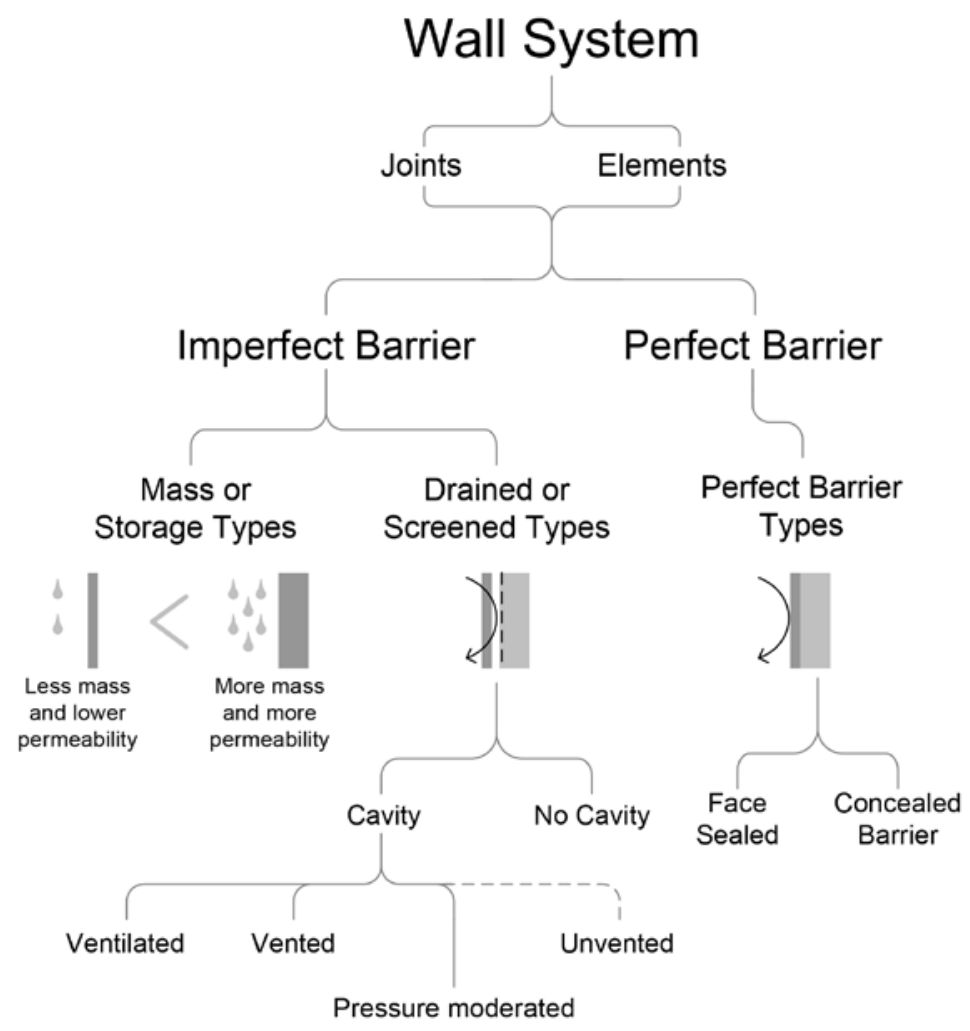

Figure 2.9. Rain control strategies in wall systems [186].

The last approach to controlling rainwater is to accept that some water will penetrate the outer surface and provide drainage to remove it by reducing the amount of water transmitted at each of several layers [2, 40]. Then, a “rainscreen” resists rain penetration in three ways: (1) the exterior cladding layer sheds most water at its outer surface; (2) it anticipates that some water will penetrate behind the outer surface, and intercepts it with a dedicated air space/capillary break; and (3) this space is vented to the outside to not only assist drainage but to encourage drying as well [289]. They are also referred to as two-stage tightening as the rain barrier (rainscreen) and air barrier (inner layer) are separated in different layers [182]. Some examples of drained wall systems include cavity walls, brick and stone veneer, lap siding and panel cladding system. Historically, this rain control concept included a drainage space acting as capillary break, so water that passed the cladding would not enter the interior enclosure layers [290]. In this regard, Choi [32] suggested that the drainage space inbetween the air barrier and the rainscreen ought to be vented to the outside of the building through vent (weeps) holes in the rainscreen. And Bomberg et al. [39] commented that the screened-drained wall systems did not require any storage capability. Therefore, there 
are four necessary requirements of any successfully drained wall system [292]. These requirements are a drainage plane (a water repellent plane), a drainage space (often a clar air space), flashings at the base to direct water out of the drainage gap and weep holes to allow water out of the drainage gap [283]. Field testing and some field experience has shown that small gaps may be sufficient to provide drainage [33]. To act as a capillary break, the drainage space should be at least 6 to $8 \mathrm{~mm}$ wide, since this is approximately the size of a gap that can be spanned by water [286, 283]. Moreover, water will be retained by surface tension in a cavity less than $5 \mathrm{~mm}$ deep [33].

In general terms, the bigger and deeper the air cavity is the more air intake is needed and the bigger the air vents need to be [63]. To allow for ventilation airflow, the gap should be as unobstructed and as large as possible [283]. Small gaps (3 mm) can allow a small and potentially beneficial amount of ventilation flow, but larger gaps (over $1 \mathrm{~cm}$ ) are usually required to ensure significant ventilation. A ventilated air space allows some degree of pressure moderation across the cladding. Pressure moderation is the term given to the mechanism whereby wind pressure differences across the cladding are reduced by connecting an air space behind the cladding with the wind-induced pressure acting on the exterior [283]. Note that experience indicates that the smaller the cavity volume, the faster the moderation of the cavity pressure [281]. When the inner layer is much more airtight than the outer layer, the air cavity will pressure equalized with the exterior, reducing the air pressuer over the outer screen [263]. Hence, pressure-equalized rainscreens are a very special case of drained-screened systems that moderate wind pressure to reduce the transmission fraction of the screen [40].

Screened wall systems are inherently more forgiving than either mass or perfect barrier systems [283]. However, failures in screened systems tend to occur because drainage was not provided, either through a design or construction failure [2, 283, 286]. Pressure equalized screened systems offer only marginal benefits in most situations since the reduction in water penetration that may result from pressure equalization does not aid rain control, so long as drainage and capillary breaks are provided [283]. Failures in pressure equalized will still be by a failure to drain. In addition, some field measurements [293-295] have shown that pressure equalisation is rarely achieved in practice, but that moderation of the pressure can be practical and beneficial for some types of wall systems. Rear-ventilated façades, the focus of the Ph.D-work, are enclosed in this last appoach to controlling rainwater. They are typically conceived or perceived as pressure moderated drained-screened wall systems, where the pressure difference across the rainscreen is typically lower than 25 Pa under static conditions [296].

The last "D" described in the rain control approach meant the Drying. When rainwater hits the enclosure surface, a significant amount of water will usually remain attached to surfaces by surface tension, another part will be absorbed into materials by capillary forces and a part might penetrate within the wall system, all promoting the storage of moisture. The moisture stored in the wall must be dried in a timely manner to avoid moisture related durability issues. Moisture is usually removed from an enclosure by liquid water drainage, evaporation from the inside or outside surfaces, vapour transport by diffusion and vapour convection (e.g. ventilation). The amount of drying required will depend on the physical characteristics of the enclosure, the environmental conditions on both sides of the enclosure, and the frequency and intensity of rain events [286, 298].

Ventilation, or exterior airflow behind the cladding of drained and screened wall systems driven by wind pressures on the face of the building or solar heated air rising, is useful since it accelerates drying [283]. Water does not always accumulate in the drainage gap quickly enough to drain, so the water is stored in the enclosure. Since most claddings have relatively low vapour permeance, ventilation of the space behind the cladding can be an important 
means of both drying and avoiding inward vapour drive wetting [299]. Other past studies have shown that ventilation airflow can remove significant amounts of moisture from the building enclosure [299-303]. Schumacher et al. [304] showed a correlation between the amount of airflow (air change rate) and the drying rate of the enclosure. Falk and Sandin [305] assessed that the cavity design (cavity depth and batten configuration) was of major importance for the drying rate if the material adjacent to the cavity is wet over its entire extension, concluding that convective moisture transport in small cavities $(\mathrm{d}<10 \mathrm{~mm}$ ) is much less efficient than in wide ( $\mathrm{d}$ = 25-40 mm). Results that are in line with other studies (e.g. Rousseau et al. [297] and Gudmundsson et al. [306]). Falk and Sandin [305] also stated that the drying time was prolonged when the cladding support system was horizontal instead of vertical.

However, Salonvaara et al. [307] conducted a literature review and found that not all authors agree on the positive effects of cavity ventilation. Hens et al. [308] for instance, stated that there is no real benefit of cavity ventilation on heat transmission within the air space. Some studies even reported negative effects of of cavity ventilation. For example, when the absolute humidity of the air flowing through the air cavity is high, the moisture in the air results in a hygroscopic moisture loading [298]. Note that the focus of these latter authors were cavity walls not ventilated rainscreen claddings.

\subsection{MECHANISMS OF RAINWATER PENETRATION THROUGH JOINTS}

Garden [27] summarises that the emerging of water leakage in building envelopes requires the simultaneous action of the following regarded factors:

(i) presence of water on the wall,

(ii) existing opening(s) on the wall (such as cracks or joints) to permit its passage and

(iii) forces driving the water into the opening.

Control of rainwater penetration depends on being able to control any of these conditions [34]. So, when one of these factors is cancelled out, the water is then not able to cause leakage on the building envelope. Since the presence of water on a building exterior is practically impossible to prevent, wall design strategies are usually focused on eliminating forces driving water through the openings.

The forces acting in support of water ingress in open joint claddings are: kinetic energy of raindrops, surface tension, gravity action, pressure differences, local air currents, hydrostatic pressures and capillary forces [30, 31, 33- 37, 215 and 309 amongst others]. If all of the driving forces for rainwater can be controlled or eliminated, then water even if present on the wall will not infiltrate through the building enclosure [27]. Of these, kinetic energy and differential pressure are a function of weather events [310] as well as local air currents. The rest are a function of material properties and constructive design of the joints. Among these, gravity action, capillary forces and air pressure differences are generally the most significant driving forces [36, 311]. However, there is a general belief among researchers that the most common cause of water leakage is due to pressure differential [32]. The other forces help to bring the water towards the leakage point, but it is usually the pressure differential induced by strong 
winds which is the major force driving the water through [48, 214, 215, 312]. Besides, the effects of wind velocity can be greater than the effects of gravity, resulting in regions of the wall where wind-driven rain actually flows upwards or sideways. Therefore, if total prevention is desired, apart from reaching optimal pressure equalization, joints in the rainscreen of rear-ventilated façades must be designed to counteract all the other forces which drive water inside, mainly gravity and capillary action [281].

When considering the water management features of rear-ventilated façades, the analysis might be carried out taking into account two stages:

(i) the response to wind driven rain and runoff film of the open joint itself and

(ii) the response to wind driven rain and runoff flow of the panel.

When considering the response scenario to wind-driven rain and water runoff of the joint, the construction detail of horizontal and vertical joints must be regarded. For instance, Fig. 2.10 illustrates two different ways of solving the vertical and the horizontal joint in a rear-ventilated façade.
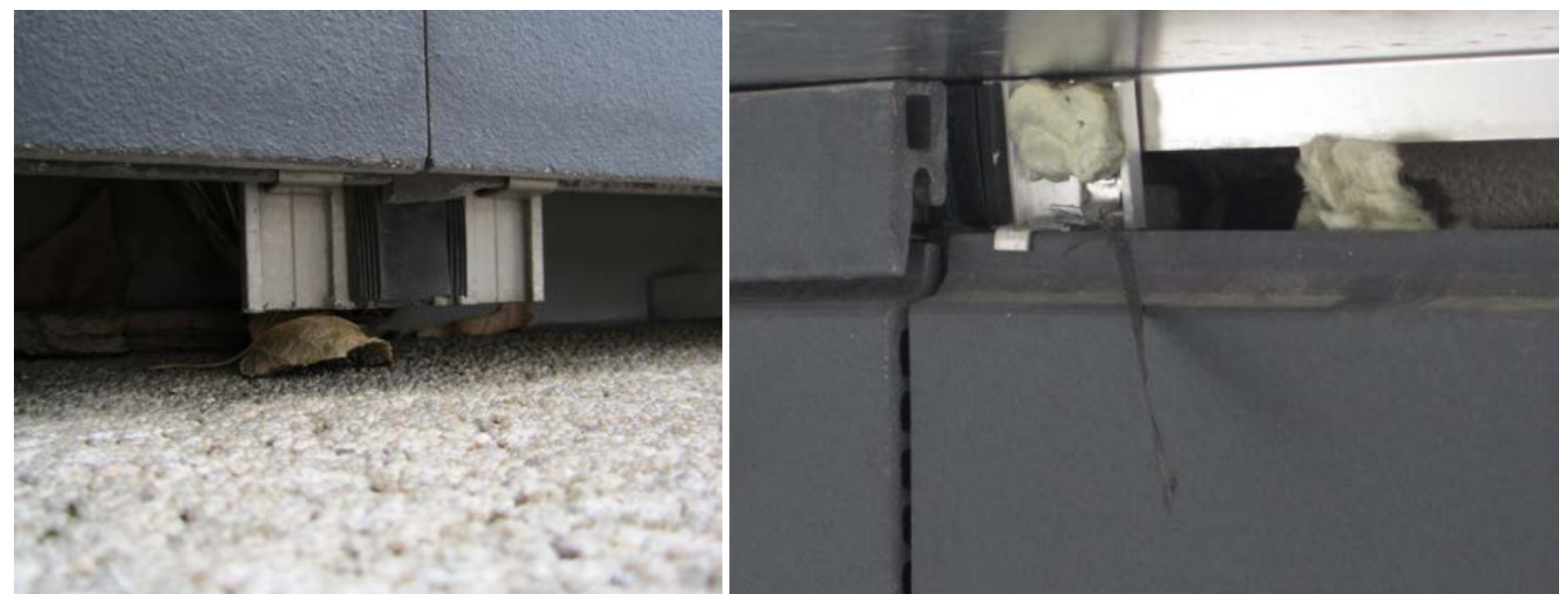

Figure 2.10. Pictures of the vertical (image on the left) and horizontal joint (image on the right) construction detail in a rear-ventilated façade whose rainscreen is made of ceramic tiles.

In the following lines the possible response scenarios to wind driven rain and runoff flow of the joint are briefly analysed and discussed:

\section{Gravity action; refer to (a) in Fig. 2.11.}

Gravity is the tendency of water to flow downwards the face of a wall and into the openings that lead inwards and downwards $[31,186]$. Note that in horizontal joints of less than $0.5 \mathrm{~mm}$ rainwater will not flow through the opening by gravity due to surface tension [151]. In addition, even when little or no wind is acting (no pressure difference across the opening), water may enter under the action of gravity alone and in substantial quantities if water is present at the openings [79]. Regarding the runoff film, as the thickness of the water film increases, gravity forces will exceed surface tension forces, allowing the film to run down $[115,140]$. Then, the greater the rise in the mass 
flow (up to a certain value), the higher mean velocity this water falling film on a vertical wall might have due to gravity action.

2. Surface tension; refer to (b) in Fig. 2.11.

Surface tension is the contractile tendency of the surface of a liquid that allows it to resist an external force (cohesive forces). The surface tension between the interface of two different means depends on their nature and represents an equilibrium that corresponds to the minimum part of the free surface forces of the whole system. A consequence of this equilibrium is that the mean with minor internal cohesion forces (the air) will tend to surround the one with major internal cohesion (the water). The equation of Dupre determines the wetting pattern of the rain drop. The tendency of rainwater drops to spread out over a flat, solid surface increases when the surface tension of the solid-liquid phase is lower than the surface tension of the solid-gas phase. Then, the smaller the wetting angle, the better the wettability of the liquid film. A higher wettability induces a larger surface that is exposed to water, so more absorption can occur [140]; see Fig. 2.12.

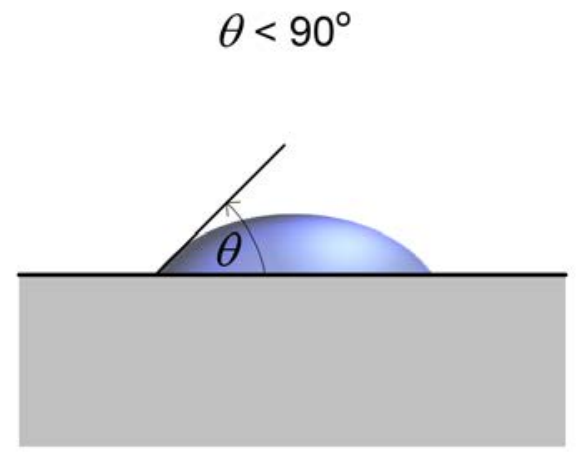

- Wetable surface.

- Non-water repellent surface (hygroscopic surface).

- Water more attracted to surface than to itself.

- Surface energy of surface greater than surface energy of water.

- Water "spreads out".

- Low contact angle.

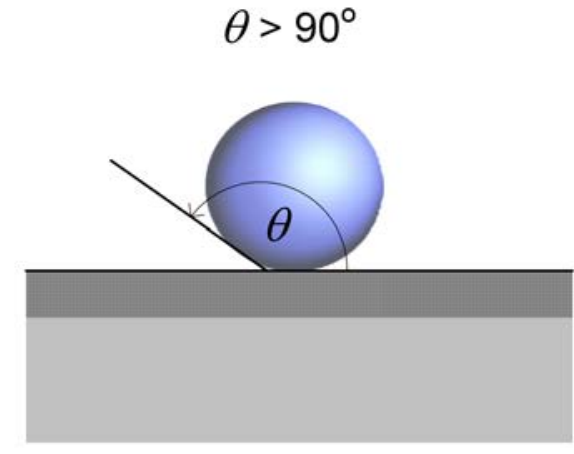

- Non-wetable surface.

- Water repellent surface (hygrophobic surface).

- Water more attracted to itself than to surface.

- Surface energy of water greater than surface energy of surface.

- Water "beads up".

- High contact angle.

Figure 2.12. Contact angles and water repellency [286].

Therefore, surface tension can be described as the tendency of water to stick to the surface of the wall that is already wet [31]. The cohesive forces of flowing rainwater, surface tension, on an exterior material can be greater than the force of gravity resulting in situations whereby water can flow horizontally along the bottom edges of returning surfaces actually directing water back toward the interior $[33,116]$ and thereby, wetting areas not directly exposed to rain or in the path of water flowing down the face of a building. Observations for a smooth granite façade showed that, at low rates of flow, a water film flows round the edge and along the underside of the horizontal return, and then on the adjacent vertical surface [111]. As the flow rate increases, the water begins to bead and 
drops from the underside of the return [111]. At higher flow rates, the momentum of the water film is sufficiently large to break the surface tension at the edge and to fall free [111].

In small openings, the surface tension of water will introduce a meniscus on the interior sides of the joint when no water is supplied at that location due to rivulet formation [263]. It means that the opening can be occluded creating a bridge that will allow the water of the rivulet to overflow it and continue its way down. Water will enter the joint gap once the surface tension is breached by another acting force, like gravity or pressure differences.

3. Capillary action; refer to (c) in Fig. 2.11.

Capillary action occurs in situations where water is absorbed into an envelope substrate by a wicking action. Capillarity is the ability of a liquid to flow in narrow spaces without the assistance of, and in opposition to external forces. According to Bassett et al. [31], the capillary action is the tendency for liquids to fill small openings, lifting water up against the force of gravity.

Capillary action is influenced by the diameter of the gap. The smaller the radio of the gap is, the higher the capillary action is. It is an effect that acquires major importance when the joint width is less than $0.5 \mathrm{~mm}$ [151]. According to Mas et al. [281] and Morrison Hershfield [311], capillary action and surface tension have less importance in joints of $0.8 \mathrm{~cm}$ or above. Furthermore, the process of evaporation of capillary rainwater is longer.

\section{Kinetic energy of raindrops caused by wind velocities; refer to (d) in Fig. 2.11.}

Kinetic energy is the energy that possesses a body due to its motion which propels raindrops into unprotected holes. Having gained this energy during its acceleration, the body maintains this kinetic energy unless its speed changes. Wind forces can easily lead rainwater droplets through openings along the building enclosure during rain events, since wind gives the rain a horizontal velocity component that provides the droplets with an oblique trajectory. Then, rain drops encouraged by wind-blow penetrate into open joints owing to their kinetic energy; some passing through directly, others repeating rebounds [269]

In order to have rainwater infiltration by means of this phenomenon, it is required joints of more than $4 \mathrm{~mm}$ [151]. Pardal and Paricio [51] and Huedo et al. [280] studied this phenomenon in rear-ventilated façades. The formers assumed that in order to prevent the impact of the wind driven rain droplet onto the exterior side of the inner leaf, the air cavity thickness should be enough to minimize the kinetic energy of the droplet acquiring then a perpendicular trajectory. The latters, stated that this pehonemon is even more pronounced in vertical joints than in horizontal joints. Avellaneda [314] assessed that an air cavity thickness between 7 and $29 \mathrm{~cm}$ has not an impact on the water infiltration rate onto the inner leaf. However, the design of the joint (width, thickness and edge profile) is a key factor when working with air cavity thicknesses below $7 \mathrm{~cm}$ [51].

\section{Pressure differences; refer to (e) in Fig. 2.11.}

Wind pressure on a building will lead to a pressure differential between inside and outside. When the external pressure is greater than the internal, water on the outside surface will be forced through openings and thereby, allow water to enter the wall inwards through small openings that might otherwise resist leakage. For newly 
constructed façades without defects and with pores or openings smaller than $1 \mathrm{~mm}$, the pressure difference across the façade is the most sensitive parameter related to water penetration [95]. According to Seo and Yoda [269] water penetrations into joints of more than $12 \mathrm{~mm}$ do not depend upon pressure.

In rear-ventilated façades, negative interior pressure might also result from the "stack effect” due to the difference between interior and exterior temperatures causing a depression in the chamber that makes it easy for air and water to enter through the joints of the rainscreen [280]. According to these authors, it is a phenomenon that might typically occur in both vertical and horizontal joints of $3 \mathrm{~mm}$-wide.

\section{Local air currents; refer to (f) in Fig. 2.11.}

At a point where a high rate of inward air flow occurs as a result of an opening and an air pressure drop, water can be dragged along the walls of the opening and cause rain penetration [27]. Air pressure drops can be induced by mechanical conditioning equipment, stack effect or wind pressures [286]. Water can penetrate a wall by being transported along a stream of moving air. It will percolate across barriers or through openings, cracks and holes if the air flow speed is high enough [31]. Control of penetrating water usually also requires considering the control of air movement of the surrounding environments. Air-currents occurs through joints, depending upon air slit and wind pressure affecting not only wind-driven rain, but also the state of water film which penetrates along the upper face and the state of water staying at the bottom [269]. These authors stated that it might make severe penetration to occur since the water film, which has hardly any harm itself, becomes a dangerous factory by the effect of the air-current. Such severe states are occurred with comparatively small amounts of water in the case of narrow joints, and with large amounts of water in the case of wide joints, under a fixed air-current [269]. Besides, there is for all joints a critical velocity of the order of $5 \mathrm{~m} / \mathrm{s}$ at which individual droplets would be carried through in the airstream [279].

\section{Hydrostatic pressure; refer to (g) in Fig. 2.11.}

Hydrostatic pressure is the pressure exerted by a fluid at equilibrium conditions at a given point (with a particular hydrostatic height) within the fluid, due to the force of gravity. It increases in proportion to depth measured from the surface because of the increasing weight of fluid exerting downward force from above. For instance, if there is a closed container full with water and you make a hollow in it, water will leak outside due to hydrostatic pressure. The bigger diameter the hole has, the higher hydrostatic pressure will be and the lower external pressure difference applied should be in order to breach the meniscus of the outwards water flow [263]. Therefore, hydrostatic pressure on an envelope is created by the weight of water above that point (e.g., the height of water due to its weight creates pressure on lower areas referred to as hydrostatic pressure). Water under this significant pressure will seek out any failures in the envelope, especially the areas of weakness that is the terminations and transitions between the envelope components [37]. In this way, when the water is not drained sufficiently, hydrostatic pressures across little cracks may cause water to flow to the interior [315]. The influence of the negative pressures introduced by the hydrostatic pressure of the water runoff by means of the Venturi Effect on the watertightness performance of rear-ventilated façades is uncertain. 


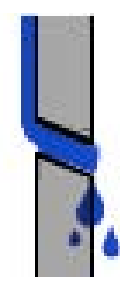

a

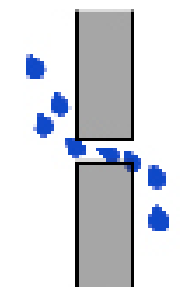

d

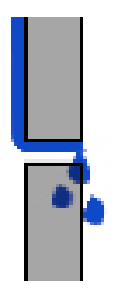

b

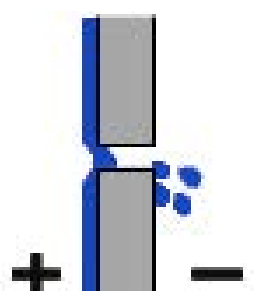

e

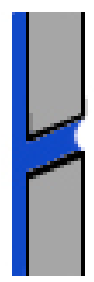

C

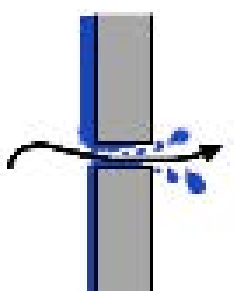

f

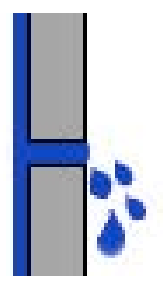

g

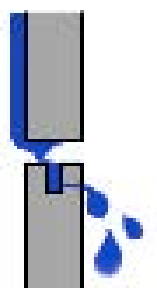

g

Figure 2.11. Rain penetration mechanisms through vertical and horizontal joints of rear-ventilated façades.

In the second stage, the response scenario to wind-driven rain and runoff flow of the cladding element is analyzed.
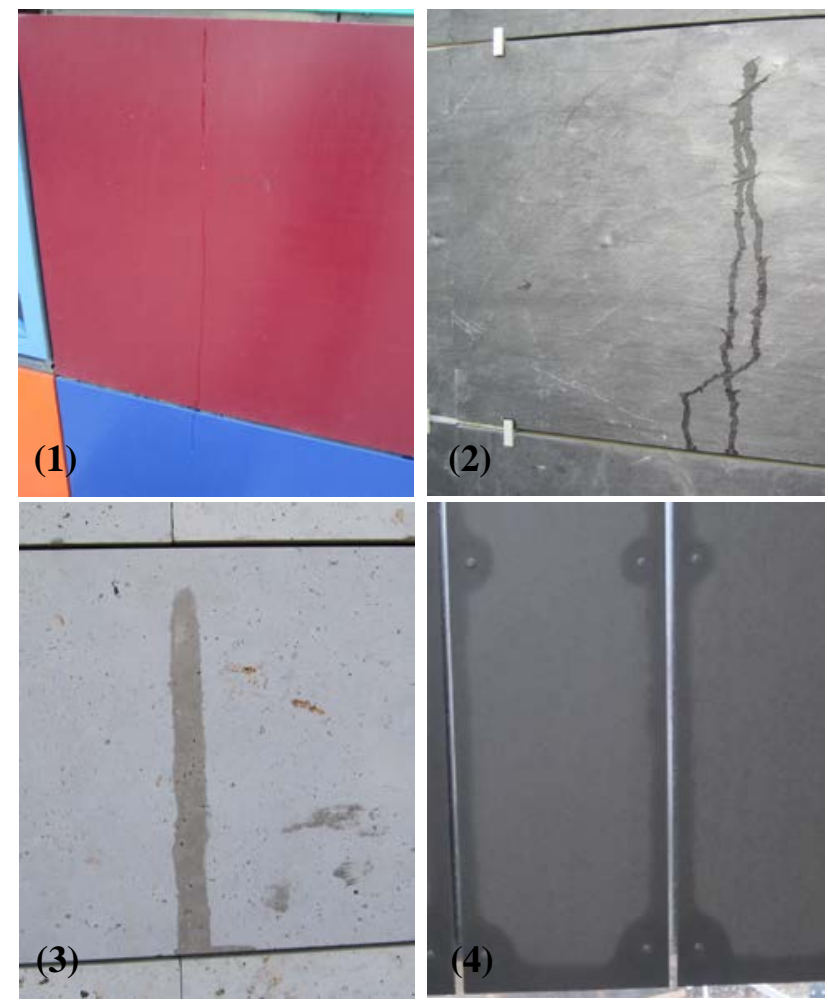

Figure 2.13. (1) Shows a completely impervious material (aluminium cassette). In (2) and (3) there are examples of materials that absorb rainwater by the surface. The former is a slate plate, whereas the latter is a limestone plaque. (4) Exhibits a material that absorbs rainwater by the edges and not by the surface (fiber cement panel). 
Each group is prone to promote different wetting patterns and rainwater mechanisms through both, the cladding and the open joints of rear-ventilated façades. Note that absorption can be defined as the maximum amount of water that the surface may hold [140]. Nevertheless, this stage of study remains out of the scope of the present Ph.D-work.

\subsection{PRESSURE MODERATION: THE RAINSCREEN PRINCIPLE}

The driving forces for rainwater penetration have been discussed in the previous section of the chapter. Among these, gravity, capillary action and air pressure differences are generally the most significant [331]. The relative significance of these forces depends on the type of application and construction [312]. However, there is a general belief among researchers that air pressure differential is the major driving force contributing to rainwater penetration [32, 48, 312]. Air pressure differences across the walls can be induced by stack effect, mechanical systems and wind [312]. Among these, the higher pressure differentials might be caused by the wind. Wind induces large air-pressure difference across exterior walls, especially during gusty wind conditions while mechanical ventilation and stack effect cause smaller but steady pressure differentials [63]. In response to this situation, pressure equalized rainscreen approach to wall design has been suggested.

Many building components rely on pressure equalization to achieve a good performance in respect to watertightness. The same can be applied to rear-ventilated façades, which are conceived as Pressure Equalized Rainscreen (PER) walls. The pressure difference across the rainscreen is typically lower than $25 \mathrm{~Pa}$ under static conditions [296], regardless of the applied pressure in front of the wall assembly. The pressure-equalized rainscreen wall design is based on the "open rainscreen principle", which aims to control all forces that can drive water into the wall assembly (e.g. kinetic energy, surface tension, gravity action, pressure differences, local air currents, hydrostatic pressures and capillary forces). Note that with respect to rain penetration, the concept of cavity walls is based upon the control of some of the forces acting on the cladding, i.e., gravity, surface tension, capillary action, and raindrop momentum (kinetic force) [63] and consequently, should not properly referred to as rainscreen walls.

The first literature reference to a rainscreen was made by Johansson [316]. The author defined rainscreen as "a water-repelling screen fitted to a brick wall applied so that water vapour coming from within is automatically removed by ventilation of the wall and screen”. Early examples of rainscreens can be found in the wall construction of Norwegian style barns, which were built using a layer of open-joint wood battens or siding set over traditional stone wall [26]. The primary function of a rainscreen is to keep away most of the driving rain from the structural leaf (air barrier) [312].

According to AAMA CW-RS-1 [317], the "rainscreen" represents the outer surface of a wall or wall element and the "rainscreen principle" is a principle of design that prescribes how penetration of this screen by rainwater may be prevented. The rainscreen principle was formalized by Birkeland in 1962 and by Garden in 1963. Birkeland [319] suggested that venting the cavity behind the screen would equalize the pressure on either side of the screen and essentially eliminate air pressure differences as a rainwater penetration force. Garden [27], apart from 
including the pressure equalization concept, proposed the compartmentalization of the air chamber to minimize lateral or vertical air movement. As the exterior pressure is not constant, the pressure in the cavity will also vary depending on the degree of pressure moderation. Even in static conditions air flow in the cavity may arise from lateral air movements within the cavity as may occur when air is drawn from the perimeter of the wall due to suction arising from the leeward flow of air on adjacent walls. This is a situation where lateral air movement within back-ventilated cavities depends upon the direction of the wind acting on the façade. As a result, Garden [27] coined the "open rainscreen principle" and the term "open rainscreen wall" to refer to pressure-equalized rainscreen walls, whose basic premise is the control of all forces that can carry the rain to the inside.

However, design principles and the practice of rainscreen claddings were first studied by Anderson and Gill [26]. These authors leaned towards a category system of the rainsceen based on the rainwater control strategy that uses the wall. In this way, a distinction was established between drained and screened cavities from ventilated and pressure moderated cavities. The drained and screened wall assemblies rely on the cavity to permit drainage from and the drying-out any residual amounts of water as may inadvertently infiltrate into the cavity. In this wall type the outer or "screen" layer is intentionally vented to the exterior, while the air barrier is located at the inner layer or backup wall. Common simple rain screen wall types include brick or stone veneer on concrete block backup, stucco or vinyl siding on wood or steel frame construction, etc. Therefore, conventional or basic rainscreen walls do not address all forces that can carry rain to the inside since the compartmentalization and pressure equalization are not necessary requirements in them. Alternatively, ventilated and pressure moderated cavity wall employ drainable compartmentalization to limit water penetration and facilitate rapid pressure equalization. The pressure equalization concept is simple: when the outside air pressure is transferred to an air space behind the exterior cladding, the cladding is exposed to a near-zero pressure differential [296].

In 1967, Birkeland [318] emphasized that pressure equalization alone cannot prevent all the rainwater penetration. Consequently, Pressure Equalized Rainscreen (PER) walls are not only about pressure equalization across the rainscreen. Other forces are at work as well (e.g. kinetic energy, surface tension, gravity action, local air currents, hydrostatic pressures and capillary forces), and their control is part of the PER wall strategy for rain penetration control in exterior walls [296].

A critical review related to pressure equalization of rainscreen walls has been conducted by Kumar [312]. The author highlighted that pressure equalized rainscreen (PER) walls have three main components including (i) rainscreen, (ii) cavity and (iii) air barrier.

The rainscreen is the first line of defence against wind-driven rain. I should contain enough vent openings to provide quick pressure equalization within the air cavity in order to minimize/reduce wind induced air pressures difference across the cladding [307]. Hence, two major issues arise concerning the venting requirements: (a) the amount of venting needed for adequate pressure equalization under static and dynamic pressures, (b) the placement of the venting for each compartment [296] and (c) the edge profile of the vents to offer little resistance to airflow. The rainscreen should be made less airtight than the air barrier.

A cavity is located between the rainscreen and the air barrier system. It acts as a site for the outside pressure to be transferred, a capillary break and a channel for drainage. The various design features of cavity are (a) cavity depth and (b) compartment size [312]. The net width of the cavity should be about $25 \mathrm{~mm}$ [63]. Experience indicates that the smaller the cavity volume, the less airflow is necessary to equalize pressures and thereby, the faster the 
response time of the cavity pressure [312].

The key to pressure equalization is a continuous air barrier on the interior surface of any pressure equalized component [286]. The primary function of air barrier is to restrict airflow through it. Therefore, it controls heat flow through the envelope. The various design features of air barrier concerning only the rain penetration aspect are (a) effective leakage area and (b) air barrier stiffness [312]. The degree of tightness of an air barrier system (ABS) is likely to affect the degree of driving pressure across the wall, and consequently, the water infiltration rates. Experience indicates that the tighter the air barrier, the better the pressure equalization [63, 263, 281, 296, 312, 320]. Moreover, the larger the vent area, the shorter the time to pressure equalization. In addition, the air barrier should be rigid to keep the volume of the cavity constant [63]. A constant volume helps the cavity "bounce back" quickly in response to rapid pressure fluctuations (during wind gusting), whereas a flexible membrane deflecting in the cavity under wind pressure can promote some pumping in of outside air.

In the literature, a number of works concerning pressure equalization have been published from experimental studies as well as theoretical approaches. On the one side, extensive studies have been conducted in wind tunnel experiments [e.g. 179, 321-329] and full-scale laboratory experiments [e.g. 40, 325, 330, 336, 333] to examine different aspects of PER walls design, but few field tests [e.g. 301, 330- 335]. For instance, Ganguli and Dalgliesh [330] determined that wind load is transferred onto the air barrier. Further, their results showed that the degree of pressure moderation depended on the position of the panel in the building façade. Inculet [325] reported that high ratio of 'air leakage area' $\left(A_{a b}\right)$ to 'venting area' $\left(A_{r s}\right)$ of the openings in the rainscreen contributed to poor pressure equalization. He also found that a large venting to cavity volume ratio (i.e. $A_{\mathrm{rs}} / \mathrm{V}$ ), small compartment size, and well sealed air barriers improved the pressure equalization characteristics of the system. Bentum et al. [335] studied the pressure moderation in a ventilated cavity without compartmentalization obtaining that pressure equalization occurred very quickly and that the cavity pressures were able to follow the external pressures very well. Surprisingly, Lou et al. [179] obtained that the gap inner pressure acting on the internal skin of strip type double skin façades was usually larger than the net pressure on the external skin.

On the other hand, two types of models have been used to simulate pressure equalization in PER walls: those based on the Helmholtz theory, and those based on the ideal gas law. Latta [337] suggested that adequate pressure equalization might be achieved when the vent area of the rainscreen $\left(\mathrm{A}_{\mathrm{rs}}\right)$ and leakage area of the air barrier $\left(\mathrm{A}_{\mathrm{ab}}\right)$ follows that $\mathrm{A}_{\mathrm{rs}}>10 * \mathrm{~A}_{\mathrm{ab}}$. This assumption was taken based on incompressible flow and flow through sharpedged orifice openings in both layers. Alternatively, Killip and Cheetham [338] found that 99\% pressure equalization could be achieved for instances where $A_{r s}>25$ to $40 * A_{a b}$. These authors supposed a turbulent flow on the exterior side (opening in the rainscreen) and laminar flow on the interior side (opening in the air barrier). In this context, Fazio and Kontopidis [339] assumed that sharp-edged orifice flow was only valid for large openings, whereas the unintentional cracks present in a typically constructed rain screen and air barrier would be so small that the resulting air flows would be laminar in nature.

In this context, account must, however, be taken of the lack of data regarding the: (a) Behaviour of PER walls in real conditions when they are built with open joint claddings; (b) Degree of pressure equalization of PER walls during rain events [263], and; (c) Influence of pressure equalization on achieving watertightness in wall assemblies [263]. 


\section{6|DISCUSSION: REAR-VENTILATED FAÇADES}

In this section a synopsis of the state of the art of rear-ventilated façades is provided. It is a compilation of all the issues previously treated, but particularly applied to rear-ventilated façades. This summary first encloses a brief definition of the rear-ventilated façade typology in accordance with the standards. Subsequently, a discussion of the hygrothermal performance of rear-ventilated façades is carried out. The dicussion deals not only with the response to wind-driven rain, but also with the fluid and thermal response, considering in the latter the airflow induced by thermal buoyancy and the airflow induced by wind. Note that the drying process and the thermal performance of these façades is out of the scope of the present Ph.D-work and consequently, will be only briefly addressed.

According to ETAG 034 [49], rear-ventilated façades can be considered as vertical exterior wall claddings consisting of an external cladding, mechanically fastened to a framework (specific to the kit or not) by means of anchorage points (see Fig. 1.11 of Chapter 01). The framework is fixed by angle brackets to the external wall of new or existing buildings. Note that irrespective of the definition provided in ETAG 034 [49], the fixation method to the framework can also be adhesive or mechanical and adhesive [69]. An insulation layer is usually attached to the external wall and these typically can be made of materials as provided in Table 1.1 of chapter 01.

Rear-ventilated façades, in an EU context, are the result of the adaptation of the rainscreen concept to multi-layer envelopes [25]. According to AAMA CW-RS-1 [317], the "rainscreen” represents the outer surface of a wall or wall element and the "rainscreen principle” is a principle of design that prescribes how penetration of this screen by rainwater may be prevented. Garden [27] utilized the concept “open rainscreen principle” as a way to prevent through-wall penetration of rain by incorporating an air chamber into the wall where the air pressure can be equalised to that on the outside. However, design principles and the practice of rainscreen claddings were first studied by Anderson and Gill [26]. These authors distinguished between drained and screened cavities from ventilated and pressure moderated cavities. The drained and screened wall assemblies rely on the cavity to permit drainage from and the drying-out any residual amounts of water as may inadvertently infiltrate into the cavity. Whereas, ventilated and pressure moderated cavity wall employ drainable compartmentalization to limit water penetration and facilitate rapid pressure equalization. Hence, the "open rainscreen principle” entails the control of all the forces acting to drive water through openings in the cladding and that can be managed by a drained cavity wall in addition to minimising air pressure differences acting across the cladding [63].

The overall system of rear-ventilated façades is supposed to be designed and function following the open rainscreen principle [27]. Between the cladding elements and the insulation layer, there is an air space of at least $30 \mathrm{~mm}$ [74], which must always be drained and ventilated in accordance with the principles established for drained and screened wall systems [40]. The claddings will normally contribute to durability by providing enhanced protection from the effects of weathering for in-board elements of the system. They are not intended to ensure the airtightness of the building structure [49]. Airtightness can be achieved by the application of suitable components on the interior layer of the wall system. Hence, in a rear-ventilated façade, the exterior surface of the cladding plays the role of the water shedding surface; the air space is the drainage plane (and also acts as the water-resistive barrier if the thermal insulation layer is not waterproof and is not covered by a water-resistive barrier); the exterior 
surface of the thermal insulation layer acts as water-resistive barrier and the interior layer of the inner leaf is supposed to be the air barrier [312, 340]. Experience indicates that the tighter the air barrier, the better the pressure equalization. Then, if the air barrier system of rear-ventilated façades is properly implemented it could provide complete pressure equalization. However, in most instances the installed system simply achieves pressure moderation in the air cavity [263, 281, 312, 320] because there are always unintentional openings in the air barrier.

Rear-ventilated façades are typically conceived as Pressure Equalized Rainscreen (PER) walls, where the pressure difference across the rainscreen is typically lower than $25 \mathrm{~Pa}$ under static conditions [296], regardless of the applied pressure differential across the wall assembly. As the exterior pressure is not constant, the pressure in the cavity will also vary depending on the degree of pressure equalization or pressure moderation. Even in static conditions air flow in the cavity may arise from windward to leeward side, causing lateral air movements. This is a situation where lateral air movement within back-ventilated cavities depends upon the direction of the wind acting on the façade. Consequently, to achieve pressure equalization where significant pressure differences are expected to arise across the exterior cladding, the air cavity must be compartmentalized such that the cavity volumes are not excessive and pressure equalization can occur [51, 280]. A lack of pressure equalization (due to inadequate compartmentalization) may induce higher wind loads on the façade components and as well, change the overall watertightness of the wall system. In respect to compartmentalization of the air cavity, fire safety constraints in these types of façades (fire risks are related to the chimney effect as takes place within the cavity) should also be considered. Given that there are, as yet, few methods, guidelines or standards that permit determining how and when to compartmentalize cavities, rear-ventilated façades are not in practice compartmentalized [7]. In this context, Fernández-Madrid [13] states that the air cavity ought to be vertically compartmentalized in 2 or $3 \mathrm{~m}$ wide lateral stripes, apart from the corners. Horizontally, he said that is very convenient to compartmentalize at each floor or at least every two floors. Alternatively, Sánchez-Ostiz [7] proposes to vertically compartmentalize the air cavity every $6 \mathrm{~m}$ and $2 \mathrm{~m}$ from the corners; and horizontally, at each floor or every $4 \mathrm{~m}$.

According to Rousseau et al. [296], PER walls are not only about pressure equalization across the rainscreen. Other forces are at work as well, and their control is part of the PER wall strategy for rain penetration control in exterior walls. Rear-ventilated façades are not watertight systems [49]. The degree of watertightness of rearventilated façades relies upon the characteristics of the materials used, the geometry of the external cladding element and the edge profile of the joints. As such, rear-ventilated façades incorporate water management features into the design and construction (drained and screened walls), unlike perfect barrier systems and traditional construction as is evident of, e.g., brick and stone masonry "mass buffered" or vented walls. However, whichever water management features are present, the hygrothermal performance of the whole enclosure system might nonetheless not work properly due to, e.g., improper design of constructive details, construction flaws in the façade, or other gaps in the practitioners understanding of the mechanisms of rain infiltration causing water to penetrate the interior wall assembly [18, 180-183]. According to Bomberg et al. [39], failure is recognized when water penetrates through an entire assembling to the inner surface of the wall or whether the transmission of rainwater reaches a sensitive layer of the wall assembly and is likely to cause damage, degrade performance, or affect its durability (long-term performance). Few publications exist where water infiltration problems on rearventilated façades have been reported in a systematic way. Nevertheless, this does not necessarily indicate that problems would not arise in practice. In several papers, reports on systemic defects caused by environmental actions (i.e. wind, rain and solar radiation) have been provided; these include: corrosion problems to the fastening 
system due to water entry [18, 181, 281, 341]; rupture and detachment of stone panels from walls [18, 281, 342, 343]; the presence of both longitudinal and transverse fractures of stone panels [342, 343]; the cracking and spalling of stone masonry panels close to anchorage systems [18, 178, 281, 342, 344]; stone panel decay through flaking and scaling [281, 343, 344]; damage to stone panels as evident from staining, soiling brought about by design features that hinder rain water runoff [18, 141, 344-346]; by salt migration as marked by efflorescence [181, 281, 341, 344]; or by biological colonization [347, 348]; and finally, problems as may arise due to the action of wind pressure on the connections between panels and the substructure [180, 181].

The cladding of rear-ventilated façades is expected to deflect the largest portion of the wind-driven rain that impinges on the exterior surface. Only a minimal portion infiltrates through the open joints since using pressure equalization mechanism reduces the rainwater penetration caused by wind-induced differential pressure [312]. This residual amount of water is supposed that is either drained at the bottom of the wall, temporarily stored in materials, or dries out to the exterior and in some instances to the interior. In this way, the air gap of ventilated façades as well as being a capillary break for rainwater, acts as a channel for drainage of infiltrated rainwater [312]. So, the joints between panels must be designed to minimize water penetration caused by all the forces acting to cause water ingress, allow the contraction and expansion of panels due to temperature effects, and offer little resistance to airflow thereby promoting pressure equalization across the cladding.

To ensure energy efficient ventilation and drying capability of the excess moisture absorved by the wall materials, of the adhered water to the surface of the wall materials and of the liquid water infiltrated into the air cavity, it is required a good ventilation design combined with optimum air-tightness of the air barrier (interior layer of the wall system). Nonetheless, ventilation also varies greatly depending on cladding design (size and opening of joints secondary structure configuration, façade colour, etc.) and the specific outdoor conditions (surrounding topography and buildings, climate, etc.), apart from the air cavity design [305]. The forces affecting ventilation (air change rate, $\mathrm{ACH}$ ) inside the air cavity are the thermal buoyancy and the wind. If we call our attention to the airflow induced by thermal buoyancy we should take into consideration the stack effect and the solar heating, where we can have up to fifty per cent reductions in energy consumption. On the other hand, the airflow induced by the wind through the open joints allows the pressure equalization of the air cavity.

Salonvaara et al. [307] conducted a literature review and found that not all authors agree on the benefits of venting/ventilating the air cavity. For instance, Hens [349] conducted a series of field and laboratory studies concluding that ventilation had an insignificant effect on heat transmission within the air space. Further, Tenwolde et al. [350] noted that conditions inside the cavity are not always dry enough to provide sufficient moisture exchange, i.e., drying. In such instances, the cavity can actually have a negative effect by contributing to an additional source of hygroscopic moisture load. Hence, the question arises under what climatic conditions and in which types of building envelopes does the air cavity provide a beneficial moisture and thermal performance [307]. In the case of rear-ventilated façades several authors have stated that these can achieve high energy saving rates, typically above $40 \%$ compared to the same façade unventilated during the summer period [8-11]. These energy performances are less advantageous for low values of solar radiation and it improves when the external layer of the cladding has low values of thermal conductivity, high values of density and high values of specific heat [8]. Therefore, rear-ventilated façades are energetically more advantageous for low values of thermal diffusivity of the external layer [8]. 
The stack effect due to the thermal buoyancy within the air cavity might cause pressure differences through joints, which might give rise to local air-currents. These air-currents would depend on the joint width, and roughness of panel edges. How air currents affect the watertightness performance of rear-ventilated façades is not, as yet, entirely clear. Neither is the influence of negative pressures introduced by the hydrostatic pressure of water runoff by means of the Venturi effect. The airflow induced by thermal buoyancy in the cavity (stack effect) may acquire values for air velocity ranging from 0.2 to $0.6 \mathrm{~m} / \mathrm{s}$ with wind speeds of between 0 to $5 \mathrm{~m} / \mathrm{s}$ [351 (studies on top and bottom ventilated façades), 352 (studies on $5 \mathrm{~mm}$ open joint ventilated façades)]. Further, Falk and Sandin [305] conducted laboratory measurements of airflow velocities due to thermal buoyancy effects in drained and ventilated cavities (ETICS walls with drainage). They obtained relations amongst the different cavity configurations, with top and bottom ventilation openings, for air flow velocities to the driving forces in the cavity. The outgrowth from this work was that the magnitude of these forces was rather small (driving forces larger than 2 Pa occurred less than $5 \%$ of the time). However, when a strong buoyancy-driven airflow was established in the cavities, wind-induced airflow was suppressed. It was a mode of action particularly clear in the cavities with horizontal profiles as the average driving force was larger in the cavities with horizontal profiles than in the cavity with vertical profiles [305]. In addition, the experimental results conducted in ventilated rainscreen façades by Marinosci et al. [353] confirmed that large cavity depths (e.g. $24 \mathrm{~cm}$ ) lead to very low air velocities within the air cavity (less than $0.12 \mathrm{~m} / \mathrm{s}$ ). In contrast to airflow induced by thermal buoyancy, wind induced airflow is irregular with frequent changes in both velocity and direction [305]. Moreover, its magnitude is significantly greater than that of airflow induced by the effects of thermal buoyancy and its influence on water infiltration rates in open joint ventilated façades systems is uncertain.

Therefore, it can be surmised that the watertightness performance of rear-ventilated façades is still somewhat unclear [51]. Indeed, there is a lack of knowledge concerning both the basic principles that govern the design of features for water management of walls and reliable quantitative data that validates these principles. Securing reliable quantitative data will in turn provide the means of determining the moisture load to which the wall is to be subjected during a rain event and for which the wall must be able to manage, either by eventual dissipation of moisture from the back ventilated cavity, moisture uptake by the inner wall (without any negative consequences), or drainage at the base of the wall. Apart from the lack of experimental work to quantify water infiltration of wall assemblies, there are as well, few construction guidelines [5, 49, 51, 354-357] or sector documents that relate specifically to the design of rear-ventilated façades $[4,14,66]$, unlike that for ETICS, brick cavity walls or flat roofs.

The protection against dampness is a basic demand being addressed in the CTE [74]. According to Table 1.2 of Chapter 01, this demand has three performance characteristics: (i) the watertightness degree, (ii) the drainage capacity of the air cavity and (iii) the condensation constraints. Hence, the watertightness degree of rear-ventilated façades should be assessed. Thereupon, an assessment criterion is defined in the DB-HS [74]. Nonetheless, the CTE does not set up the verification method [75]. When consulting the ETAG 034, something similar happens. The Guideline establishes that the water running down the wall shall not reach the inside face of the wall and that the materials likely to be adversely affected by water shall not become damp. However, it does not provide with a verification method. Therefore, when manufacturers request for a performance assessment of the watertightness degree of rear-ventilated façades, accredited testing laboratories draw on other European Standards such as the ISO Standards, EN Standards and so on. Notwithstanding, it should be borne in mind that there is not any 
laboratory or field test standard to specifically assess the watertightness degree of rear-ventilated façades. Nor to assess the drainage capacity of the ventilated air cavity. A review of the existing field and laboratory watertightness test standards is presented in Chapter 03. 
